ANATOLIJ KonstantinOVIČ MikUŠEV

\title{
Finnopermisch-samojedische Kontakte im Spiegel der Folklore
}

Die Finnopermier und die Samojeden erscheinen im europäischen Nordosten am Ende des 1. und zu Beginn des 2. Jahrtausends unserer Zeitrechnung. Obgleich die schriftlichen Quellen von relativ späten finnopermisch-samojedischen Kontakten (seit der Mitte des 15. Jahrhunderts) zeugen, halten die Historiker es auch für möglich, daß diese einander benachbarten uralischen Völker sich schon ein paar Jahrhunderte früher kennengelernt haben. ${ }^{1}$

Die Komi-Syrjänen nannten ihre samojedischen Nachbarn, die Nenzen, Jaranen, was in zahlreichen syrjänischen Dialekten belegt ist. ${ }^{2}$ Es gibt eine ganze Reihe widersprüchlicher, bisweilen auch einander ausschließender Ansichten über die Bedeutung dieses Ethnonyms. ${ }^{3}$ Am überzeugendsten erscheint mir jedoch die Hypothese A. I. Turkins: Das Wort jaran ist aus der Benennung der nenzischen Sippe jar mit Hilfe des Ableitungssuffixes -an

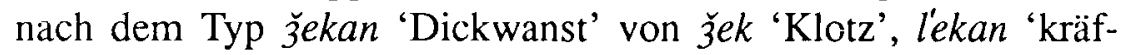
tiger Span' von l'ek 'abgehauenes Stück von einer Stange', tugan 'Baumwipfel' von tug 'Pinsel' entstanden. ${ }^{4}$ Übrigens kommt das Ethnonym jar in dem ižma-kolvinischen Epos - dem Forschungsgegenstand dieses Artikels - tatsächlich recht häufig vor.

Während ihrer historischen Entwicklung haben die nordsamojedischen Völkerschaften einander nicht nur ethnisch beeinflußt, sondern auch aktiv Komponenten anderer Nationalitäten, darunter finnisch-ugrischer, in sich aufgenommen: Unter den Tundranenzen in Sibirien gibt es zahlreiche Sippen ostjakischer Herkunft, 
und nenzische Gruppen waren an der Ethnogenese von KomiSyrjänen, Ostjaken und Wogulen beteiligt. 5

Ein anschauliches Beispiel ethnischer Vermischung bildet die Gruppe kolva jaran, die kolvinischen Jaranen, das sind komisierte Waldnenzen im europäischen Nordosten, die im 18.-19. Jahrhundert ihre Muttersprache vollständig vergaßen und zum KomiSyrjänischen übergingen. Ihren Namen erhielten die Kolvinen vom Fluß Kolva, einem rechten Nebenfluß der Pečora, wo ein bedeutender Teil dieser gemischten syrjänisch-nenzischen ethnischen Gruppe noch heute lebt. Wie ich lange Jahre hindurch beobachten konnte, vermischten sich die Kolvinen, die sich ihrer Blutsbande mit Nenzen und Syrjänen zwar bewußt sind, dennoch weder mit den einen, die sie vynenči, also Tundranenzen, noch mit den anderen, die sie Syrjänen nennen.

Die einzigartige Kultur der Kolvinen, die durch Vermischung von syrjänischen und nenzischen Kulturtraditionen entstanden ist, und zwar insbesondere ihr Epos, bietet in vielerlei Hinsicht völlig neues Material von Fakten, wie es benötigt wird, wenn man verstehen will, wie sprachliche und folkloristische Elemente verschiedener Nationalitäten einander wechselseitig beeinflussen. Wie L. P. Lašuk kann man nur bedauern, daß die moderne Wissenschaft an der erstaunlichen Frische des Materials immer noch achtlos vorübergeht und den Kolvinen immer noch „ungerechtfertigt wenig Aufmerksamkeit zuteil wird". 6

Im Zusammenhang mit den Kolvinen taucht erneut das alte Problem der Pečera auf. Keine große Uneinigkeit herrscht über die These, daß die Pečora, einer der wasserreichsten Flüsse, ihren Namen nach einem alten Ethnonym der Ureinwohner dieser Gegend erhalten hat. Aber die Wissenschaft hat bisher auf die Frage, wer sich hinter der Bezeichnung Pečera verbirgt, keine auch nur einigermaßen überzeugende Antwort gegeben. Und dabei hat schon Epifanij Premudryj im 14. Jahrhundert zwischen pečera und samojad' unterschieden. ${ }^{7}$ Ein ebenso deutlicher Unterschied wird zwischen diesen beiden im „Leben des Dmitrij Priluckij“ gemacht, wo es heißt, , ...heidnische Leute mit Namen Jugra und Pečera, und wo Čuden und Samojeden wohnen". 8 
Während die Archäologen und Ethnographen, die sich mit der Ethnogenese der nordosteuropäischen Völker beschäftigen, einzelne Aspekte des Pečera-Problems unterschiedlich deuten, stimmen sie doch darin überein, daß an der Entstehung der Pečera sowohl Samojeden als auch Finno-Ugrier Anteil hatten. So betrachtet L. P. Lašuk, der vorbehaltlos den Standpunkt von B. O. Dolgih teilt, die Pečera der Chronik als eine Gruppe von Ureinwohnern, an deren Ethnogenese ein samojedisches Element beteiligt war. ${ }^{9}$ Auch der Archäologe V. I. Kanivec kommt aufgrund des Materials der von ihm an der Pečora entdeckten archäologischen Lebjad-Kultur (2.-1. Jahrtausend v. u. Z.) zu dem Schluß: Die Pečera ,entstand auf der Basis der alten Lebjad-Bevölkerung, die im 1. Jahrtausend v. u. Z. zahlreiche Elemente der Ananinokultur übernahm. Anscheinend fand in der frühen Eisenzeit bei der Bevölkerung an Vyčegda und Pečora ein Prozeß kultureller und sprachlicher Annäherung an die Stämme von Ananino und Gljadenov statt." 10

Eine überzeugende Etymologie des Ethnonyms Pečera, die bestätigt, daß diese Benennung von den Ureinwohnern stammt, haben B. O. Dolgih und Ju. B. Simčenko vorgelegt; ihrer Ansicht nach tritt in den nordsamojedischen Sprachen das Wort čera 'das, was anfüllt' in Verbindung mit dem Determinanten eines Territoriums auf: moučera 'diejenigen, die die Erde bewohnen', linačera 'diejenigen, die die Ebene besiedeln', laptančera 'Bewohner der Tundra' und pečera 'Waldbewohner'."1

Von einem frühen Beginn der finnopermisch-samojedischen kulturellen Kontakte zeugen auch andere linguistische Daten: Im Syrjänischen gibt es 145 nenzische Entlehnungen, vor allem in den nördlichen Dialekten; umgekehrt weist das Nenzische 46 aus dem Syrjänischen entlehnte Wörter auf.12 (Die Anzahl ähnlicher Entlehnungen in der Lexik des ižma-kolvinischen Epos liegt noch weitaus höher.) Außerdem haben die Toponymiker im Syrjänischen drei große Gruppen von entlehnten nenzischen Toponyma gefunden: 1. Benennungen, die sich ganz und gar aus dem Nenzischen erklären (Ajačjaga, Juńjaga, Hal'mersale, Pajhoj); 2. gemischte Benennungen, bei denen die erste Komponente nenzisch 
und die zweite, ein geographischer Terminus, komi-syrjänisch ist (Amd'orma + jol', Sjabu + šr, Hal'mer + ju, Hosej + myl'k); 3. parallel gebrauchte syrjänische und nenzische Benennungen: syrj. Aźva - nenz. Hyrmor, Kolva - Točjaga, Usva - Sabrejjaga. Wie man sieht, deutet auch das toponymische Material auf den aktiven Charakter der finnopermisch-samojedischen historisch-kulturellen Kontakte hin. Des weiteren bezeugt es, bis wohin sich die früheren Ansiedlungen der samojedischen Stämme, die einstmals an der mittleren und unteren Pečora, in den Einzugsgebieten der Flüsse Ał́va, Ižma, Kolva und Cil'ma sowie am Oberlauf des Vym' lebten, erstreckten. ${ }^{13}$

Während die Archäologen, Ethnographen und Linguisten recht erfolgreich das Problem der finnopermisch-samojedischen Kontakte lösen, läßt sich dies von den Folkloristen keinesfalls behaupten. Noch in jüngster Zeit sind die Folkloristen auf Schritt und Tritt auf weiße Flecke gestoßen, aber im günstigsten Falle beschränken sie sich auf die Feststellung einzelner Fakten und versuchen gar nicht erst, bis zu dem Mechanismus der Wechselwirkung der eigentlichen Folkloretraditionen vorzudringen und ihn zu erklären.

Das Pathos in den neuesten Untersuchungen des ungarischen Gelehrten P. Domokos resultiert daraus, daß er vehement für die längst fällige komplexe Betrachtung der Wechselbeziehungen zwischen den uralischen Literaturen eintritt. ${ }^{14}$ Wenn aber P. Domokos' Aufruf schon für die Untersuchung einer so jungen Erscheinungsform des literarischen Schaffens bei den uralischen Völkern seine Gültigkeit hat, wie es die schöne Literatur ist, so hat er sie erst recht in bezug auf die mündlichen Quellen des literarischen Schaffens und auf die wechselseitigen Kontakte in der Folklore, speziell in bezug auf solche nicht nahe verwandten, aber schon seit vielen Jahrhunderten einander benachbarten Völker, wie es die Finnopermier und Samojeden, in erster Linie Syrjänen und Nenzen, sind.

Ich habe schon mehrfach dargelegt, daß man auf dem Gebiet der finnopermisch-samojedischen folkloristischen Beziehungen als ein unikales Phänomen das ižma-kolvinische Heldenepos wer- 
ten muß, von dem die Wissenschaft erst vor ein paar Jahrzehnten detaillierte Kenntnis erhalten hat.

Im Zusammenhang mit dem ižma-kolvinischen Epos taucht erneut das Problem des in der Chronik erwähnten Volkes Pečera auf, von dem schon weiter oben die Rede war. Wenn die Pečera und die Kolvinen genetisch miteinander verbunden sind (und die Intensität dieser Verbindung muß erst noch anhand komplexer historisch-philologischer Daten bestimmt werden) und wenn diese Verbindung alt ist, dann werden auch viele Aspekte bei der Entstehung des ižma-kolvinischen Epos verständlich und erklärbar. Tatsächlich gibt es eine ganze Reihe von Ähnlichkeiten in der ižma-kolvinischen, in der finnisch-ugrischen und in der samojedischen Epik, aber diese Ähnlichkeit bedeutet keine Identität der Traditionen.

Es war übrigens M. A. Castrén, der in den 40er Jahren des 19. Jahrhunderts Feldforschungen bei den Finno-Ugriern und Samojeden des europäischen Nordostens, darunter auch bei den Vorfahren der heutigen Kolvinen, betrieb und als erster auf die Verwandtschaft der folkloristischen Traditionen der finnisch-ugrischsamojedischen Völker, insbesondere auf die Analogien zwischen den samojedischen sudbabc und dem karelisch-finnischen Kalevala, hinwies. ${ }^{15}$ Leider hat Castrén bei der Beurteilung der ,unzweifelhaften Verwandtschaft" zwischen den finnisch-ugrisch-samojedischen Stämmen und ihren Kulturen nicht das finnopermische Material herangezogen, das geeignet gewesen wäre, den Charakter der syrjänisch-nenzischen Kontakte zu beleuchten. Aus heutiger Sicht erscheint es seltsam, daß ein so aufmerksamer Beobachter und Wissenschaftler, wie Castrén es war, bei seinem Aufenthalt mitten im Zentrum des Gebiets, in dem das ižma-kolvinische Epos entstanden und lebendig war, nämlich in den Dörfern Kolva, Nes', Peša und Ižma, in dem Gebiet also, wo später in den 60er bis 80er Jahren unseres Jahrhunderts das Gros der ižmakolvinischen epischen Lieder und Sagen aufgezeichnet wurden, sich mit keinem Wort über diese Werke geäußert hat, obwohl er als einer der ersten eine beachtliche Anzahl von Schöpfungen der syrjänischen und nenzischen Folklore aufgezeichnet hat. Mög- 
licherweise konnten die Kolvinen, die gerade dabei waren, „Sprache und Sitten der Komi-Syrjänen zu übernehmen“, wie Castrén selbst es ausdrückte, das Epos noch nicht auf Syrjänisch wiedergeben: Das Epos befand sich in einem Zustand eigenartiger sprachlicher „Diffusion“.

Es wird vermutet, daß es so etwas wie das Problem des ižmakolvinischen Epos' gar nicht gibt und daß es sich bei der ganzen Sache um die mehr oder weniger genaue Übersetzung von Folkloretexten aus einer Sprache in eine andere handelt. Eine solche Annahme ist verlockend und erscheint auf den ersten Blick gerechtfertigt, jedoch nur auf den ersten Blick und nur einem Dilettanten, der mit der finnopermischen und der samojedischen Folklore wenig vertraut ist.

Die Rolle der mündlichen anonymen Übersetzung bei der Verbreitung fremdsprachiger Folklore ist vielfach erörtert worden, und dabei wurden zahlreiche Beispiele aus der mündlichen Dichtung verschiedener Völker angeführt. Wir wollen jedoch den Gegenstand unserer Forschungen nicht ausweiten, sondern uns auf die Folklore der Syrjänen beschränken. Ein weit verbreiteter Typ mündlicher anonymer syrjänischer Übersetzung ist das epische Lied "Il'l'a da Idolišče "(Ilja und Idolišče) vom Oberlauf der Pečora, eine genaue, ja wörtliche Übersetzung der nordrussischen Byline „Il'ja Muromec und der Zar Kalin". Mit einem anderen, etwas komplizierteren Typ von Folkloreübersetzung haben wir es in den epischen Liedern „Pedör Kiron" (Pedor Kiron), „Kirjan-Varjan bagatyr" (Der Held Kirjan-Varjan) und "Mića Röman" (Der herrliche Roman) zu tun. Wenn auch in dem letztgenannten Fall anders als beim ersten Typ - der russische Text in der Umgebung einer anderen Nationalität bis zur Unkenntlichkeit verändert worden ist und wenn auch das syrjänische epische Lied ein selbständiges Denkmal mit künstlerischem Eigenleben und einer nur ihm eigenen Spezifik der poetischen Struktur geworden ist, so läßt sich doch auch dafür durch vergleichende Analyse zweifelsfrei eine konkrete genetische Quelle in einer anderen Sprache, nämlich die russischen geistlichen Lieder über Fëdor Tiranov und die Bylinen über den Fürsten Roman und Mar'ja Jurevna, ermitteln. ${ }^{15}$ 
Von ganz anderer künstlerischer Natur ist das ižma-kolvinische Epos. Zweifellos ist es im Sinne einer Nachfolge kontinuierlich mit dem samojedischen Epos verbunden. Aber ebenso unzweifelhaft ist seine Verbindung mit der finnopermischen und der obugrischen Epik. Es wäre ein Irrtum, das Wesen dieser Verbindung in den beiden oben genannten Typen der mündlichen anonymen Übersetzung zu sehen. Wie bei den ostseefinnischen Runen, den nordkaukasischen „Narten“, den nahöstlichen und mittelasiatischen „Kör-Ogly“ und den jakutisch-evenkischen olonho kann man auch bei dem ižma-kolvinischen Epos von der selbständigen nationalen Fassung eines gemeinsamen oder ähnlichen epischen Sujets sprechen.

Es ist nicht unsere Aufgabe, eine erschöpfende Analyse des ižma-kolvinischen und des nenzischen Epos zu liefern, sondern möglichst genau zu bestimmen: Was verbindet, was trennt die beiden verwandten Epen, was macht ihre Spezifik aus. Bei dem Bemühen, die gegenseitige Beeinflussung der finnopermischen und der samojedischen Traditionen dynamischer darzustellen, beschäftigten wir uns mit nenzischem epischen Material aus drei unterschiedlich alten Quellen, auf die in der ersten Hälfte des 19. Jahrhunderts M. A. Castrén ${ }^{17}$, zu Beginn des 20. Jahrhunderts T. Lehtisalo 18 und in der Mitte unseres Jahrhunderts Z. N. Kuprijanova ${ }^{19}$ hingewiesen haben. Die folgenden Abschnitte über die finnopermische und die ižma-kolvinische Dichtung beschränken sich im wesentlichen auf die Feldforschungsmaterialien in meinem Manuskriptband „Das Volksepos der Komi (Syrjänen)“ (KNÈ), die in den Jahren 1960-1980 aufgezeichnet und erstmalig in dem Buch ,Epische Formen der syrjänischen Folklore“20 charakterisiert wurden. Dieser Artikel beschäftigt sich mit drei zu erforschenden Aspekten: mit dem Sujet, mit Komposition und Stil und mit der poetischen Struktur.

Dem Sujet nach stehen das ižma-kolvinische und das nenzische Epos einander zweifellos nahe: Viele Situationen und Episoden der Handlung kommen in beiden Epen vor. Die Sujets des ižmakolvinischen Epos, wie es in der Mitte unseres Jahrhunderts, also 
in seinem Endstadium, von der Wissenschaft angetroffen wurde, erweist sich jedoch im Vergleich zu denen des nenzischen Epos als vielschichtiger und heterogener und enthält mehr Zusätze aus jüngerer Zeit.

Bei den ižma-kolvinischen epischen Sujets zeichnen sich in historisch-kultureller Hinsicht und dem Genre nach deutlich drei Hauptschichten ab: eine archaische (peripher-epische), eine jüngere (die des eigentlichen Heldenepos) und eine (sozial-novellistische) aus jüngster Zeit. Diese Schichten unterscheiden sich durch ihren ideologischen Grundgehalt, d. h. durch die Ideologien der historischen Epoche, die sich in ihnen spiegelten. Die Ideologien der verschiedenen Zeiten kommen im ižma-kolvinischen Epos jedoch nicht direkt, sondern nur mittelbar zum Ausdruck: Sie unterlagen der Korrektur, die von den lebenden Trägern des Epos in dessen Endstadium an seiner Thematik vorgenommen wurde. Wenn auch in den ižma-kolvinischen Liedern und historischen Erzählungen Elemente uralter Anschauungen - wie Avunkulat, Exogamie, Totemismus u. a. - deutlich sichtbar werden, so sind diese Elemente doch dank der neuen Weltanschauung der Menschen, die die alten Auffassungen längst vergessen haben und sie als fernen Nachhall vergangener Zeiten oder als Produkt künstlerischer Phantasie auffassen, deformiert, umgestaltet, modifiziert.

In der archaischen Sujetschicht spiegelt sich gleichermaßen alte samojedische wie alte finnopermische Ideologie, und zwar besonders totemistische Motive. Diese Schicht wird vor allem von den Prosaerzählungen „Kyk nyy" (Zwei Mädchen), "Siźim ćojavoka“ (Sieben Geschwister), „Joma pomlas" (Von Joma), „Bur ińka da Joma" (Die gute Samojedin und Joma), "Olis-vylis staruha-vnuk" (Es waren einmal eine Großmutter und ihr Enkel) vertreten. Hauptpersonen dieser archaischen Erzählungen sind häufig die komi-nenzischen Märchenwesen S'udbej-Gundyr, S'udbeihaJoma und S'udbejs Tochter Joma-nyy als die wichtigsten Gegenspieler des Guten und der Gerechtigkeit.

Obgleich die zweite Sujetschicht anscheinend in einer Form auf uns gekommen ist, die durch die Zeit verändert wurde, kann man doch davon ausgehen, daß ihr Kern sich lange vor der Entstehung 
des ižma-kolvinischen Epos herausgebildet hat. Ebenso wie in der archaischen Schicht ist auch hier die Ideologie des Totemismus, der Exogamie und des Anthropomorphismus erkennbar, freilich mit noch größerer realer Orientierung auf das historische Faktum und auf die späte historische Zeit. So geartet sind die Sujets der Lieder "Kerča-ju Hözain" (Der Herr vom Kerča-Fluß), „Važen völi öti Sudbej" (Es war einmal ein S'udbej), "Sero Jovl'o", „Kujim Jeว̌yd sîn" (Die drei Weißäugigen), "N'osi - ozyr mort “. (N'osi, ein reicher Mann). Daß diese den nenzischen śudbabc und jarabc nahestehen, unterliegt keinem Zweifel, und ebenso unzweifelhaft ist ihre Verbindung mit der finnopermischen Epik. Nehmen wir eines der am weitesten verbreiteten Sujetschemen aus der zweiten Schicht, das aus den folgenden Komponenten besteht: Der Tod der Männer einer Rentierzüchterfamilie, die wunderbare Errettung eines Waisenknaben, die Kindheit und die Spiele des Helden, bei denen er seine Kräfte offenbart und zugleich vom Tod der Familienmitglieder erfährt; die Reisevorbereitungen des Helden; der Held gelangt an die Stätte, an der sein Vater und seine Brüder umkamen; der Held kämpft mit den Feinden und rächt sich an ihnen; der Held gewinnt die Reichtümer der Familie zuruick; der Triumph und die Hochzeit des Siegers. Genau dem gleichen Sujetschema begegnen wir im Epos der Komi-Syrjänen vom Vym', in dem es um Šmvukva sowie um den Tod und die Auferstehung des Vaters und der Söhne geht: Nachdem die Familie umgekommen ist, gebiert die Frau den noch von ihrem Mann gezeugten zwölften Sohn; es folgen Kindheit und Spiele, in deren Verlauf der Held durch Nachbarn oder Joma von seinem Vater und seinen Brüdern erfährt; der Held begibt sich auf die Suche und kommt zu einer Jägerhütte, die einst seinem Vater gehört hatte; der Held begegnet dem Großen Vymiären, der sechs seiner Brüder gefressen hat, besiegt ihn im Zweikampf und erweckt die befreiten Brüder wieder zum Leben; er begegnet dem vezyrvinschen Bären, besiegt ihn und erweckt den befreiten Vater und fünf Brüder wieder zum Leben; gemeinsam mit seinem Vater, seinen Brüdern und seiner Frau, die er in der Jagdhütte gefunden hat, kehrt der Held nach Hause zurück. Wie man sieht, unterschei- 
den sich das finnopermische und das ižma-kolvinische Sujet kaum voneinander.

Die dritte Schicht des ižma-kolvinischen Epos entstand offenkundig in einem späten historischen Stadium der Formierung sozialer Klassen. In den Liedern über soziale Ungerechtigkeit spiegelten sich solche wahren Begebenheiten aus dem 19. und vom Beginn des 20. Jahrhunderts wie die gewaltsame Kolonisation und Christianisierung der Gebiete jenseits des Polarkreises, die soziale Bewegung der nenzisch-ostjakischen Armen mit dem legendären Vauli Piettomin an der Spitze, der Marsch der nomadischen Stämme auf Obdorsk und die grausame Ausbeutung durch die örtlichen Kulaken. Hierher gehören die Lieder „Vavl'o pomlas" (Von Vavl'o), „Böža ku parka“ (Der Hermelinpelz), "Kańin Bydtas" (Kanins Zögling), „Sizímlae ńukl'aśema mort da Bydtas" (Der von sieben Herrschaften Gedemütigte und sein Adoptivkind), "Zol'a Tyngos" (Der jüngste Tyngos) und die Erzählungen „Obdorskee pomlas" (Von Obdorsk), „D'ik Val'ej" (Der ungestüme Valej) usw.

Für eine vergleichende thematische Analyse des ižma-kolvinischen und des nenzischen Epos sind die Motive der Brautwerbung des Helden, der Blutrache und der sozialen Ungerechtigkeit, die zur zweiten und dritten Schicht gehören, von größter Bedeutung.

Das ižma-kolvinische Sujet der Brautwerbung des Helden ist am konsequentesten in den Liedern vom Jüngsten Herm des Kerča-Flusses (KNÈ, Nr. 1) durchgeführt: Am Ufer des Kerča-ju, also des Kerča-Flusses, lebt eine große Familie: drei Brüder mit ihren Frauen, ihre Schwester und zehn Hirten, und dort weidet auch ihre zehntausendköpfige Rentierherde. Nach zehnjährigem Schlaf erwacht der jüngste Bruder, und die Familie beginnt, über seine bevorstehende Heirat zu beraten. Die Brüder und ihre Frauen bestimmen eine in der Nähe wohnende Braut für ihn, die er jedoch ablehnt. Statt dessen wendet er sich an jur pasluh, den „Haupthirten“ Jevl'o Hupl'o um Rat. Dieser benennt ihm die Tochter des Kapherrn, die in einem fernen Lande wohnt. Der Rat des Jevl'o Huplo wird von der Familie des Bräutigams mißbilligt (eine der Schwägerinnen schlägt den Hirten sogar mit einem glühenden 
Holzscheit), vom Bräutigam jedoch akzeptiert. Der Bräutigam, seine Schwester und Jevlo Huplo begeben sich auf die Reise in das ferne Land. Sieben Tage und sieben Nächte sind sie unterwegs und zerstören einen Čum, der in einer Entfernung vom Lager des Kapherrn liegt, die ein Rentierzug auf einmal ohne Rast bewältigen kann. Kurz darauf begegnen die Reisenden der Sippe Ly goryš 'Knochenkehle', deren Leute eine junge Frau durch Aufhängen an sizzim uuja dub jyle, der 'Eiche mit sieben Zweigen', opfern wollen. Der Jüngste Herr vom Kerča-Fluß und Jevl'o Huplo retten die Frau und bringen sie in den Cum der Schwester vom jort pyd'd'i 'als eine Freundin' und fahren selbst ohne Gepäck, um die Braut zu holen. In der Tundra begegnen die beiden Freunde einer alten und einer jungen Frau, denen gegenüber sie sich als Leute aus der Sippe pu sad'ej, 'Hölzerne Idole', bezeichnen. Die alte blinde Frau erkennt in Jevl'o Huplo ihren Sohn, der einst bei einem Überfall von Nomaden entführt worden war, und lädt die beiden ein, sie auf dem Rückweg von der Hochzeit zu besuchen. Die Freunde gelangen ins Land des Kapherrn. Unmittelbar nach der Brautwerbung finden drei Wettkämpfe mit dem Jüngeren Bruder der Braut statt: Springen über vierzig vańd'ej-Narten, Schaukeln auf eisernen Schaukeln und Schießen mit schwerem Bogen. Es folgen Sieg und Triumph der beiden Freunde, die Hochzeit des Jüngsten Herrn vom KerčaFluß, der Heimweg, der Verrat des Sohnes an der Mutter, der Kriegszug gegen die Sippe Knochenkehle, Sieg und schwere Vorahnungen der Frau des Helden, Heimkehr, ein Überfall der Feinde auf den Čum des Helden, ein neuerlicher Sieg mit Siegesfeier sowie die wunderbare Verwandlung des Jevlo Huplo in ein hölzernes Idol.

Das Sujet der Brautwerbung des Helden in der nenzischen Fassung kommt in allen drei analysierten Publikationen vor:

a) In Castréns Sammlung ist das Sujet durch ein einziges Lied mit dem Titel „Sieben Bellende" vertreten (MSFOu 83, S. 289294). Dieses Lied ist in seiner Art beispiellos: Zusammen mit einigen anderen wurde es in der ersten Hälfte des 19. Jahrhunderts, also zu der Zeit, als die syrjänische Fassung des ižma-kolvini- 
schen Epos entstand, und zwar im Zentrum der Gegend, wo es lebendig war, nämlich im Dorf Kolva, zu Protokoll gegeben. Umso mehr gewinnt das Lied an dokumentarischem Wert und Glaubwürdigkeit in der aufgezeichneten nenzischen Variante, wenn es gilt, die folkloristische Tradition der Kolvinen zu erhellen. $\mathrm{Zu}$ deren Sujet gehören die folgenden Komponenten: Der Held teilt seiner Sippe mit, daß er zu heiraten gedenkt, die Brüder raten ihm ab, eine Braut zu wählen, die weit entfernt wohnt, der Held hört auf niemanden und begibt sich auf die weite Reise; unterwegs begegnet er zwei Ostjaken, die ihm ebenfalls Schwierigkeiten und schwere Prüfungen voraussagen und als Brautwerber mit ihm fahren; der Brautvater stellt die Kräfte des Helden auf die Probe; dieser besteht die Proben und erschlägt die Leute in dem fremden Nomadenlager, wobei er jedoch den Čum der Braut nicht anrührt, und kehrt dann mit der Braut nach Hause zurück.

b) Der folgende Zeitabschnitt, der Beginn des 20. Jahrhunderts, spiegelt sich in dem Sujet vom Herrn der siebzig Čums in den Aufzeichnungen T. Lehtisalos (MSFOu XC, S. 214-252): Ein Herr hat drei Frauen; von der ältesten und der mittleren hat er jeweils zwei Söhne, von der jüngsten eine Tochter und einen Sohn. Der Herr beschließt, den jüngsten Sohn mit einer Frau aus einem fernen Land zu verheiraten. Die ganze große Familie mit Ausnahme des ältesten Sohnes trifft Reisevorbereitungen. Der Herr bestraft den ungehorsamen ältesten Sohn. Die Brautwerber kommen in das fremde Land und lagern auf einem Hügel. Die Mutter des Bräutigams geht über die Höhe des Brautpreises verhandeln und kehrt dann zum Herrn zurück. Im Lager trifft der Abgesandte Mando ein und raubt den Bogen und die Pfeile des Bräutigams. Es folgen ein Überfall der Feinde mit dem Abgesandten Mando an der Spitze, der Kampf des Bräutigams mit den Feinden, die Ankunft des Bruders, der dem Helden zu Hilfe eilt, Sieg und Triumph der Sieger.

c) Den dritten Zeitabschnitt, die Mitte des 20. Jahrhunderts, vertritt das Sujet der drei Brüder Nositètè in den Aufzeichnungen Z. N. Kuprijanovas (Kuprijanova, S. 204-210): Am Ufer eines großen Sees stehen die siebzig Čums der drei Brüder Nositètè. 
Die beiden älteren Brüder beschließen, den jüngsten zu verheiraten und schlagen als Braut ein Mädchen aus den ,nahegelegenen Ländern" Tasinij und Harjuci vor, aber der jüngste Bruder will nur ein Mädchen aus dem fernen Land des Lamdo zur Frau nehmen. Die beiden Brüder Nositètè machen sich als Brautwerber auf den Weg. Zunächst begibt sich der ältere Nositètè als Brautwerber in Lamdos Čum und erhält eine Absage, dann geht der jüngere Nositètè und raubt Lamdos Tochter mit Gewalt. Der alte Lamdo verfolgt die beiden Nositètè, um sie zu töten und die Tochter zurückzuholen, erleidet jedoch eine Niederlage.

Eine vergleichende Analyse des ižma-kolvinischen und des nenzischen Sujets der Heldenbrautwerbung beweist, da $\beta$ wir es mit selbständigen, wenngleich recht ähnlichen Sujets, mit einer ähnlichen, jedoch völlig selbständigen Behandlung der Ereignisse und mit einer in ihrer Konsequenz selbständigen Linienführung der Sujets zu tun haben.

Besondere Beachtung verdient die Tatsache, da 3 nicht einmal innerhalb eines kleinen Gebiets, zum Beispiel in einem gemischt syrjänisch-nenzischen Dorf, zwischen dem ižma-kolvinischen und dem nenzischen Sujet völlige Übereinstimmung besteht. Eines dieser gemischten Dörfer ist Nes' auf der Halbinsel Kanin. Im Frühjahr 1972 wurde auf meinen Vorschlag eine Schülerin von Z. N. Kuprijanova, die nenzische Folkloristin L. F. Bobrikova, in die Folklore-Expedition der Komi Filiale der Akademie der Wissenschaften der UdSSR, die sich auf die Halbinsel Kanin und ins Pečoragebiet begeben sollte, aufgenommen. Wir studierten das russische und das syrjänische (ižma-kolvinische) Folklorerepertoire des Dorfes Nes', während L. F. Bobrikova die Aufgabe hatte, das nenzische Epos des Dorfes möglichst vollständig aufzuzeichnen. Frau Bobrikova aus Narjan Mar hat mir liebenswürdigerweise das nenzische Material und die von ihr angefertigte russische Übersetzung zur Verfügung gestellt, darunter den jarabc „Die drei Rentierzüchter Vèli“, der dem Sujet nach dem ižmakolvinischen Epos vom Jüngsten Herrn vom Kerča-Fluß am nächsten steht: Im Lager leben der älteste Vèli und seine Frau Noho, der mittlere Vèli und seine Frau Robci sowie der jüngste Vèli und 
seine Frau Pjakoj, und außerdem ,der, der den jarabc singt“ - der sich quälende Vèvako Vèli. Der jüngste Vèli beschließt, Vèvako zu verheiraten, und berät sich mit seiner Frau. Er schlägt einige Mädchen aus der Nachbarschaft als Braut vor, aber seine Frau Pjakoj ist mit keiner von ihnen einverstanden (,ihre Ärmel sind nicht angenäht, und die Rockschöße der Malica sind weit geöffnet" - nach Ansicht der Nenzinnen ist das der Gipfel der Unmoral), sondern verweist auf das ferne Land der drei Tungusen. Es folgt eine lange Fahrt durch die Tundra. Vèvako Vèli und Pjakoj zerschlagen ein Nomadenlager in der Nähe des Tungusenlandes und freien dann um die tungusische Braut. Man begegnet den Brautwerbern freundlich und richtet die Hochzeit aus. Hier jedoch erscheint "der alte Riese, das nganasanische Ungeheuer", und droht, dem Bräutigam die Braut wegzunehmen. Er macht sich mit dem jüngsten Vèli bekannt und schließt Freundschaft mit ihm. Kurz darauf erscheint ein anderer Nebenbuhler, ein tungusisches Ungeheuer auf eisernen Skiern, der sich ebenfalls mit dem jüngsten Vèli bekanntmacht und anfreundet. Es beginnt ein Wettkampf zwischen dem nganasanischen und dem tungusischen Ungeheuer: Der Tunguse wickelt sich eine Eisenstange um den Finger und fordert den Nganasanen auf, sie wieder abzuwickeln und geradezubiegen. Im Wettkampf mit Eisenstäben besiegt Vèvako Vèli erst das tungusische, dann das nganasanische Ungeheuer. Vèvako Vèli kehrt mit seiner Frau in das heimatliche Lager zurück. Nach Krankheit und Tod des Jüngsten Vèli geht Vèvako Vèli in die Tundra, um seinen Kummer zu zerstreuen, begegnet dort zunächst Leuten aus der Sippe Nohos und dann Verwandten der Robci, kämpft mit ihnen und geht als Sieger aus dem Kampf hervor.

Nicht weniger Selbständigkeit und ebenso offenkundige Ähnlichkeit zeigen die ižma-kolvinische und die nenzische Fassung des zweiten epischen Stoffes, des Sujets vom jungen Rächer. Vergleichende ethnographische und folkloristische Untersuchungen zeigen, daß die Quellen des ižma-kolvinischen Sujets ebenso wie der Stoff von der Brautwerbung des Helden, auf eine Zeit urgesellschaftlicher Ideologie zurückgeht, die in dem Lied "Sizim aresa d'etina" (Der siebenjährige Junge; KNÈ Nr. 3) ihren cha- 
rakteristischen Ausdruck gefunden hat: In einem Nomadenlager leben ein Mann und seine Schwester, die sich in der Tundra versteckt hält und dort ihren siebenjährigen Sohn aufzieht, nachdem ihr Mann von Feinden erschlagen worden ist. Bruder und Schwester gehen auf die Jagd zum Gänsesee (źoźega ty vyjim, lysoo źoźeg una, lysoo łoźegse kyjny, svežej jaj kole śojny 'der Gänsesee liegt da, es gibt dort viele Gänse in der Mauser, man muß sich mausernde Gänse fangen, man muß frisches Fleisch kosten'). Bei der Jagd werden Bruder und Schwester vom bösen Mando erschlagen, der auch den siebenjährigen Jungen bis an das Steilufer des Meeres verfolgt (more čell'a surema 'das Meeressteilufer zeigte sich'); der Junge springt vom Steilufer (das skod vyysum 'in vollem Lauf') auf eine Eisscholle und rettet sich so vor Mando. Er treibt auf der Eisscholle und ernährt sich von gefangenem Wild (ötik södse lićki, stavnas čög taj 'er fing einen Bären, einen sehr fetten'). Eine Stimme vom Himmel weckt den Jungen, warnt ihn vor einer Gefahr, ruft ihn aufs Festland und zeigt ihm einen im Wasser treibenden Baumstamm (va kylasse nooledle, vays taj nooledle 'in der Strömung treibt ein Baumstamm, er treibt mit der Strömung'). Mit Hilfe des Baumstamms gelangt der Junge ans Ufer. Zwei Schwestern finden den vor Hunger halbtoten Jungen, bringen ihn in den Čum zu ihren Eltern und pflegen ihn (bur sojan vylas bydme, bur paskem vylas d'etinays bydme 'bei gutem Essen wächst er auf, in warmer Kleidung wächst der Junge auf'). Der Junge wächst zu einem Recken heran. Der Herr des Cums übergibt ihm einen schweren Bogen. Der Held begibt sich an den Ort, wo seine Mutter und sein Onkel ums Leben kamen, findet die Beleidiger, rechnet mit ihnen ab und befreit „das unschuldige Volk“, die Knechte (Narodys taj una, bezvinnejse og vörźed 'da ist viel Volks, das unschuldige Volk rühre ich nicht an'). Die Rentiere, die die Feinde ihm einstmals geraubt hatten, treibt er mit sich fort, die restliche Herde verteilt er an das Volk. Nachdem er die Blutrache vollzogen und die Gerechtigkeit wiederhergestellt hat, kehrt der Held zu seinen Retterinnen, den jungen Mädchen, zurück und nimmt eine von ihnen zur Frau. 
Die nenzische Fassung des Sujets vom jungen Rächer ist in den von uns ausgewählten Folkloresammlungen ebenfalls vollständig genug vertreten. Ihre charakteristischen Komponenten begegnen in den folgenden Sujets:

a) Im Sujet von Enkel und Großvater in der Aufzeichnung T. Lehtisalos (MSFOu XC, S. 282-291). Der Enkel erfährt durch seinen Großvater vom Tod seiner Familie und fährt zum Fluß, d. h. er macht zur Probe eine Erkundungsfahrt, die zugleich Initiation ist. Dort sieht er uralte sáa'ej-Idole, um die der Wind pfeift und deren „Augen funkeln“, opfert ihnen und kehrt in den Čum zu seinem Großvater zurück. Er trifft Reisevorbereitungen und erhält vom Großvater einen schweren Bogen. Im feindlichen Land trifft er seine Schwester, die dort gefangen ist und Brennholz und Schnee für die Trinkwasserbereitung in die Čums schleppt. Der Held kämpft mit den saju-Feinden, erleidet eine Niederlage, flieht zu seinem Großvater, dem Wassergeist, und bittet ihn um Hilfe, und der Großvater hilft dem Enkel, den Feind zu besiegen.

b) Im Sujet vom Sohn des Herrn Jabta Salja, das Z. N. Kuprijanova im Jahre 1946 in der Ortschaft Varandej des Nenzischen autonomen Gebiets von O. I. Pyrerki aufgezeichnet hat; außerdem hat sie in den Jahren 1949, 1958 und 1959 auf der Insel Vajgač und in der Bol'šezemel'skaja Tundra drei Varianten notiert.

Variante eins (Kuprijanova S. 122-149): Am Ufer eines Sees verbirgt sich eine Frau mit zwei Kindern in einem Čum. Sie werden von dem bösen Han Hadengot verfolgt, der ihnen auf die Spur kommt. Er entführt die Tochter des Herrn Jabta Salja und droht, beim nächsten Mal ihren Bruder zu töten. Der Junge, den seine Mutter zu Fuß in die Tundra geschickt hatte, damit er die Greuel des Han Hadengot nicht sehe, trifft seine Schwester, die die Rentierherde Han Hadengots hütet. Die Kinder fliehen zum Ufer des Meeres, werden dort aber von Han Hadengot eingeholt. Mit Hilfe der $\chi$ orej-Stange springen die Kinder auf eine treibende Eisscholle, treiben auf dem Meer herum und gelangen schließlich wieder an Land. Im Reich der Toten erleiden sie Qualen, und heimlich hilft ihnen die Frau des Lamba Hadengot. Die Kinder begegnen der Schwester Sem' Sohos, die ihre Retterin wird und 
dem Knaben hilft, zu einem Recken heranzuwachsen, den väterlichen Bogen zurückzugewinnen und Sem' Sohos Brüder zu besiegen, die einst an dem Überfall auf den Herrn Jabta Salja beteiligt und an seinem Tod mitschuldig gewesen waren. Der Held kämpft gegen die Bewohner der 70 Cums von Javotarkachècja und Javomalhècja, besiegt sie, wobei ihm der Recke Njamdasi Harëè hilft. Schließlich kehrt der Held zu seiner Schwester und zu der Schwester Sem' Sohos zurück und rüstet sich zum Kampf mit den Hauptfeinden, den Brüdern Hadengot, die er auch besiegt. Danach trifft er in der Tundra seine Mutter und bringt sie $\mathrm{zu}$ ihrem alten Lagerplatz zurück.

Variante zwei (Kuprijanova S. 161-173): In einem Weidengebüsch versteckt sich eine Mutter mit ihren beiden Kindern in einer Rasenhütte vor Han Hadengot. Hadengot findet sie, entführt die Tochter und droht, beim nächsten Mal den Sohn zu töten. Um den Sohn zu retten, schickt die Mutter ihn allein in die Tundra. Dort trifft er auf seine Schwester. Gemeinsam fliehen sie zum Ufer des Meeres, werden jedoch von Han Hadengot verfolgt und am Ufer eingeholt. Die Kinder retten sich auf eine Eisscholle, die von der Meeresströmung wieder ans Ufer getrieben wird. Im Totenreich und bei Lamba Hadengot machen die Kinder allerlei durch. Die Frau Lambas hilft den Kindern jedoch und schickt sie ins Land des Sem' Soho. Dessen Schwester und die Tochter des Herrn Jabta Salja ziehen Jabta Saljas Sohn, den künftigen Rächer, unter dem Decknamen Ninmja Jabtako (Schmale Taille) groß. Der Held zieht in den Kampf mit Sem' Soho, schlägt ihn und zieht dann in den Kampf gegen den Hauptfeind, Han Hadengot, schlägt ihn, kehrt als Sieger heim und feiert Hochzeit.

Variante drei (Kuprijanova S. 182-189): Han Hadengot träumt, da $B$ irgendwo eine Frau den künftigen Rächer, den Sohn des von ihm erschlagenen Herrn Jabta Salja, großzieht. Han Hadengot will den Jungen töten und seine Schwester zur Frau nehmen. Bruder und Schwester fliehen vor dem Verfolger und retten sich auf eine Eisscholle im Meer. Später gelangen die Kinder aufs Festland, ins Totenreich und unerwartet zum Čum Han Hadengots. Eine Frau hilft ihnen, indem sie sie ins Land des Sem' Soho schickt, dessen 
Schwester den Helden aufzieht und bewaffnet. Der Held bezwingt deren Brüder, macht sich auf die Suche nach seiner Mutter und bringt sie zu ihrem Wohnplatz zurück. Im Kampf besiegt er auch Han Hadengot und feiert Hochzeit mit der Schwester des Sem' Soho.

Variante vier (Kuprijanova S. 194-198): In einem Rasenčum wohnt eine Mutter mit Sohn und Tochter. Bei ihnen erscheint eines Tages Han Hardat. Um ihr Leben zu retten, fliehen die Kinder zu einer Landzunge im Meer und springen mit Hilfe einer kupfernen $\chi$ orej-Stange auf eine Eisscholle; es folgen Abenteuer auf der Eisscholle (,Wenn ein Bär kommt, tötet meine ältere Schwester ihn mit der $\chi$ orej-Stange aus Kupfer, wenn ein Walroß kommt, tötet meine Schwester es mit der $\chi o r e j-S t a n g e$ aus Kupfer. Sie zieht ihnen das Fell ab, und das Fleisch essen wir"). Auf dem Festland geraten die Kinder zum Čum der Tochter Mandos, bei der sich gerade Lamba Hadengot, der die Kinder ebenfalls verfolgt, mit Heiratsabsichten aufhält. Mandos Tochter hilft den Kindern, zieht sie groß und übergibt dem Jüngling einen Bogen mit drei Glöckchen. Tochter und Sohn des Herrn Jabta Salja ziehen zusammen mit Mandos Tochter in den Kampf gegen Lamba Hadengot und Han Hardat. Die Blutrache wird vollzogen und die Hochzeit gefeiert.

Wie wir sehen, bezeugen die beiden Sujets von Heldenhochzeit und Blutrache, die wir oben betrachtet haben, daß die ižma-kolvinische und die nenzische Version sich selbständig entwickelt haben, und gleichzeitig, daß es Berührungspunkte zwischen ihnen gibt. Der Grund dafür lag offenbar in Folgendem. Sicherlich spiegeln beide Sujets die Realität zur Zeit der Urgesellschaft. Aber die urgesellschaftlichen Gesetze waren bei Kolvinen und Nenzen nicht zur gleichen Zeit wirksam. Von daher wird verständlich, daß auch die Sujets und die ästhetischen Bilder, die eine weit zurückliegende historische Epoche betreffen, nicht kongruieren.

Aber das ižma-kolvinische und das nenzische Epos vermitteln uns nicht nur ein Bild von weit zurückliegenden historischen Zeiten. Als ein lebendiges Phänomen, das sie bis heute geblieben sind, konnten diese Epen um die Wende vom 19. zum 20. Jahrhundert 
auch an den neuen historischen Realitäten, den neuen gesellschaftlichen Gesetzmäßigkeiten, d. h. vor allem an den sich zunehmend vertiefenden Klassenunterschieden in der Gesellschaft und an der Verschärfung des Kampfes zwischen Arm und Reich, nicht vorübergehen. Tatsächlich nahm in den Epen der Kolvinen und Nenzen die Anzahl der neuen Sujets mit sozialkritischen Tendenzen merklich zu. Und wiederum müssen wir bei einem Vergleich der Sujets feststellen, daß sie einerseits selbständig sind und daß es bei ihnen andererseits zahlreiche Überschneidungen gibt.

Das Spezifische der ižma-kolvinischen Version des Sujets von den Mißgeschicken des Helden und von der sozialen Ungerechtigkeit zeigt sich am deutlichsten in der liedhaften Prosaerzählung „Kańin bydtas" (Kanins Zögling) ${ }^{21}$ und in dem Lied „Vavl'o pomlas" (Von Vavl'o, KNÈ Nr. 11): Die Herren eines Lagerplatzes reisen in eine entfernte Gegend, um die Nahrungsmittelvorräte für das kommende Jahr aufzufüllen, und lassen den Zögling zur Bewachung der Rentiere zurück. Nach vielen Tagen kehren die Herren nach Hause zurück, aber nicht mit den Rentierfuhren, sondern auf einem Schiff zusammen mit einer unbekannten Amtsperson und einer Kirche an Bord des Schiffes. Die Herren verkaufen den Zögling an den Beamten. Der Zögling widersetzt sich, droht, die Kirche zu zerstören, die an Land gebracht worden war, und das Schiff zu versenken, als er aber vom Treuebruch seiner früheren Herren erfährt, die ihn in die Fremde verkauft haben, fügt er sich in sein Schicksal. Der Beamte nimmt den Zögling mit ins fremde Land und gibt ihn zum Zaren in Dienst. Der Zögling rettet den Zaren vor den Gundyr-S'udbejs, seinen ehemaligen berććan jortjas, d. h. Kampfgefährten, besiegt sie, weigert sich aber, vom Zaren eine Auszeichnung dafür anzunehmen.

Ein anderes Lied „Von Vavl'o“ beginnt mit der Ansprache eines Rentierzüchters an seinen Neffen:

Das vojas taj ig vööle,

Eni da Obdorskee ig vole, Nanńnum taj i,

Pödém ńań śojam,
Zehn Jahre lang waren wir nicht, waren wir nicht in Obdorsk, unser Brot, verschimmeltes Brot essen wir, 
Dad' pydeśśys öktenys,

Babajasnum taj viśtalenys:

Jem-ćuńpomkuys byrema.

(KNÈ, Nr. 11, 13-19) die letzten Krumen scharren wir in den vańd'ej-Narten zusammen, die Frauen beklagen, daß Nadeln und Fingerhüte ausgegangen sind.

Onkel und Neffe bringen ihre Rauchwaren (kyñ-ruc, wörtlich: Blau- und Rotfuchs) in neun vańd'ej-Narten nach Obdorsk; auf dem Eis des Lar"jah-Sees werden sie von einem bösen Omen aufgehalten, das ihnen ein Unglück prophezeit (tölyn zoźeg lebale 'im Winter fliegt eine Gans'). Der Junge fordert den Onkel auf, in den Čum zurückzukehren, aber der Onkel lacht ihn aus. Kurz vor Obdorsk werden die Reisenden von den Leuten des Kaufmanns Gön Arseń mit dem Beinamen 'der Behaarte' empfangen, die dem Onkel Honig ums Maul schmieren und ihm versprechen, ihn zum Fürsten der Ostjaken zu machen. Sie locken die beiden nach Obdorsk ins „Quartier“ des Gön Arseń. Dort machen die falschen Hausherren den Onkel erst betrunken und binden ihn dann mit einem Eisendraht, während es dem Neffen gelingt zu entfliehen. Der gefesselte Vavl'o wird den Ob hinauf Richtung Berëzov und Tobol'sk gebracht, unterwegs mißhandelt und am Obufer in der Nähe des Dorfes Muži erschlagen.

Die nenzische Fassung des Sujets von den Mißgeschicken des Helden und von der sozialen Ungerechtigkeit (MSFOu 122, S. 374-392): der Held, ein Rentierhalter und Jäger, will in Geschäften nach Obdorsk reisen, und sein Vater sagt zu ihm:

Wir bleiben ohne Axt, wir bleiben ohne Messer, nach Obdorsk

begibst du dich wohl. (MSFOu 122, S. 374)

Der Herr von Obdorsk kauft ihm seine Felle ab und gibt ihm dafür Waren. Während der Abwesenheit des Sohnes überfallen die saju-Feinde sein Wohnlager, erschlagen den Vater und treiben die Rentiere mit sich fort. Der Sohn kehrt nach Obdorsk zurück, kauft 
bei einem bekannten Händler ein Gewehr und rächt sich an den Feinden. Dieses Sujet wurde von M. A. Castrén aufgezeichnet. ${ }^{22}$

In den Aufzeichungen M. A. Castréns und T. Lehtisalos zeigt sich noch eine Abart des Obdorsker Sujets, das eine konkrete zeitgeschichtliche Grundlage hat und die Willkür des zaristischen Gerichtswesens illustriert, das in den Städten jenseits des Ural von Obdorsk bis Tobol'sk für die Nomaden eingerichtet worden war. Eine dieser Varianten sieht folgendermaßen aus: Ein reicher Rentierhalter wird beschuldigt, seine Ehefrauen getötet zu haben. Der Verbrecher, überzeugt von der Macht seines Reichtums, gesteht seine Schuld nicht ein und streitet sich mit den Wachmännern. Man stellt ihn vor Gericht, aber er kauft sich mit Rot- und Schwarzfuchspelzen von dem Richter in Obdorsk, Berëzov und Tobol'sk los. Die Richter erklären ihn für unschuldig und bringen ihn auf einem Pferd in seinen Čum zurück (MSFOu 83, S. 273-280).

Das zweite Sujet wurde 70 Jahre nach M. A. Castrén von T. Lehtisalo aufgezeichnet. Diese Variante enthält einen Hinweis darauf, daß die Gerichte von Obdorsk, Berëzov und Tobol'sk hierarchisch strukturiert waren, aber im Unterschied zu Castréns Variante ist sie freundlicher und von zaristischen Illusionen geprägt (MSFOu XC, S. 321-327): Der Held geht nach Obdorsk, wo er unversehens vom Herren der Stadt ergriffen, verurteilt, mißhandelt und zu Pferde unter Bewachung auf eine weite Reise gebracht wird. Der Held kommt zum Zaren, der dem Nenzen einen Schutzbrief gibt und befiehlt, alle diejenigen aufzuhängen, die den unschuldigen Rentierzüchter gequält haben. Den Helden ernennt er zum Fürsten der Ostjaken.

Lehtisalos dritte Variante ist mit Abenteuer- und Märchenelementen angereichert, aber auch sie enthält noch den Glauben an den guten Zaren (MSFOu XC, S. 381-405): In einem Zweikampf besiegt der Held seine Feinde, weswegen er von der Wache des Zaren ergriffen wird. Sieben Monate lang wird er herumgeschleppt: zunächst nach Obdorsk, dann nach Berëzov, schließlich nach Tobol'sk und von dort direkt zum Zaren. Dieser befiehlt, den Helden zu verbrennen, aber irrtümlich wird statt seiner jemand 
anders verbrannt; der Zar befiehlt, ihn an einen Baum zu nageln, aber wieder geschieht das versehentlich mit einem anderen; er soll bei lebendigem Leibe begraben werden, aber man begräbt einen andern; er soll in ein $\mathrm{Faß}$ gesteckt und in den $\mathrm{Ob}^{\prime}$ geworfen werden, aber wiederum bleibt ihm das erspart. Zuguterletzt ist der Zar so beeindruckt, daß er dem Helden verzeiht, ihm einen Schutzbrief gibt und ihn zum Herrn der Tundra ernennt.

Vermutlich erschöpft sich mit der Heldenhochzeit, der Blutrache, den Mißgeschicken des Helden und der sozialen Ungerechtigkeit die Zahl der ižma-kolvinischen und nenzischen einander ähnlichen Sujets, bei denen zumindest die Hauptmotive übereinstimmen. Für die Sujets der übrigen Werke in den Sammlungen Castréns, Lehtisalos und Kuprijanovas finden sich auf ižma-kolvinischer Seite weder vollkommene Entsprechungen noch konsequente Übereinstimmungen. Umso weniger kann es sich um so ähnliche konkrete Parallelen handeln, wie man sie bei einem Vergleich der komi-syrjänischen Lieder „Ilja und das Götzenbild“, „Der herrliche Roman“ und „Pedor Kiron“ mit den russischen Quellen „Il'ja Muromec und der Zar Kalin“, „Fürst Roman und Marjja Jur'evna“" sowie den geistlichen Gedichten über Fëdor Tiranov findet.

Bei der wechselseitigen Beeinflussung einerseits der ižma-kolvinischen und nenzischen und andererseits der komi-syrjänischen und der russischen folkloristischen Tradition sind nicht nur quantitative, sondern auch qualitative Unterschiede zu beobachten. $\mathrm{Da}$ das Problem der russisch-syrjänischen Beziehungen in der Folklore erst unlängst ziemlich umfassend von V. M. Kudrjašova ${ }^{23}$ behandelt worden ist, können wir es hier außer acht lassen und eine Antwort auf die Frage zu finden versuchen, wie die Wechselwirkung zwischen der ižma-kolvinischen und der nenzischen epischen Folkloretradition im Bereich der Thematik charakterisiert werden kann.

Das Wesen der Sache liegt unserer Ansicht nach in Folgendem: Obgleich eine relativ vollständige und konsequente Übereinstimmung der Sujetlinien im ižma-kolvinischen und im nenzischen Epos gar nicht so häufig und eher die Ausnahme als die Regel ist, 
muß man doch berücksichtigen, daß einem auf Schritt und Tritt Übereinstimmungen einzelner Sujetkomponenten begegnen, und zwar derjenigen Elemente, aus denen das ižma-kolvinische bzw. das nenzische Sujet besteht.

Es ginge über den Rahmen eines Aufsatzes hinaus, die permanent übereinstimmenden Sujetkomponenten aufzuzählen. Deshalb beschränken wir uns auf die typischsten Übereinstimmungen, die die Tendenz der finnisch-ugrisch-samojedischen Kontakte in der Folklore ausreichend verdeutlichen.

Es sind vier Sujetkomponenten, die sich am häufigsten wiederholen: a) Die Bilder von einem großen Nomadenlager; b) die wunderbare Errettung und das Heranwachsen des künftigen Rächers; c) die Vorbereitungen für die weite Reise und d) der Kampf des Helden.

a) Die Bilder des Nomadenlagers (nach den ižma-kolvinischen Quellen). Diese äußerst beliebte Komponente begegnet in den Werken aller drei Typen (Hochzeit des Helden, Blutrache und soziale Ungerechtigkeit): In dem Lager am Ufer eines Flusses lebt eine große Sippe, zumeist die Eltern, Brüder mit ihren Frauen, eine oder mehrere Schwestern und die Rentierhirten:

Keræa-ju bökyn olam,

Kujim vok i olam,

Kujim vok-e olam,

Das-e da pasluh-e vyjim,

Das-e da pasluh-e vyjim,

Das-e da tyśeća kör-e vyjim,

Das-e da tyśeća kör-e vyjim,

N'el'amyn vańd'ej vyjim,

Kyń-rućen i tećema.

(KNÈ Nr. 1, 1-9)
Wir wohnen am Ufer des Keræa-Flusses, wir sind drei Brüder, wir sind drei Brüder, wir haben zehn Hirten, wir haben zehn Hirten, wir haben tausend Rene, wir haben tausend Rene, wir haben vierzig vańd'ej-Narten, alle sind mit Pelztieren (wörtl. mit Blau- und Rotfuchs) angefüllt.

Ähnliche Formeln finden sich in den folgenden Liedern: KNÈ Nr. 2, 1-7; Nr. 6, 1-7, Nr. 7, 1-10; Nr. 9, 1-10; das Lager kann aus $3-5$, bisweilen aus 30 (KNÈ Nr. 15) und sogar aus 300 Cums bestehen. 
Stets wird zum Ausdruck gebracht, was die Bewohner des Lagers in der Tundra oder der Waldtundra für ein isoliertes Leben führen: Trundrayn ved ola eni, munyse-loktyse ved abu taj 'ich lebe jetzt in der Tundra, einen Fortgehenden oder Ankommenden gibt es hier nicht'.

Trundra ved trundra i vyjim:

N'ikyten pu abu,

N'ikyten olys ved abu taj,

N'ikyten olyś ved abu,

N'ikyten ćom abu,

N'ikyten kör ved oz tydoo,

Eta myjtem źeml'a muna da, Looja kőr tuj ig ał̧́yy,

Tyrtem da źeml'a völema taj.

(KNÈ Nr. 6, 613, 622; 487-498)
Tundra ist Tundra:

kein Baum ist zu sehen, kein Mensch ist zu sehen, kein Mensch ist zu sehen, kein Čum ist zu sehen, kein Ren ist zu sehen, über soviel Land bin ich gefahren, eine frische Renspur habe ich nicht bemerkt, ein ödes Land ist dies.

Die Menschen im Lager betreiben Rentierzucht oder Jagd. Es fällt auf, daß im ganzen ižma-kolvinischen Epos das Thema Jagd und die Gestalt des Jägers einen höchst ehrenvollen Platz einnehmen und häufig sogar die Themen der Rentierzucht verdrängen, was dieses Epos vom nenzischen unterscheidet. Zweifellos stellt diese Tatsache die poetische Reflexion des Lebens dar, das die Kolvinen als Rentierzüchter im Wald führten. Tatsächlich findet sich schon in der allerersten Aufzeichnung ižma-kolvinischer Lieder vom Beginn unseres Jahrhunderts der folgende charakteristische Gedanke: „Me vistala: Eta munem (?) promys abu. Vokjas viśtaleny, kyim vokys... : Kyź abu promys?"24 ('Ich sage: In diesem Land kann man nicht von der Jagd leben. Die Brüder sagen, drei Brüder... : Wieso kann man davon nicht leben?').

(Diese unqualifizierte und kaum zu entziffernde Amateuraufzeichnung stammt von dem syrjänischen Lehrer P. I. Kiselëv, der sie am 23. August 1911 auf Bitten des ungarischen Reisenden B. Barátosi machte. Da Kiselëv jedoch aus Sysola gebürtig war, verstand er anscheinend den Ižma-Dialekt des Syrjänischen noch schlecht. Es war der bekannte ungarische Folklorist M. Istvánovics, der mich im Jahre 1971 liebenswürdigerweise auf diese Archivquelle hinwies.) 
Das Thema der Jagd in dem Lied „Kujim Vaj vok" (Die drei Vaj-Brüder), das wir in derselben Gegend der Bol'šezemel'skaja Tundra 60 Jahre nach Barátosi aufgezeichnet haben, sieht folgendermaßen aus:

Važen völi kujim Vaj vok,

Vaj vokjas taj olenys:

N'inemnys abu nyle-en,

Nylenlen ńinemys abu...

Nya taj prömyšl'ajtenys,

Nylen taj ńinem i ńin oz sed.

(KNÈ Nr. 9, 1-10, 135-139, 441-451)
Es lebten einst drei Brüder Vaj, die Vaj-Brüder lebten so dahin; sie haben nichts, nichts haben sie,... sie machen Jagd auf das Wild, sie bekommen keins zu Gesicht.

So wie der komi-permjakische Jäger, der Held Pera, und der komisyrjänische Jäger Jurka, wie der enzische Morradè, d. h. der Jäger wilder Rentiere, so jagt der ižma-kolvinische Held wilde Rentiere und Elche, wobei er sie dutzendweise auf einem Pfeil aufreiht ${ }^{25}$ - die beliebteste Hyperbel bei der Charakteristik des nördlichen Jägers:

Keræa da ju modorśań,

Lyźa že bara modoršań yskoote,

Lyźa ved bara ved yskoote,

Das-e d'ikej hora na ńöö jylas.
Vom anderen Ufer des Ker`aFlusses, Vom anderen Ufer kommt ein Mann auf Skiern, ein Mann kommt auf Skiern, auf seinem Pfeil sind zehn wilde Rentiere aufgereiht.

(KNĖ Nr. 7, 255-258, 10-35, 284-295, 299-302, 355-363; Nr. 6, $862-867,919-925$; Nr. 3, 820-855)

Es gibt auch Bilder von der Jagd auf Gänse und Taucher (KNÈ Nr. 3, 10, Nr. 16), auf Blau- und Rotfüchse, (Nr. 2, Nr. 16) usw. Und nicht zufällig werden im ižma-kolvinischen Epos, ebenso wie in den enzischen epischen Überlieferungen von einer Sippe rentierloser Jäger und Fischer namens Sonuko (Soner) ${ }^{26}$, aber anders als im nenzischen Epos, ab und zu ,rentierlose Leute“, Jäger, erwähnt, und der Held nennt sich Körtem starik pi 'Sohn des rentierlosen Alten'. Und durch dieses Faktum wird wiederum eine Besonderheit im Leben der Kolvinen, die Waldbewohner 
waren, zum Ausdruck gebracht. Der Hauptheld des Liedes „Kujim Jě̆yd sin" (Die drei Weißäugigen) hält bei der Vorbereitung einer Blutrache eine Zeitlang seinen Namen geheim und vertauscht ihn gegen einen allegorischen. Zwischen ihm und dem gastfreundlichen Kańin nyrd hözain, dem 'Herrn des Kaninkaps', entspinnt sich der folgende bemerkenswerte Dialog:

„Myjen ne tene Suenys?“

Me taj viśtala taj:

„Menam ved bur niime abu,

Mene taj sulyylasnys-e

Körtem starik pijen..."

„Zabyl', ved, zabyl' svate, sił̧,

S'innam da ved ig že aźźy,

Pel'nam da kyylyylam že, suas, Sexem narodjas vyjymeś ńin, Körtem da narodjas vyjymes.." „Me ved, körtem starik pi ved, Prömyšl'ajta vetlala,

Kyśke bajdyk, bajdyk kyja l'i,

Kyśke köćtor, gaške, kyja, Kömum aby da, śojny pyr kole."

(KNÈ Nr. 6, 435-457)
„Wie heißest du?"

Ich sage:

„Einen guten Namen hab ich nicht, man nennt mich Sohn des Rentierlosen Alten." "Gewiß, Gevatter, so ist es, mit den Augen hab ich es nicht selbst gesehen, aber mit den Ohren hab ichs gehört, es gibt wohl so ein rentierloses Volk, ein gibt es rentierloses Volk." „Ich, Sohn des Rentierlosen Alten, wandere umher und suche mein Auskommen, hier fange ich ein Rebhuhn, ein Rebhuhn fange ich, dort fange ich vielleicht einen Hasen, Rene habe ich nicht, aber essen muB ich."

a) Die Bilder von einem großen Nomadenlager (nach den nenzischen Quellen). Das große Nomadenlager befand sich in der Tundra oder am Ufer des Meeres.

An der Meeresküste

auf der Seite der Bucht

sind siebenhundert Zelte,

die Bewohner der siebenhundert

sind Sieben Sandleute.

(MSFOu 83, S. 188; MSFOu XC, S. 224, 252, 294)

Die Leute des Nomadenlagers, Rentierzüchter oder Jäger, leben isoliert von der Außenwelt (Kommende haben wir nicht, Gehende 
haben wir nicht. - MSFOu XC, S. 327-328; s. MSFOu 83, S. 215: Sie leben. Es gibt keinen, der geht, es gibt keinen, der kommt). In dem jarabc „Sjuhunes älterer Bruder“", der viele Jahrzehnte nach M. A. Castrén und T. Lehtisalo aufgezeichnet wurde, begegnet dieselbe anschauliche Formel: „So begannen wir zu leben, niemand geht von uns fort, niemand kommt zu uns" (Kuprijanova, S. 691). Das ist das sogenannte „eigene Land“, das dem „fremden“ oder „,anderen Land“ gegenübersteht, genau wie im ižma-kolvinischen Epos. Wie es in den Liedern heißt, sind die Leute des Nomadenlagers hauptsächlich mit der Rentierzucht beschäftigt, aber sie kennen auch die Jagd, vor allem auf Wildrene:

\author{
Auf dem Eise des Sees \\ etwa siebzig \\ wilde Rentierstiere lagen, \\ näher \\ kam er, \\ mit seinem Stabe \\ durchschnitt er ihre Hälse, \\ an den Stab spießte er sie, \\ ging (sie) tragen. \\ In seinem Zelt \\ langte er an, \\ auf die Erde legte er sie. \\ (MSFOu 83, S. 237; MSFOu XC, S. 204)
}

b) Die Sujetkomponente b (nach den ižma-kolvinischen Quellen) - die wunderbare Errettung und das Heranwachsen des Rächers begegnet seltener als die zuvor genannte Komponente, und zwar vor allem in den Liedern über Blutrache: Die Feinde haben den Sohn eines erschlagenen Rentierzüchters kör čaśse vyle 'zum Glück der Rentierherde' am Leben gelassen, wollen ihn aber schließlich den Göttern opfern, da sie seine Rache fürchten. Der Junge kann fliehen (im Lied „Kyk Marko" 'Die zwei Marko', KÈPB, S. 250-253). Die Großmutter rettet den Jungen, zieht ihn auf, lehrt ihn das Jägerhandwerk und den Rebhuhnfang und erklärt ihm, wozu die wilden Rentiere da sind (in der Erzählung „Baba-nuka“ 'Großmutter und Enkel', ÈFKF S. 55). Bisher sind 
sechs Varianten dieser Erzählungen in verschiedenen Gegenden der Bol'šezemel'skaja Tundra und auf der Halbinsel Jamal aufgezeichnet worden. Diesen Varianten stehen die epischen Lieder vom Bydtas, dem 'Zögling', nahe, der ein von allen gedemütigter und eingeschüchterter Waisenknabe ist, den Verwandte oder einfach gute Menschen vor dem Hungertod und der Verfolgung durch die Feinde retten und der ein wirklicher Held wird. Das sind die Lieder „Bördyś-gorzyś d'etina" (Der weinende, schreiende Junge) und "S'izimlae ńukl'aśema mort da Bydtas" (Der von sieben Herren Gedemütigte und der Zögling) und andere. Während der Abwesenheit des Recken, unter dessen Schutz der Zögling steht, macht dieser elternlose Junge für die Čums der Holzgesichtigen Brennholz, läuft ,schnell wie ein Pfeil mit der schweren Tracht Holz" und ,verrichtet alle Arbeiten“, er ist absolut rechtlos und wird obendrein „von den Töchtern des Herrn verspottet". Als die Holzgesichtigen sehen, daß er von Tag zu Tag kräftiger wird, rufen sie die Leute aus dem Nachbarland herbei und beschließen, ihn zu töten (KNÈ Nr. 13, 47-74).

Die Sujetkomponente b nach den nenzischen Quellen weist ein ähnliches Schema auf: Leute aus einem „fremden Land“ überfallen das Nomadenlager, verwüsten die Wirtschaft der Sippe, töten die Männer und führen die Frauen in Gefangenschaft. Wie durch ein Wunder bleibt ein kleiner Junge am Leben, den der Feind verfolgt und zu töten versucht, da er seine Rache fürchtet (MSFOu 83, 215-222). Als Knecht und Hirte wird der Junge am Leben gelassen und heimlich von der Großmutter, einer unbekannten Frau oder sogar von der Frau des Gegners, der Schwester, aufgezogen. Durch ihre Unterweisung kommt der Unerfahrene zu Vernunft und Verstand, sie erklären ihm, wozu die dicke Wurzel der Weide gut ist, wie Pfeil und Bogen gemacht werden und wie man mit ihnen umgeht. Hierher gehört zum Beispiel der śudbabc „Siv Noecja“ (Kuprijanova, S. 77). Die Großmutter. verbietet dem Enkel, das von Weiden bewachsene Flußufer entlangzugehen. Es folgen die Übertretung des Verbots, der Kampf des Feindes mit dem Enkel, manchmal der Tod und die wunderbare Auferstehung des Helden (MSFOu XC, S. 282). Auch das Sujet des jarabc „Ser 
Ja Jeval'o" enthält diese Komponente: Eine Frau und ihr Sohn werden von Zeit zu Zeit heimlich von dem Rentierhalter Njadaka besucht. Den Worten der Mutter entnimmt der Held, daß Njadaka ihr älterer Bruder, für ihn also Großvater, ist, daß die Feinde den Mann der Mutter getötet haben und daß auch ihm, dem Sohn, Gefahr droht (Kuprijanova, S. 358-361). (Nach dem Verwandtschaftsklassifikationssystem wird nicht nur der Erzeuger von Vater oder Mutter, sondern auch ein älterer Bruder der Eltern als Großvater (iri) bezeichnet.)

c) Sujetkomponente c (nach den ižma-kolvinischen Quellen), die Reisevorbereitungen des Helden: Um eine Braut zu suchen oder um Blutrache zu nehmen bereitet sich der Held auf eine weite Reise vor. Dabei werden die Vorbereitungen mit einer stets gleichbleibenden Formel folgenden Typs beschrieben:

Pasluhjasys śibedisnys,

Das-e tyśéca körse śibedisnys

Pasluhjasys jöralisnys,

Vitśo myda suutema...

Körys taj mynema,

Tol'ko taj kol'ema,

Gorde bykjas kol'ema,

Sije taj ‘ökti domoony.

(KNĖ Nr. 2, 54-73; Nr. 1, 244-250)
Die Hirten trieben heran, zehntausend Rene trieben sie heran, die Hirten trieben sie in die Hürden, Fünfhundert Rentiere waren dort, die Rentiere liefen auseinander, es blieben nur übrig, die Rentiere von roter Farbe blieben übrig, ich befahl, sie anzuspannen.

Gerade solche anschaulichen Formeln beschreiben oft detailgenau das Leben der Rentierzüchter, wobei die Abbildung der Wirklichkeit mit einer gleichbleibenden Metapher wechselt, die ausdrückt, mit welch ungestümem Tempo das Rentiergespann aufbricht: Nya taj voedisnys, purga pete tolko, me taj ylla vylyn sulala 'Sie jagten davon, nur der Schneestaub stiebte hinter ihnen auf, und ich stehe auf der Straße' (KNÈ Nr. 6, 291-293; Nr. 4, 99-100, 532- 535). Diese Metapher begegnet auch in den folgenden Varianten: Dad'halsulasys bi ved, šuas, ćećcale 'Unter dem halsula-Ring stoben nur so die Funken hervor' (KNÈ Nr. 1, 296-297, 334-335, 432-435; Nr. 2, 128-132, 174-175, 508-509, 554-560); Lym palahjasys sutl'aleny tolko 'Die Schneewehen fliegen pfeifend nur so auf' (KNE Nr. 1, 
453-454); Tuusoo tolajasys ötor-mödor bökas mort moz kol'enys 'Die Frühlingsschneewehen bleiben zu beiden Seiten des Weges wie lebendige Menschen stehen' (KNÈ Nr. 5, 91-95).

Die Sujetkomponente c (nach den nenzischen Quellen) weist dieselbe Struktur auf wie die ižma-kolvinische: Der Held begibt sich auf der Suche nach einer Frau oder, um Blutrache zu nehmen, in ein fremdes Land, und in diesem Zusammenhang beschreiben die Erzähler ausführlich, wie das Rentiergeschirr, die Fuhren und die Schlitten mit den Rauchwaren zurechtgemacht werden:

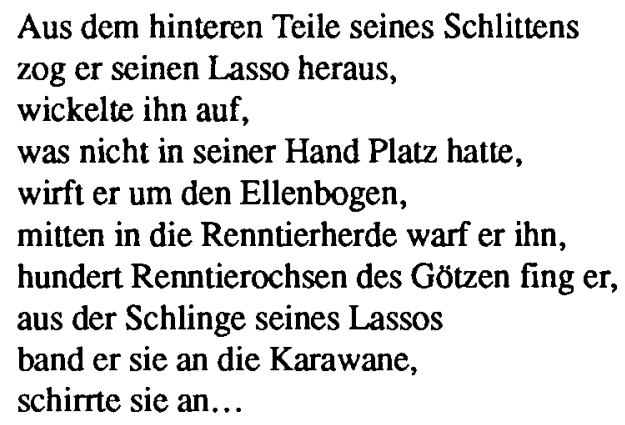

(MSFOu 83, S. 34)

Ähnliche bildhafte Formeln, wie sie schon in den 40er Jahren des vorigen Jahrhunderts festgehalten wurden, sind in den folgenden Aufzeichnungen T. Lehtisalos und Z. N. Kuprijanovas nahezu unverändert geblieben. Hinzugefügt wurden einzelne spezielle Details aus dem Gebiet des Brauchtums und der Psychologie, aber die bildhafte Formel selbst ist im wesentlichen unverändert geblieben: „Er warf das Lasso, fing drei Rentiere im Galopp und riß sie zu sich heran“, „die Knechte trieben die Rentiere herbei, trieben sie in einem Kreis aus Narten zusammen und spannten sie an" oder ,ich nahm die Lenkriemen in die Hände, gehe unter den Rentieren herum und binde vier weiße Rentiere, vier schwarze Rentiere, vier gelte Rentiere an den Lenkriemen" (siehe MSFOu XC, S. 220):

Sie trieben die Renntiere, im Kreise ihrer Schlitten, brachten sie zum Halten, banden die Renntiere, 
schirrten ihre Karawanen an, begaben sich auf die Umzugsreise.

(MSFOu XC, S. 231)

Ebenso wie im ižma-kolvinischen Epos endet die Szene der Reisevorbereitungen traditionell mit der eiligen Abreise entweder der ganzen Familie, die mit einem Zug (einer Karawane) aus Rentierfuhren reist, oder dem nicht weniger plötzlichen Verschwinden des Helden, der sich entweder mit einer Rentierfuhre oder auf Skiern fortbewegt, die unten mit Otternfell beschlagen sind; an dieser Stelle steht regelmäßig die formelhafte Phrase „hinter ihm stiebte der Schnee nur so auf" (Kuprijanova, S. 206).

d) Die Komponente d (nach den ižma-kolvinischen Quellen), der Kampf des Helden, kommt etwa gleich häufig wie die Komponente a, und zwar in den Liedern und Erzählungen aller drei Typen vor, d. h. im Zusammenhang mit der Hochzeit des Helden, der Blutrache und der sozialen Ungerechtigkeit. Das Schema dieser Komponente sieht gewöhnlich folgendermaßen aus: Es beginnt mit einer Prüfung, der Initiation des Helden, der in Spielen mit seinen Brüdern oder Altersgenossen seine Kräfte erprobt. Me ved balujta 'ich treibe Schabernack', sagt er, als er einen Pfeil auf seinen Bruder abschießt, nur um ihn zu erschrecken (KNÈ Nr. 7, S. 305-319). Zu den unabdingbaren Attributen des Recken gehören der schwere Bogen und die Mammutpfeile, die xorej-Stange, der siebenteilige Säbel und manchmal eine Flinte. Mit gleichbleibenden Floskeln wird auch der Kampf des Helden beschrieben, der stets schier endlos und erschöpfend ist. Und hervorgehoben wird darin natürlich auch die Unverwundbarkeit des Helden, der mit Sicherheit alle noch so zahlreichen Feinde besiegt, der Kampf mag dauern, so lange er will. Die Stärke des Helden wird durch das folgende Bild beschrieben:

Kyće da, suas, lyja,

Vorga moz i mune,

Comjys, suas, pöre, Mortys, suas, pöre,
Wohin ich den Pfeil schieße, dort bahnt der Pfeil gleichsam einen Weg wie eine Niederung, der Čum stürzt um, der Mensch stürzt hin, 
Siź me lyjśí. so schieße ich die Pfeile ab.

(KNÈ Nr. 2, 705-709; Nr. 10, 114-119)

Der Held selbst verfügt über die wunderbare Fähigkeit, die feindlichen Pfeile mit der Hand zu fangen und damit dann seine Gegner niederzustrecken (KNÈ Nr. 7, 1059-1070). In dieser Hinsicht ähnelt er den Helden der Islandsagas, die die feindlichen Lanzen im Fluge fingen und damit den Gegner töteten, wie es in der Gisla-Saga, der Njáls-Saga, der Ingjald-Saga und der HolmseinSaga berichtet wird. ${ }^{27}$

Dem Kampf des Helden funktional vergleichbar sind die Erprobungsspiele. Gelegentlich droht der Held oder sein Gegner, bald „zu Besuch“ zu kommen, d. h. einen Überfall zu machen und Blutrache zu nehmen (KNÈ Nr. 1, 428-432; Nr. 10, 70-80; Nr. 11, 385-393).

Sujetkomponente d (nach den nenzischen Quellen): Häufig sind Szenen, in denen zunächst einmal die Kräfte des Helden auf die Probe gestellt werden, einer Initiation, von der es zumeist zwei Varianten gibt. In der einen heißt es, daß der Junge unter Anleitung und Aufsicht der Älteren ,spielt“, d. h. lernt, das Lasso zu werfen und mit Pfeil und Bogen umzugehen; trotz des Tabus, des Verbots, wandert er das weidenbestandene Ufer flußaufwärts, bisweilen auch flußabwärts. In anderen Varianten zieht eine Frau oder ein Mädchen, von den Leuten oder den Brïdern unbemerkt, den Jungen in einem Weidengehölz in der Tundra auf. Sie beauftragt die Schwester des Helden, ihren Bruder herbeizubringen, damit er durch Augenschein feststelle, ob der Held zu der großen Tat bereit und stark genug geworden sei. Und erst, wenn sie von der Reife und der Kraft des Helden überzeugt ist, übergibt sie ihm die Waffen und rüstet ihn für die Reise aus. In gleichbleibender Weise wird die Bewaffnung des Helden beschrieben. Fast immer werden Bogen und Pfeile erwähnt. Der Bogen des Recken wird immer als schwer, groß, gewaltig bezeichnet. Ein gewöhnlicher Sterblicher kann ihn nicht vom Boden anheben, und auch der Held selbst kommt anfangs kaum damit zurecht, kann ihn kaum hinter sich herschleifen. Der Bogen des Schwiegervaters, den der 
Schwiegersohn so gern haben möchte (für den Fall der Verweigerung droht er sogar mit Krieg), dieser Bogen also ist so straff, daß der Held ihn anfangs nicht zu spannen vermag: In der Richtung nach vorn ein Fußgänger schleppt einen Bogen, es war eine Kerbe am Bogenende, dahin kam er, dort begannen sie zu stehen (MSFOu 83, S. 204). Die Mutter, die den Sohn für die Reise ausrüstet, sagt ihm über den Wunderbogen:

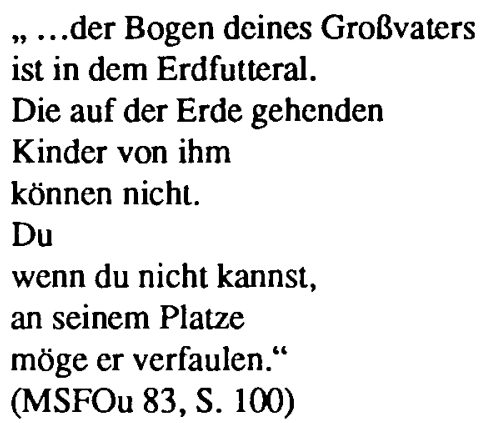

Mit großer Sorgfalt beschreibt der Erzähler die einzelnen Details des Reckenbogens und benennt dessen verschiedene Spielarten. Hinsichtlich dieser Ausführlichkeit steht das ižma-kolvinische Epos hinter dem nenzischen zurück. In dem śudbabc „Argiš reist“ holt eine schwarze Frau aus der mittleren vańd'ej-Narte einen siebengliedrigen Bogen für den Helden (MSFOu 83, S. 77). In einem anderen sudbabc schleppt der Held mit Namen Siv Noecja gleich mehrere schwere Bögen mit sich herum, einen straffen Bogen, einen aus Dürrholz, einen schuppenartigen, einen grünen und einen bequemen Bogen, und während des Kampfes tauscht er je nach Bedarf den einen gegen den andern aus. Ebenso verschiedenartig sind seine Pfeile: Er hat gegabelte Pfeile und Mammutpfeile, die einen besonders gefährlichen Gegner beeindrucken sollen (Kuprijanova S. 87-94).

Etwas seltener ist die Bewaffnung mit der 4 Sashen langen kniedicken $\chi o r e j-S t a n g e$ (Kuprijanova S. 90, 123, 125); der ižmakolvinische Erzähler vergleicht die vier Sashen lange xorej-Stange mit dem Balg eines Rentierkälbchens (tel'a vol' paśta). Auch das siebengliedrige Schwert des Recken wird erwähnt: Seine Frau 
nahm aus dem Schlitten ein Schwert hervor, sie zog gerade das siebengliedrige Schwert (MSFOu XC, S. 225).

Die nenzische poetische Formel für den Kampf des Helden zeichnet sich durch beeindruckende Gleichförmigkeit aus: Die Gegner schießen eine unzählbare Menge von Pfeilen aufeinander ab, und sobald die Pfeile alle sind, beginnt der Nahkampf. Dabei bemüht sich der Held, den Gegner über sich zu werfen oder ihn hochzuheben und dann zu Boden zu schleudern. Der Kampf dauert ein Jahr, drei oder sogar zehn Jahre, die Zugvögel, Gänse und Schwäne, ziehen immer wieder über die Kämpfenden hinweg: „Zehn Jahre schießen sie. Die Zugvogel-Gänse kommen, gehen." (MSFOu XC, S. 255, 280, 307; MSFOu 83 S. 259, 260, 46-47, 71-73, 78, 88, 90, 97, 201-203, 214).

Auch der Ausgang des Kampfes ist traditionell stets gleich: Nach dem langjährigen Kampf sind alle Feinde erschlagen mit Ausnahme eines einzigen mächtigen Gegners, mit dem der Held sich noch geraume Zeit schlagen muß, aber schließlich bleibt keine Seele am Leben, nicht einmal ein jando-Hund.

Ebenso wie für das ižma-kolvinische Epos ist es charakteristisch auch für die nenzischen śudbabc und jarabc, daß der Kampf des Helden metaphorisch ersetzt werden kann, zum Beispiel durch Spiele, in denen der Held und seine Verwandten mit dem Herrn des fremden Landes oder dessen jüngstem Sohn ihre Kräfte messen. Dieser Herr, der Brautvater, stellt dem Bräutigam schwer erfüllbare Aufgaben, aber der Held wird mit allen Schwierigkeiten fertig und besiegt den mächtigen Gegner.

So steht es mit der Sujetebene im ižma-kolvinischen und im nenzischen Epos, und so sehen die vier wichtigsten Sujetkomponenten aus, die im Epos der Kolvinen und Nenzen mit auffallender Häufigkeit immer wiederkehren. In der Fülle der nicht formelhaften epischen Verse und der stark improvisierenden poetischen Struktur des ižma-kolvinischen und des nenzischen epischen Textes dienten solche konstanten bildhaften Sujetformeln den Erzählern gewissermaßen als Orientierungspunkte, die den schöpferischen Akt begünstigten.

Neben den Mitteln des Sujets waren es die der Komposition 
und des Stils, die im epischen Schaffen der Kolvinen und Nenzen den Erfolg der Improvisation gewährleisteten. (Ab hier bis S. 80 ist R. A. Mikušev Mitautor des Textes.) Die Epen der Kolvinen und Nenzen sind ihrer ureigensten Natur nach und in vollem Umfang Produkte der Improvisation. Natürlich hat in der Poesie aller Völker zu allen Zeiten die Improvisation eine bedeutende Rolle gespielt. Dabei waren die Improvisiertheit und die Traditionalität zwei Hypostasen ein und derselben Erscheinung. Aber beim ižma-kolvinischen und beim nenzischen Epos wird die Improvisiertheit noch zusätzlich durch eine charakteristische NichtFormelhaftigkeit des epischen Verses verstärkt, von der weiter unten die Rede sein soll. Darüber hinaus ist im ižma-kolvinischen und im nenzischen Epos die Rolle der Variationsparallelismen auf ein Minimum reduziert - im Unterschied beispielsweise zu den ostseefinnischen und obugrischen epischen Liedern mit ihren obligaten Variationsparallelismen, die den Prozeß der Improvisation erleichterten und die seinerzeit von W. Steinitz beschrieben worden sind.

Und schließlich verdient noch ein Umstand hervorgehoben $\mathrm{zu}$ werden. Die epischen Lieder der Nenzen und noch mehr die der Kolvinen imponierten durch ihren Umfang, die große Zahl der Verszeilen. So zählt das ižma-kolvinische Lied "Kerča-ju hözáain" (Der Herr des Kerča-Flusses, KNÈ Nr. 1) 1085 Verse, „Sero Jovlo “ 775, „S'izim aresa d'etina" (Der siebenjährige Junge, KNE Nr. 3) 1005, „Važen olis öti S'udbej“ (Es war einmal ein S'udbej, KNÈ Nr. 4) 983, „N'ośi - ozyr mort" (N'ośi, ein reicher Mann, KNÈ Nr. 5) 1432, „Kujim Ježyd sinma“ (Die drei Weißäugigen, KNÈ Nr. 6) 1252, "Kujim Tyngos" (Die drei Tyngos, KNE Nr. 6) 1256 und "S'ad'ej starik pi" (Der Sohn des alten S'ad'ej, KNÈ Nr. 8) 1258 Verse. Zum Vergleich sei erwähnt, daß die Heldenlieder bei den Nachbarn der Kolvinen, den Obugriern, nach Angaben $\mathrm{H}$. Paasonens ${ }^{29}$ knapp fünftausend Verse umfassen.

Die nenzischen śudbabc und jarabc stehen den ižma-kolvinischen Liedern an Umfang nach. So besteht beispielsweise das Lied „Der Name des Herrn von 70 Čums“ aus 1234 Versen, aber alle anderen bewegen sich in einem Rahmen von 100 bis 450 Ver- 
sen. Das gleiche Bild ergeben auch die Angaben Castréns: Nur der śudbabc „Argiš reist" umfaßt 1076 Verse (Nr. 3), das Lied Nr. 4 dagegen 948, und alle andern zwischen 20 und 400 Verse.

Angesichts der Tatsache, daß das Epos nicht formelhaft ist, die Variationsparallelismen nur gering an Zahl sind und das Werk selbst einen enormen Umfang besitzt, haben die kompositionellstilistischen Ausdrucksmittel bei den Ižma-Kolvinen und den Nenzen eine besondere Bedeutung erlangt.

Die Komposition des ižma-kolvinischen Epos hat im finnischugrischen Epos kein Analogon, genauer gesagt, fast keines; statt dessen finden sich Gemeinsamkeiten in der Komposition des samojedischen Epos. Die epischen Lieder der Völker und zumal diejenigen von so gewaltigem Umfang, wie es die ižma-kolvinischen sind, stellen eine organische Kette von Bildern und Episoden dar, die konsequent miteinander verbunden sind. Die kompositionelle Verbindung solcher ins Detail gehenden Episoden kann in anderen poetischen Systemen oftmals gar nicht wiedergegeben werden oder ist dort kaum verständlich. So erging es auch der Komposition der ižma-kolvinischen epischen Lieder: Sie entstand als eine neue unikale Qualität beim Zusammentreffen des samojedischen und des finnisch-ugrischen poetischen Systems.

Bekanntlich gibt es in der samojedischen Volksdichtung besondere kompositionelle Verbindungselemente, die die Logik und Einheitlichkeit des epischen Sujets und die Kontinuität der verschiedenartigen Episoden gewährleisten, die sogenannten „vadasudbabc", russ. slovo-pesńa, slovo-vozduh, wörtlich: „Gesang, Lied", „Lied-Luft", von Castrén in seiner samojedischen Volksdichtung deutsch mit „Heldenlied“" wiedergegeben.

Die kommunikative Rolle des nenzischen kompositionellen Verbindungselements, des „Lied-sudbabc", dürfte kaum einem Zweifel unterliegen. Es verbindet einzelne, bisweilen auch heterogene Episoden zu einem einheitlichen künstlerischen Ganzen. Seine Funktionen sind recht mannigfaltiger Natur und bestehen nach Z. N. Kuprijanova in Folgendem: Es ,findet die Helden, von denen es erzählen wird, ...stellt sie dem Leser vor, gibt ihnen Namen, ...tritt als aktiv handelnde Person in Erscheinung, ... beob- 
achtet die Taten der Helden, ... wandert durch das Nomadenlager und lauscht den Gesprächen seiner Bewohner, und ergreift... schließlich das Wort, um den Helden des Liedes eine Einschätzung abzugeben" (Kuprijanova S. 37-38).

Ein ähnliches kompositionelles Verbindungselement findet sich in der Folklore eines anderen samojedischen Volkes, der Enzen, in deren historischen Überlieferungen es zum Beispiel eine „slovorec" diese „Lied-Rede“ stellenweise mit der enzischen Kategorie "ngo". Nach den Beobachtungen G. N. Gračevas steht die Kategorie "ngo" mit dem traditionellen Weltanschauungssystem der Nganasanen und mit der geistigen Aneignung der Wirklichkeit in Verbindung. Wie auch das Wort "ngo " für sich in der Bedeutung 'Himmel, Luft, Himmelsbewohner, Gott' verwendet wird. ${ }^{31}$

Es gibt noch eine weitere charakteristische Besonderheit bei der Verwendung der enzischen „Lied-Rede“. In den enzischen Überlieferungen, beispielsweise in der Überlieferung „Morrèdè und die Märchenleute", wird bald in der ersten, bald in der dritten Person erzählt, und diese unterschiedlichen Teile werden durch die „Lied-Rede" miteinander verbunden.

Anders als in der enzischen Folklore ist, nach den Publikationen Castréns, Lehtisalos und Kuprijanovas zu urteilen, im nenzischen Epos ein ähnlicher Wechsel zwischen erster und dritter Person nicht zu beobachten. Der Unterschied zwischen den Typen des epischen Erzählers wird bei den Nenzen durch die Gattungsprinzipien der sudbabc und jarabc hervorgehoben: Während im sudbabc als Erzähler eine dritte Person auftritt (in diesem Fall hat das Fehlen oder Vorhandensein eines "Gesangs“ im Text keinen Einfluß auf den Charakter der Erzählung), wird im jarabc in der ersten Person erzählt. Zwar sind Ausnahmen von der Regel dennoch zu beobachten: Einer von sechs sudbabc in den Aufzeichnungen T. Lehtisalos ist von der Person des jungen Helden, $d . h$. in der ersten Person, erzählt. Dasselbe Bild bieten die Aufzeichnungen Z. N. Kuprijanovas: Zwei Varianten des sudbabc „Der Sohn des Herrn Jabta Salja" haben die Form der ersten Person. Beachtung verdient der Terminus jarabc, der als „Klagelied“ 
übersetzt wird. Obgleich diese Gattung des nenzischen Epos nichts mit den rituellen Klagen zu tun hat und sich von den Klageliedern der russischen Folklore unterscheidet, weist er dennoch in nicht geringem Ausmaß Merkmale persönlicher Klagen auf: den lyrisch-epischen Charakter und den autobiographischen oder den biographischen Anfang.

Etwas Ähnliches ist auch in der Folklore der Komi-Syrjänen von der Ižma, den Nachbarn der Tundranenzen, zu beobachten. Bei ihnen gibt es neben den rituellen Bestattungs-, Hochzeits- und Rekrutierungsklagen (kulemaly, kölyś dyrśa, armijae kolt'edigen) spezifische lyrisch-epische Improvisationen autobiographischen Charakters, sogenannte nurankyy, die auf der Grenze zwischen den nenzischen jarabc, den lappisch-karelischen Joikus und den obugrischen Schicksalsliedern stehen. Vielen nurankyy ist, ebenso wie den nenzischen jarabc, ein erzählerisches Element, das sie dem Epos annähert, nicht fremd. Und ebenso wie bei den Nenzen werden bei den Komi-Syrjänen von der Ižma mit ein und demselben Terminus börd'eććankyy (wörtlich: Klagelied) sowohl die rituellen Klagen als auch die lyrisch-epischen Improvisationsnurankyy bezeichnet.

Als eine distinktive Besonderheit des "Gesangs“ ist ohne Zweifel seine räumlich-zeitliche, kommentierende und erzählende Funktion zu werten. Ein anschauliches Beispiel für die räumliche und zeitliche Perspektive bildet der Beginn des Liedes „Der Sohn des Herrn Jabta Salja“ (Variante b), in dem ein "Gesang" die Hauptrolle spielt: „An einem kleinen Flüßchen, dessen Ufer mit Weiden bewachsen war, stand ein kleiner Čum. Der Gesang ließ sich durch den Rauchabzug in den Čum hinab. In diesem Čum lebt eine Frau. Sie zieht zwei Kinder auf, einen Sohn und eine Tochter." So sieht der erste Plan der epischen Erzählung aus, der ohne einen merklichen und noch weniger einen akzentuierten Übergang mit einem nach Zeit und Raum ganz anderen, zweiten epischen Plan verbunden ist. Und so wird mit Hilfe des „Gesangs" in einem Lied stets aufs neue wiederholt: „Von hier eilte der Gesang mit dem Wind von dannen. Dort irgendwo war ein Čum. In diesem Čum wohnte Han Hadengot. Han Hadengot 
schlief und träumte: An einem Flüßchen mit weidenbewachsenen Ufern steht ein kleiner Čum, und in diesem Cum zieht eine Frau zwei Kinder auf" (Kuprijanova S. 182). Die Verbindung von zwei räumlich und zeitlich verschiedenen epischen Plänen mit Hilfe des "Gesanges" begegnet ebenso organisch in einer anderen Variante dieses sudbabc: Das Mädchen und der Junge springen auf eine Eisscholle im Meer, um sich vor Han Hadengot zu retten, und treiben auf dem Meer $\leftrightarrow$ das Mädchen und der Junge befinden sich schon auf dem Festland (Kuprijanova S. 126).

Vielfältig ist auch die kommentierende Funktion des Kompositions-,,Gesangs": Er kommentiert und präzisiert die Handlung, den Ort und den Charakter der Handlung sowie den Namen der handelnden Person: „Am weidenbewachsenen Ufer eines Flüßchens steht ein kleiner Čum. Der Gesang sah: Dort lebte eine Frau“ (Kuprijanova, S. 77); „Der Gesang sah: Am fauligen Steilufer eines Sees steht ein kleiner Čum, ein armseliger Čum, und in diesem Čum wohnt eine Frau“ (ebenda S. 122); ,Der Gesang sah: Zwei Kinder liefen ganz weit fort“ (ebenda S. 130); „Er legte die siebte Waffe an und machte sich auf den Heimweg. Er schleppt sieben Bögen. Der Gesang nannte ihn beim Namen: 'Das wird sicherlich Siv Noecja sein"“ (ebenda S. 80). Kurz darauf holt Siv Noecja in der Tundra einen Unbekannten ein, und sofort kommt der "Gesang" den Zuhörern zu Hilfe, indem er den Namen des Unbekannten nennt: „Das ist sicherlich Sidja Pariseè (ebenda S. 81). So macht der „Gesang“ im sudbabc „Siv Noecja“ uns mit den Personen namens Pèkocja Huhur, Tivak Vakacjam Sjakalpadaraha, Jes' Tota und Nèva Syhydëda bekannt (Kuprijanova $S$. 83-85). Im śubabc „Der Sohn des Herrn Jabta Salja“ wird berichtet, daß die fliehenden Kinder in der Tundra am Ufer des Meeres einen eisernen Lastschlitten sahen, dessen Kufen tief in die Erde eingesunken waren. Und hier schaltet sich wieder der „Gesang“ in die Erzählung ein, um sie fortzusetzen: „Der Gesang sagte: Der Schlitten gehörte dem Herrn Jabta Salja" (Kuprijanova S. 125).

Schließlich kann der "Gesang“ in der Rolle des epischen Erzählers auftreten, der das Sujet vorantreibt und dieses oder jenes Ereignis vorbereitet. Charakteristische Formeln, mit denen sich 
der „Gesang“ in die Handlung einschaltet, sind z. B. die Wendungen „der śudbabc sagt“, ,der sudbabc berichtet jetzt von ihm“, „,der sudbabc erzählt" und andere: Das Heldenlied berichtet (jetzt) von ihm, der andere (Bruder) blieb (MSFOu 83, S. 143); Das Heldenlied sagt: Nur ein Mann geht zu Fuß. Der von ihm gehaltene Stab, Faulbaumstab, ist sein Name (MSFOu 83, S. 223).

Ebenso wie in der Komposition der nenzischen śudbabc und jarabc gibt es auch in der ižma-kolvinischen kompositionelle Verbindungselemente mit unterschiedlichen Bezeichnungen: körennej sylys 'Ursänger', körennej mojdys 'Urerzähler', pöslevića 'Sprichwort' oder einfach auf Russisch vozduh 'Luft' (vozduhys vistale 'die Luft erzählt'). Die Funktionen der ižma-kolvinischen kompositionellen Verbindungselemente sind identisch mit denen, die das „Heldenlied, der Gesang“ im nenzischen Epos erfüllt. Diese Frage ist in meinem Buch ,Die epischen Formen der syrjänischen Folklore“ (S. 110-112)16 ausführlich behandelt, und deshalb beschränke ich mich hier auf einen ergänzenden Aspekt des Problems, der für das Verständnis der syrjänisch-nenzischen Kontakte im Bereich der Folklore wichtig ist, und zwar auf die Umgestaltung und Transformation der samojedischen epischen Komposition auf finnopermischem Boden. Wie oben bereits bemerkt, war dem finnopermischen metaphorischen System die Formel des „Ursängers“ absolut fremd und unverständlich. Allerdings lassen sich mehr oder wenige nahe Analogien zum nenzischen „Gesang" im Epos der obugrischen Völker finden, wo in der Rolle des kompositionellen Verbindungselements ziemlich häufig der „Mensch aus dem Lied“ oder der „Mensch aus dem Märchen" begegnet. Und auch der Held selbst erinnert, wenn er das Schicksal beschwört, manchmal an das „Lied“ und an das „Märchen“, denen es bevorsteht weiterzugehen, und bedient sich der formelhaften Beschwörung: „Wenn mein Märchen weiter geht, wenn meine Geschichte weiter geht, mögen sie alle auf diesen von mir abgeschossenen Pfeil gefädelt werden, wie Frühlingsfische, Herbstfische (auf den Bratspieß) gefädelt werden." (MSFOu 109, S. 169); „Wenn mein Lied weitergeht, wenn mein Märchen weitergetragen wird, werde dieser Birkhuhnschwarm 
von sieben Birkhühnern mit dem einen von mir abgeschossenen Pfeil wie mit einem guten Bratenspieß, auf den kleine Fische gespießt werden, ganz aufgespießt" (MSFOu 109, S. 176) ${ }^{32}$.

Fernerliegende, aber zulässige Analogien zum nenzisch-kolvinischen „Gesang“-Material bieten die isländischen Sagas, in denen bekanntlich verschiedenartige Episoden in recht eigenwilliger Weise miteinander verbunden werden: „Jetzt muß erzählt werden, was inzwischen zu Hause geschah“ (Njáls Saga), ,Jetzt muß erzählt werden, was zu Hause geschah“ (Njáls Saga), ,Jetzt muß erzählt werden, daß Aud zu Gisla geht und sagt (Gisla-Saga) u. a. ${ }^{33}$

Welchen Ausweg fanden die Schöpfer des Epos, als sie es im Ižma-Dialekt der komi-syrjänischen Sprache wiedererschufen und es der bildhaften Struktur der finnopermischen Folklore anglichen? Die Suche bewegte sich in verschiedenen Richtungen.

Wie weiter oben ausgeführt, bestand die Hauptfunktion des „Gesangs und des Ursängers" darin, die heterogenen erzählerischen Episoden zu einem einheitlichen künstlerischen Ganzen zu verbinden. So bestehen zum Beispiel die ižma-kolvinischen epischen Lieder aus einer Einleitung, quasi einer Vorgeschichte des Helden, der Erzählung, einer oder mehreren Episoden aus seinem Leben und schließlich dem Finale mit dem Triumph des Guten über das Böse. In der Einleitung werden gewöhnlich der Ort und die näheren Umstände der Handlung sowie die Beziehungen der handelnden Personen zueinander vorgestellt. Einen wesentlichen Bestandteil des Liedes bilden einige poetisch selbständige Bilder. So besteht das Lied „Hetenzej“ aus den folgenden Bildern: 1) Der Jüngling „spielt", das heißt, er schießt einen Pfeil ab, der eine Füchsin und drei wilde Rentiere durchbohrt. 2) Der Jüngling begibt sich auf die Suche nach dem Heldenpfeil. 3) Der Jüngling begegnet unterwegs einer Gruppe von Leuten aus der Sippe Vèli, die ihm von der Tragödie seiner Brüder berichten, worauf er ihnen sofort zu Hilfe eilt. 4) Der Jüngling findet die saju-Feinde und kämpft mit ihnen. 5) In der Gestalt eines Vogels kommt das Mädchen Hanovej dem Jüngling zu Hilfe geflogen. 6) Der Vogel verwandelt sich in das schöne Mädchen Hanovej. 7) Die Hochzeit des Jünglings mit Hanovej. In dem Lied „Böža ku parka“ (Der 
Hermelinpelz) gibt es ebenso selbständige Bilder: 1) Die Sippe Weißer Pelz, in der ein Knecht alle schmutzigen und schweren Arbeiten macht und in dem Status eines Sklaven lebt, begibt sich auf eine Reise. 2) Unterwegs erhebt sich ein Sturm, der alle Menschen und Gegenstände mit sich fort reißt, nur Hermelinpelz bleibt allein übrig. 3) Hermelinpelz schlägt die Ärmel gegeneinander, erhebt sich in die Lüfte und fliegt zum Čum des alten Lando. 4) Hermelinpelz beteiligt sich an einem Wettkampf, der beim Čum des alten Lando stattfindet, nimmt den Bogen in die Hand, den sonst niemand aufzuheben vermag, und trifft sicher ins Ziel.

Fast immer werden solche Episoden von verschiedenen Erzählern mitgeteilt, meistens jedoch in der ersten und dritten Person. Im nenzischen Epos nahm dieses Genre, die Natur dieses epischen, in der dritten Person konstruierten Genres der śudbabc und der in der ersten Person konstruierten jarabc dem Problem gewissermaßen die Schärfe und ließ die Übergänge zwischen den Sujets weniger spürbar werden.

Ein anderes Bild ergibt sich im ižma-kolvinischen Epos. In der ižma-kolvinischen epischen Komposition gibt es keine genaue Unterteilung in Erzählungen der ersten oder dritten Person, ja, in den meisten Liedern wechseln erste und dritte Person einander beständig ab und geraten nicht selten auch durcheinander. Ein anschauliches Beispiel dafür bietet das Lied "Vavl'o pomlas" (Von Vavl'o, Nr. 11). Darin figurieren zwei selbständige Erzähler, und zwar Onkel und Neffe. Beide berichten natürlich in ihrem eigenen Namen, d. h. in der ersten Person. Zunächst erzählt der Neffe, was sich ereignet. Von ihm erfahren wir, was sich in Obdorsk im „Quartier“ des verräterischen Arsenij des Behaarten zutrug:

Drug-e, šuas, pemdylis, Bijys taj, suas, pemdylis,

Seśśa taj bara jugdis, Bara taj i jugdis, D'ad'elyś taj bośtemaś, Pyzan da bőkas lićkemaś, D'ad'es taj i lićkemaś, Tydale taj, suas,
Plötzlich erlosch, das Feuer erlosch, und es wurde wieder hell, es wurde wieder hell, sie packten meinen Onkel, sie drückten ihn auf den Tisch, sie drückten meinen Onkel, offensichtlich 
Körtooleny, Suas,

Sutugaen taj gartenys,

Mene taj bara vosjisnys...

(KNÈ Nr. 11, 340-350) begannen sie, ihn zu binden, binden ihn mit einem Eisendraht, sie stürzten sich auf mich...

Natürlich fügen sich die Dialoge zwischen Onkel und Neffen und zwischen dem Onkel und seinen Feinden in der Wiedergabe des Erzählers wie auch in anderen epischen Liedern organisch in den Fluß der Erzählung sowohl des Onkels als auch des Neffen ein. In dem erwähnten Lied jedoch reißt der Bericht des Neffen im 393. Vers nach seinen kampflustigen Drohungen an die Adresse der Peiniger seines Onkels unerwartet ab (Korke ved vola, jur ćaškase d'ad'elyś korśa, gösti ved $i$ vola Y̌̌yd da Obdorskejjannyd 'Irgendwann werde ich kommen, den Kopf des Onkels finden, zu euch zu Besuch kommen, in euer großes Obdorsk', Nr. 11, 383-393). Der darauffolgende 394 . Vers beginnt fast unmerklich mit einem Verbindungselement in Gestalt eines präzisierenden Hinweises namens eines ganz anderen Erzählers, wobei Vavl'os Bericht ebenso wie der erste Teil in der ersten Person abgefaßt ist. Der präzisierende Hinweis lautet folgendermaßen: Me taj da, šuas, Vavl'o taj 'Ich aber, Vavl'o...' Erst nach dieser Bemerkung beginnt der neue Bericht:

Me taj da, Suas, Vavo taj,

Korkenas taj pal'ali,

Korkenas taj pal'ali,

Viźlyśi taj as vylam,

Viźlyśi taj as vylam:

Mene taj, suas, gartemaś...

(Nr. 11, 394-400)
Ich aber, Vavl'o, ich kam schließlich zu mir, ich kam schließlich zu mir, schaute an mir herab, schaute an mir herab: Man hat mich offensichtlich gefesselt...

Der erste Erzähler, der Neffe, ist an der weiteren Erzählung nicht mehr beteiligt. Von Onkel Vavl'os Mißgeschicken und Qualen berichtet nur noch dieser selbst.

In dem besprochenen Lied ist der ižma-kolvinische Sänger bei der Vereinigung der von zwei verschiedenen Personen her konstruierten Erzählpläne ohne „Gesang“ und ohne „Urerzähler“ ausgekommen. Er beschränkte sich auf eine kaum merkliche, für das 
Verständnis des Liedes jedoch wesentliche Präzisierung, die die Veränderung im Handlungsverlauf und den Wechsel des Erzählers ankündigt (Ich aber, Vavlo). So sah die eine Methode aus, die samojedische epische Kompostion auf dem Boden der finnopermischen Folklore umzugestalten, eine ziemlich produktive Methode der Annäherung zweier verschiedensprachiger metaphorischer Systeme. Jedenfalls war eine Komposition wie die des Liedes von Vavlo den finnopermischen Sängern nicht fremd, und sie hat in keiner Weise die Rezeption seines Sujetschemas erschwert. Übrigens kann man davon ausgehen, daß eine solche epische Komposition in ihrer vereinfachten Form relativ spät entstanden ist. Darauf weist auch der Inhalt des Liedes hin, in dem es um reale historische Ereignisse geht, die nicht früher als auf die erste Hälfte des 19. Jahrhunderts zu datieren sind.

Eine andere Methode war mit großem „Aufwand" verbunden, obwohl ihre Produktivität ebenfalls keinem Zweifel unterliegt. Es geht darum, daß in vielen ižma-kolvinischen Liedern bisweilen die erste und die dritte Person Singular und Plural wechseln oder zusammenfallen. So sind die Lieder „Kujim Jě̆yd śin“ (Die drei Weißäugigen, Nr. 6, 1-20), „Kujim Vaj vok“ (Die drei Vaj-Brüder, Nr. 9, 65-71) und andere aufgebaut. Das Lied „Die drei Vaj-Brüder" beispielsweise enthält das märchenhaft-novellistische Sujet einer Menschenopferung: Die drei Brüder, Jäger, haben eine Pechsträhne, sie machen keine Beute. Um dem Hungertod zu entgehen, beschließen zwei von ihnen, der älteste und der jüngste, den mittleren Bruder zu opfern. Im Lied heißt es darüber:

Me eg pooźy,

Nya 3agedisnys...

Mi virse karim...

(KNĖ Nr. 9, 66-71)
Ich (d. h. der jüngste Bruder, 1. Pers. Sg.) erschrak nicht, Sie (d. h. der älteste und der jüngste Bruder, 3. Pers. PI.) haben mich erwürgt, Wir (d. h. der älteste und der jüngste Bruder, 1. Pers. PI.) haben Blut vergossen... 
Bei aufmerksamem Lesen oder Hören des Liedes wird Folgendes klar: Der älteste und der jüngste Bruder führen ihren mittleren Bruder zur Opferstätte Y3̌yd Halimer mylk und opfern ihn (Voknyse taj, šuas, ว̆agedisnys nin $i$ 'den Bruder erwürgten sie'). Der älteste Bruder ist über die Kaltblütigkeit des Jüngsten erstaunt (Voke, in nin drögnitly 'Bruder, du hast nicht einmal gezittert'), worauf der jüngste Bruder selbstzufrieden erklärt: Me ved og $i$ poozy 'Ich habe doch keine Angst' (ich erschrecke nicht). Danach opfern sie, d. h. der älteste und der jüngste Bruder, ein ungezähmtes Rentier, und wir, das sind wieder der älteste und der jüngste Bruder, lassen das Rentier ausbluten und beschmieren sich mit dem Blut, um sich von der Sünde zu reinigen. Das sind Inhalt und Handlungsverlauf, die hinter dem Wechsel der ersten und dritten Person und dem Wechsel von Singular und Plural stehen.

In ähnlichen Liedern ist der Kolvine in der Regel auch ohne spezielle kompositionelle Verbindungselemente ausgekommen. Und obwohl der Leser oder Hörer letztendlich den Wechsel der grammatischen Genera und Numeri durchschauen mag, so hat dieser Wechsel bzw. dieses Durcheinander doch in gewissem Umfang die Aufnahme des epischen Textes erschwert.

Eine dritte Methode schließlich bestand darin, daß das samojedische kompositionelle Verbindungselement "Gesang" in mehr oder weniger umgestalteter Form als körennej mojdys oder körennej sylys 'Urerzähler, Ursänger' oder pöslevica, Sprichwort, in den syrjänischen Text einbezogen wurde. Solche kompositionellen Verbindungselemente lenken die Aufmerksamkeit der Zuhörer nicht nur auf eine Wende im Sujet bzw. Handlungsverlauf, sondern auch auf das nach Inhalt und Sinn Wichtigste. Der kolvinische Erzähler, der das Werk rezitiert, betrachtet sich selbst nur als den Überbringer dessen, was ihm ein „Urerzähler oder -sänger" von oben eingibt, der gleichsam der eigentliche, authentische und unsichtbare Erzähler oder Sänger ist. Taje ved og me vistoo, taje körennej mojdysys 'Das sage nicht ich, sondern der Urerzähler' - an solchen und ähnlichen Wendungen sind die Lieder und Erzählungen der Kolvinen im Dorf Abez' reich. Einem ebensolchen Phänomen begegnete ich in der Folklore des Dorfes Harut 
in der Bol'šezemel'skaja Tundra. Dort vergaß der Erzähler, der von den Taten des Recken Dik Valej berichtete, nicht die Replik Taje pöslevića viśtale 'Das erzählt das Sprichwort', womit er sich völlig von dem mythischen „Ursänger“" abgrenzt. Der ižma-kolvinische „Ursänger“, eine ganz abstrakte Persönlichkeit, wird nichtsdestoweniger auf Schritt und Tritt personifiziert, anthropomorphisiert und mit den Eigenschaften eines lebendigen, konkreten Menschen ausgestattet. Aus einer Quelle erfahren wir, daß der sogenannte „Ursänger" in einen Cum trat, sich auf das Bett setzte und hörte, wie jemand gähnte. Und hier setzte der Sänger (nicht der Ursänger, sondern der reale, wirklich singende - Anm. A. M.) ohne jede Pause sein Lied mit den Worten fort:

Körennejys bara na

S'yligmoz viśtale

Taje voß́es-e.
Der Ursänger aber, erneut anhebend, erzählt seine Erzählung.

Die anderen Quellen bieten nicht weniger ausdrucksvolle Beispiele: Taje bökyn sulale, körennejys 'Da steht er an der Seite, der Ursänger' oder So taj pizes pom vylas puksis da kyyze 'Da hat er sich hingekniet (zu mir) und lauscht'.

Auf den ersten Blick hat es den Anschein, als füge sich in solchen Fällen das Bild des „Ursängers" organisch in das künstlerische Gewebe des Werkes ein. Jedoch selbst in diesen, anscheinend resultativen Fällen wird die Fremdheit des Bildes und ebenso die Fremdheit des samojedischen kompositionellen Elements im finnopermischen Bildsystem deutlich. In diesem Sinne bildet auch das Lied Kujim Tyngos (Die drei (Brüder) Tyngos) keine Ausnahme; darin taucht noch eine weitere Variante des „Urerzählers" auf: mojd nuödys, 'der die Erzählung Führende', mojd nuöde 'führt die Erzählung'. In dem Bild des „die Erzählung Führenden“" sind Züge sowohl des Erzählers als auch des Helden, des Jüngsten Tyngos, der die älteren Brüder vor einer weiten Reise verabschiedet, verschmolzen:

Kyke da voke ved muninys,

Kyke da Tyngos voke ved,
Die beiden Brüder eilten davon, die beiden Tyngos-Brüder, 
Me taj kol'i ved, suas-ej,

Mojdse taj me ved nueda,

Mojd nuedyś, me ved kol'i taj,

Mameked kyken ved kol'im taj,

Mamelyś korke ved kora:

„Mame ved ńöövử vajly.“

(KNÈ Nr. 7, 132-139) ich aber bin geblieben, ich führe die Erzählung voran, ich, der die Erzählung Führende, bin geblieben, mit der Mutter bin ich zu zweit geblieben, irgendwie habe ich angefangen, die Mutter zu betteln:

„Mutter, gib mir Pfeil und Bogen.“

Danach verschwindet das Bild von dem „die Erzählung Führenden" ganz, das Lied wandelt sich zu einem gewöhnlichen und typischen komi-syrjänischen Epos.

Wie wir sehen, hat die ižma-kolvinische epische Komposition etliche Merkmale angenommen, die dem nordsamojedischen Epos eigen sind, und zwar die spezifischen Besonderheiten des kompositionellen Verbindungselements „Gesang“. Zugleich hat diese nordsamojedische Besonderheit auf der Grundlage der finnopermischen Folklore neue charakteristische Züge gewonnen, und eine so wichtige Besonderheit der Poetik, eine solche Tendenz wie die Vereinfachung der Komposition und ihre Annäherung an die Komposition der epischen Folkloregenres der finnopermischen Völker hat Gestalt angenommen.

Von ähnlichen charakteristischen Prozessen und Tendenzen zeugt die Stilistik des ižma-kolvinischen Epos. Auch sie weist eine ganze Reihe von Ähnlichkeiten mit der Stilistik des nenzischen Epos auf. Die ižma-kolvinischen und nenzischen Erzähler setzen die darstellenden Mittel der epischen Sprache (Metaphern, Hyperbeln, Epitheta, Vergleiche u. a.) bei der poetischen Reflexion der nördlichen Wirklichkeit, der Natur und des Lebens der Jäger und Rentierzüchter gleichermaßen sparsam ein. In ihren Werken fehlen die grellen Farben, die so charakteristisch für die Epen südlicher Völker sind: für „Manas“, „Kör-Ogly“ und „Narten“. Aber diese Kargheit der Farben war auf ihre Art notwendig, sie entsprach am genauesten dem bildlichen Denken der Schöpfer des ižma-kolvinischen und des nenzischen Epos, und sie war auch der Poetik der finnopermischen Folklore verwandt. 
Der Stil des ižma-kolvinischen Epos ist nicht mit Metaphern, Hyperbeln oder anderen Mitteln der Darstellung überladen. Zu diesen Mitteln greift der Erzähler nicht eben häufig. In der Regel verdanken sie ihre Entstehung den konkreten Bedingungen der Tundra und der Waldtundra, und dementsprechend spiegeln sie die Besonderheiten im Leben und in den Bräuchen der nördlichen Rentierzüchter und Jäger und enthalten eine konkrete Lebenspoesie.

Von dieser Art sind beispielsweise die ižma-kolvinischen Metaphern. In den epischen Liedern ist von der Unbeweglichkeit die Rede, von der Tundra, die unter dem grimmigen Frost und dem Wind gleichsam erstarrt ist, von der langsam dahinfließenden Zeit. Im Zusammenhang damit entsteht eine metaphorische Situation: Der jüngste Recke, Hoffnung und Stolz der großen Familie, schläft zehn Jahre lang, erwacht dann und bereitet sich darauf vor, eine Heldentat zu vollbringen. Hier bringt der Sänger wie beiläufig eine Metapher an. Vom Schlaf erwacht, sieht der Held sich im Cum seiner Familie um und bemerkt neben dem lata-Brett das Folgende: Vyl' turun petlema, važ turun kuulema 'Neues Gras ist hervorgesprossen, das alte Gras ist vertrocknet' (KNÈ Nr. 1, 1719). Bisweilen wird die konkrete poetische Handlung oder die Zeit der Handlung (zehn Jahre) metaphorisch präzisiert:

Pal'ali taj, šuas,

Lata doras taj

Das pöles-ej turunys

Petlema i kulema,

Me ved da sije lyd'd'i:

Das vo, kole vööny, uźeme,

Das vo pöles ćužemys.

Das vo taj uźeme.

(KNÈ Nr. 2, 11-18)
Ich bin erwahct, neben dem lata-Brett zehn Streifen Gras sind entstanden und vergangen, ich zăhle die Grashalme: offenbar habe ich zehn Jahre geschlafen, zehn Streifen Gras, zehn Jahre habe ich geschlafen.

Den Sinn der Metapher kann der Sänger mit Hilfe einer ausführlichen Prosareplik enthüllen. Beispielsweise enthält eine Variante des Liedes ,Der Herr vom Kerča-Fluß“ die folgende Replik, die an den soeben zitierten Text erinnert: Das pöles turun bydmylema. Turunys ved ötik vo bydmas - kyle, möd vo bara bydmas, bara 
kule. Sya das vo uźema, das pöles turun bydmylema $i$, kulema $i$. Lata dorśys aźźas da lyd'd'e bara, kymyn vo sya uźema. 'Zehn Grashalme sind hervorgesprossen. Ein Grashalm wächst ja ein Jahr lang, und dann verwelkt er. Im zweiten Jahr sprießt wieder einer hervor und verwelkt wieder. Zehn Jahre hat er geschlafen, und deshalb sind zehn Grashalme hervorgesprossen und wieder verwelkt. Er sieht neben dem lata-Brett zehn Grashalme und berechnet, wieviel Jahre er geschlafen hat.' Für eine ganze Reihe von Erzählungen über Blutrache und über den jungen Rächer ist ein ähnliches poetisches Detail typisch: Nachdem der Vater und die Männer der Sippe umgekommen waren, sind viele Jahre vergangen, während derer der wie durch ein Wunder am Leben gebliebene Junge zu einem Recken heranwuchs. Um diesen Gedanken hervorzuheben, fügt der Erzähler stets hinzu: börvyytiys ńin turun bydmema 'schon ist die Stelle (des alten Lagers) mit Gras überwachsen'.

Die Metapher der schwierigen und gefährlichen Reise, die für den Helden den nahezu unausweichlichen Tod bedeutet, gewinnt bei den Kolvinen ein unverwechselbares nördliches Kolorit, das vom Leben der Rentierzüchter nördlich des Polarkreises bestimmt ist. Der jüngste Herr vom Kerča-Fluß, der sich in das ferne, fremde und feindliche Land des Kapherrn begibt, um die schöne Braut zu gewinnen, wird von verschiedenen Leuten vor der drohenden Todesgefahr gewarnt. Ihre Warnung drücken sie durch eine Metapher aus:

Dod'd'a tujys munema

Ozyr Mandolazdore,

Loktan da gyž tujys abu.

(KNÈ Nr. 1, 139-141, 504-505)
Die Spur der Rentiere führt die Gespanne ins Land des reichen Mando, Eine zurück führende Rentierspur (wörtl.: Spur von Rentierhufen) gibt es nicht.

Auch diese Metapher hatte ihren verborgenen poetischen Sinn: Viele Freier kamen zum Kapherrn und seiner herrlichen Tochter, aber ihr jüngster Bruder tötete sie alle während der „Spiele“; keinem einzigen der kühnen Anwärter auf die Hand des Mädchens gelang es zurückzukehren. 
Auch die „Spiele“ selbst, von denen hier die Rede ist, hatten einen verborgenen metaphorischen Sinn. Der Zweikampf zwischen den Freiern und dem jüngsten Bruder der Braut wurde im Epos nie anders genannt als „Spiele“. Was waren das für „Spiele“, zu denen die herbeigereisten Gäste eingeladen wurden, was besagt die Einladung des jüngsten Bruders Gösjas, šuas, petoollej, igrajtny ved kole 'Gäste, kommt auf die Straße, es muß gespielt werden'? Über das erste Spiel sagt der Herr selbst: Vajly, šuas, ććcy, nel'amyn vańd'ejse céćy 'Nun spring, überspring die vierzig vańd'ej-Narten'. Und hier noch ein anderes „Spiel“: Öt $i$ da igra vyjim, sízim da voža ̌̌ek, seten da vyjim da pu kaćaj, seten da poźe kaćnićciny 'Es gibt noch ein Spiel, dort ist ein vielästiger Baum, dort gibt es eine hölzerne Schaukel, dort kann man schaukeln'. Natürlich geht es hier nicht um ein unschuldiges Spiel, um simples Schaukeln auf einer hölzernen Schaukel, sondern um einen lebensgefährlichen Zweikampf: Der jüngste Sohn des Kapherrn schaukelte die Freier zu Tode. M. A. Castrén hat zu dieser ižma-kolvinischen Metapher eine samojedische Parallele angeführt: „In einigen Liedern, die ich notiert habe, werden die śud$b a b c$ als fürchterliche Riesen und grausame Menschenfresser dargestellt, die den Unglücklichen, der ihnen in die Hände gefallen ist, erbarmungslos quälen, indem sie ihn auf einer Schaukel schaukeln, bevor sie ihn verschlingen."34 Und wirklich taten der Jüngste Herr vom Kerča-Fluß und Jevl'o Chuplo gut daran, zu der hölzernen Schaukel hinzugehen, auf die man sie so beharrlich einlud, denn dort bemerkten sie: Kaćaj ulas viźedam, mort lyys taj zarviźe 'Wir schauen unter die Schaukel, und dort schimmert weiß ein Haufen menschlicher Knochen'. Aus dem „Spiel“, dem Zweikampf, geht der Held als Sieger hervor, rechnet mit seinem Gegner $a b$ und erringt in einem harten Kampf die Freundin seines Lebens.

Der Metapher in einigen ižma-kolvinischen Liedern verwandt ist die detaillierte Hyperbel. Ihre wichtigste Funktion besteht darin, die erstaunlichen Eigenschaften des epischen Helden und seines wundersamen Gegners hervorzuheben, der grausam ist und über ungewöhnliche Kräfte verfügt. Ebenso wie in den komi-syr- 
jänischen epischen Liedern über Kirjan-Varjan oder Pedor Kiron schlägt auch in den ižma-kolvinischen Liedern der Held mit einem einzigen Schuß in dem Nomadenlager eine Schneise und läßt große Čums einstürzen (stav comse cašvartas-nuas medbör nóllys 'der letzte Pfeil zerstört und zerstreut alle Čums'). Der angenommene Sohn oder der Zögling des Herrn vom Kaninkap bestellt sich für den Zweikampf das kyk pydevej kört palic, 'eine zwölf Pud schwere Eisenstange'. Auch die Eigenschaften des Heldenbogens werden stark überzeichnet: $\mathrm{Er}$ ist so schwer, daß niemand außer dem Helden selbst ihn vom Boden aufzuheben vermag. Der Held dagegen nimmt ihn leicht zur Hand, spannt die Sehne und trifft ins Ziel. Im Unterschied zu den ihn umstehenden gewöhnlichen Rentierzüchtern setzt der Held mit Leichtigkeit über einen großen Cum, springt bei drohender Gefahr durch den mukota-Rauchabzug hinaus und überwindet spielend die Höhe einer vier Sashen langen $\chi$ orej-Stange; ein ganzes Rentier verspeist er auf einmal und leert einen Teekessel, der dreißig Eimer faßt.

Mit hyperbolischen Zügen sind auch die Gegner des Helden ausgestattet. Ihre ungewöhnliche Waffe, z. B. die xorej-Stange, kann so dick sein wie eine gerollte Rentierhaut (tel'a vol' pasta $\chi a$ rej šyss). Alle Gegner sind enorm hochgewachsen: Wenn S'udbej steht, stößt er mit dem Kopf an die Spitze des Čums. Seine Größe wird auch durch einen Vergleich mit dem Wald veranschaulicht: Über die kleinen Tannen steigt er hinweg, während sein Kopf bis zur halben Höhe der ausgewachsenen Bäume reicht (jurys pujas š̈ré loe). Wenn S'udbejs Frau sich auf das lata-Brett setzt, nimmt sie die Hälfte des Čums ein oder, anders gesagt, die Entfernung, die dem Zwischenraum zwischen den sieben Stützstangen des Čums entspricht (sizíim yy kolas loema paśta).

Wie man sieht, sind die in den ižma-kolvinischen Hyperbeln angegebenen Maße im Unterschied zu denen in den Epen anderer Völker nicht sonderlich eindrucksvoll. Sie sind sogar etwas erdhaft, der realen Wirklichkeit nahestehend, zulässig.

Ihre besondere Eigenart erhält die ižma-kolvinische Hyperbel oftmals durch die Verbindung mit anderen darstellenden Mitteln wie z. B. dem Variationsparallelismus, genauer gesagt, dem drei- 
gliedrigen negativen Parallelismus, und speziellen „nördlichen“ Epitheta.

Natürlich sind die Variationsparallelismen für die poetische Struktur des ižma-kolvinischen Epos in weitaus geringerem Maße charakteristisch als für das ostseefinnische und das obugrische Epos. Und dennoch ist eine solche Abart des Variationsparallelismus wie der dreigliedrige negative Parallelismus gar nicht so selten zu beobachten. In einer Hyperbel wird beschrieben, mit welcher Kraft der Held in Gestalt eines jando-Hundes einherschreitet. Und diese Hyperbel, verbunden mit dem dreigliedrigen negativen Parallelismus, verleiht der Erzählung den nötigen epischen Schwung, den epischen Charakter. Es geht um die Begegnung zweier alter Freunde und um die Brautwerbung des Bräutigamvaters, der als Brautwerber zu seinem alten Freund, dem Mammutgreis, gekommen ist, um dessen herrliche Tochter für seinen Sohn in der Gestalt eines jando-Hundes zur Frau zu erbitten. Der Mammutgreis aber will seine Tochter nicht mit einem jandoHund verheiraten.

$\begin{array}{ll}\text { Siźi śorńityganum ved, } & \text { Während eines solchen } \\ \text { Šuas, ńin-ej drug taj, suas, } & \text { Gesprächs unerwartet } \\ \text { Gymavny ved kućis top taj. } & \text { krachte ein Donner. } \\ \text { „Svate, svate, svate, svate, } & \text { "Gevatter, Gevatter, Gevatter, Gevatter, } \\ \text { Tölyn taj gymale taj. - } & \text { Es donnert im Winter. - } \\ \text { Mamantevej starik ved-e } & \text { Der Mammutgreis } \\ \text { Viśtale taj. - Gymale taj.“ } & \text { sagt. - Es donnert.“ } \\ \text { S'ad'ej starik svate ved } & \text { Der Gevatter, der alte S'ad'ej } \\ \text { Viśtale ved: „Oz ved gymoo, } & \text { antwortet: „Es donnert nicht, } \\ \text { Oz ved gymoo, sya ved abu ved, es donnert nicht, das nicht, } \\ \text { abu ved-ej gym sya, } & \text { das ist kein Donner, } \\ \text { Menam eni pijej, šuas, } & \text { das ist jetzt mein Sohn, } \\ \text { Kole vőöny, com dorys-ej } & \text { Anscheinend ist er mit seinem Gespann } \\ \text { Voedis...“ } & \text { zum Čum herangestürmt..." }\end{array}$

(KNÈ Nr. 8, 314-327)

Der dreigliedrige verneinende Parallelismus in der samojedischen Folklore bedarf der ergänzenden Erforschung. Dieser stilistische Kunstgriff begegnet sporadisch in den Folkloretexten von M. A. 
Castrén und Z. N. Kuprijanova. Ich denke an die jarabc (,Wir lieBen uns herab in das Meer", MSFOu 83, S. 295), „Die drei Lidjangako" und „Der älteste Bruder Sjuhune“" (Kuprijanova, S. 260, 687, 691): „Als ich in den Čum ging, schaute ich mich um. Es zeigte sich gleichsam eine dunkle Wolke. Ich schaute genauer hin: Das war keine Wolke, das waren Heere" (Kuprijanova, S. 260).

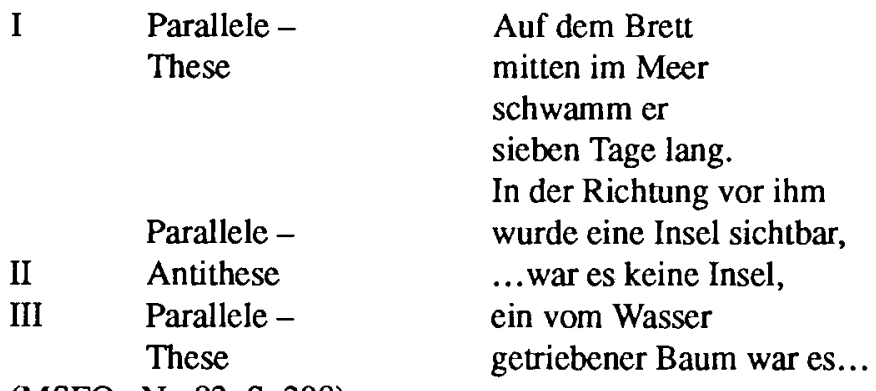

(MSFOu Nr. 83, S. 298)

Das Schema des dreigliedrigen verneinenden Parallelismus als einer Abart des variierenden Parallelismus weist also eine gleichbleibende Struktur auf: These $\leftrightarrow$ Antithese $\leftrightarrow$ These. Bezüglich der finnisch-ugrischen Folklore sind sich die Forscher darin einig, daß der dreigliedrige negierende Parallelismus charakteristisch für die mündliche Poesie der Komi-Syrjänen, der Komi-Permjaken, der Udmurten, der Tscheremissen und der Mordwinen ist. ${ }^{35}$ So heißt es in den südudmurtischen Liedern:

Als ich durch den dunklen Wald ging,

Fiel auf mein Gesicht ein Ahornblatt,

Das war kein Ahomblatt,

Sondern es war meine dahingehende, unwiederbringliche

Jugend...

Ich erhob mich früh am Morgen,

Ich ging auf die Wiesen, um die Blumen zu schauen,

Ich bin noch keiner Blume begegnet,

Unter meinen Füßen verwelkte eine Ranunkelblüte,

Nicht eine Ranunkel verwelkte da, so stellt sich heraus,

Sondern meine Jugend ist dahingegangen. ${ }^{36}$ 
Freilich ist, ebenso wie in der finnisch-ugrischen Folklore, im ižma-kolvinischen Epos der dreigliedrige negierende Parallelismus nicht immer mit einer Hyperbel verbunden. Charakteristisch hierfür ist das Lied "N'osí - ozyr mort da 3ol'a Tysja pi" (Nośi, ein reicher Mann, und sein jüngster Sohn Tysja). Bei einer Fahrt durch die grenzenlose und verschneite weiße Tundra bemerkt der Held schon von weitem etwas Schwarzes, was er für einen Rentierkadaver hält. Es stellt sich jedoch heraus, daß das kein Rentier, sondern ein von irgend jemandem erschlagener Mensch ist (Kole lony, bara ved kulem kör ved, abu taj kör völema, mort taj völema. KNÈ Nr. 5, 1065-1074).

Häufig tritt die ižma-kolvinische Hyperbel in Verbindung mit einem für die Polargebiete charakteristischen Detail auf, und zwar mit einem konstanten Epitheton, dem die Idee der Hyperbolität, der Erhabenheit bereits innewohnt, dem Adjektiv mamantevej 'Mammut-, mammuthaft'. Dieses Epitheton kommt in der aufgezeichneten mündlichen Poesie anderer syrjänischer ethnischer Gruppen nicht vor, begegnet aber in der ižma-kolvinischen Folklore auf Schritt und Tritt. Als mamantevej werden nicht nur die Knochen eines ausgegrabenen Tieres bezeichnet, wie sie an den Ufern der Tundraflüsse überreichlich anzutreffen sind, nicht nur Gegenstände, die noch immer aus Mammutknochen gefertigt werden (čalak - 'Knopf am Ende des Zugriemens zur Befestigung des Rentiergeschirrs', pjat'ej - 'kleiner Ring am Vorderteil der Narte, der dem freien Lauf der Zügel dient'; mamantevej čalak, mamantevej pjat'ej), sondern damit charakterisiert wurden die haltbarsten, solide gearbeiteten Gegenstände: mamantevej dad' 'Mammutnarten', mamantevej ńartala 'Mammutlasso' u. a. Tatsächlich erfreuten sich bei den Kolvinen die Gegenstände aus Mammutknochen großer Beliebtheit. Die Kolvinen schnitzten aus Mammutknochen Messergriffe, Pfeifen, Knöpfe für das Zaumzeug, pjat'ej-Ringe. Und in Usa berichteten uns Augenzeugen mit großem Entzücken, daß im Dorf Petrun' ein geschickter Schnitzkünstler aus Mammutknochen einen selbstgefertigten Uhrmechanismus zusammengebastelt habe (aus den Feldforschungsmaterialien des Verf. von der Folklore-Expedition zum Fluß Usa in den 
1970er Jahren). Es ist deshalb kein Zufall, daß ein gewöhnliches determinatives Adjektiv sich zu einem wertenden Epitheton gewandelt hat. Wenn also von Mammutbogen und -pfeilen die Rede ist, sind das natürlich die zuverlässigsten Waffen, die gegen den allergefährlichsten Gegner eingesetzt werden können, da er durch nichts anderes als durch Mammutpfeile zu beeindrucken ist.

$\mathrm{N}$ `öövửjasnysse ved bośtalisny

Muede kyskyśe vửnys,

Vit syy kuźa ved vửnys,

Jemdonen pojajtem vửnys,

Mamantevej karema noööjasnys.

(KNÈ Nr. 7, 90-98)
Bögen und Pfeile ergriffen sie, die Bögen liegen auf der Erde, fünf Sashen lang sind diese Bögen, mit Stahl sind diese Bögen zusammengefügt, und die Pfeile sind mammuthaft.

Mammutpfeile dienten den Helden auch für die Jagd auf die schnellfüßigsten wilden Rentiere.

Und wenn von Mammutnarten die Rede war, wurden darunter wiederum die solidesten und dauerhaftesten Schlitten verstanden, die für die lange Reise in ferne und feindliche Länder bestimmt waren: Auf solche Narten konnte man sich verlassen, sie machten Hoffnung. Der Held gibt seiner Schwester, die ihn für die Reise ausrüstet, den Auftrag:

Menćum da dad'se seded

Seten da, suas, dad'd'ys,

Mamantevej dad'd'ys.
Mach meine Narten zurecht, dort stehen meine Narten, Mammutnarten.

(KNĖ Nr. 1, 339-342; Nr. 5, 35-54, 168-171; Nr. 6, 26-27)

Und schließlich wurden die am meisten verehrten Gestalten, Rentierzüchter, zum Zeichen besonderer Hochachtung mit dem Epitheton 'Mammut-' oder mit den Prestigebeinamen „Mammutgreis“, „Mammut-ajka“ (ajka 'Vater des Ehemannes') oder Mammutgevatter" ausgezeichnet, und ihr Land wird gelegentlich als „Mammutland“ verherrlicht. Der alte S'ad'ej richtet vor seiner Reise zu dem Mammutgevatter, d. h. zu dem Herrn des Mammutlandes, an die Mitglieder seiner Sippe die folgenden Worte: 
Modor źeml'a vyjim, suas,

Mamantevej źeml'a vyjim...,

Vơrźoony ved kućam, suas,

Mamantevej źeml'ae ńin.
Es gibt ein anderes Land, es gibt ein Mammutland... wir ziehen in das Mammutland.

(KNÈ Nr. 8, 41-54, 411-414, 1194-1196)

Die ižma-kolvinische Folkloretradition hat eine Reihe eigener stereotyper determinativer Epitheta entwickelt. Außer dem typisch polaren „Mammut-, mammuthaft" gehören dazu einige Epitheta, die in ihrem Ansatz schon auf die gemeinsyrjänische und sogar auf die gemeinfinnopermische Folkloretradition zurückgehen: bur nyy 'ein gutes Mädchen', bur pi 'ein guter Bursche', bur aj pi 'Sohn des guten Vaters', bur dad' uu 'gutes Rentiergeschirr', voennej paskem 'Kriegskleidung' und voennej sabl'a 'Kriegssäbel'. Wenn auch das am weitesten verbreitete gemeinsyrjänische Epitheton zarńi 'golden' für das ižma-kolvinische Epos nicht typisch ist, so kehren doch die Epitheta yrgen 'kupfern' und kört 'eisern' immer wieder: yrgen pyž 'kupfernes Boot', yrgen dad' 'kupferne Narten', yrgen ńartala 'kupferner Lasso', yrgen tröpala 'kupferne Flachsschwinge', yrgen Com 'kupferner Čum', yrgen pil'oo 'kupferne Verzweigung der Hörner', kört kaćaj 'eiserne Schaukel'. Natürlich wurden bei den Kolvinen weder Boote noch Zelte oder Schlitten aus Kupfer gefertigt. Der Erzähler nennt diese Gegenstände, wie die Kolvinen selbst sagen, mićmedem mogys 'zur Verzierung'.

Die ,verzierende“" Funktion des syrjänischen Epithetons, die den besungenen Gegenstand oder das Objekt bzw. Subjekt episch idealisieren will, kam besonders deutlich in dem Bild der wunderbaren Skier des Helden zum Ausdruck. Am Ort des Zweikampfes erscheint der Held nicht auf gewöhnlichen einfachen Skiern, sondern auf Lärchenholzklötzen (so z. B. der jüngste Sohn des Herrn vom Kerča-Fluß). Dabei werden die Skier des Helden ,zur Verzierung“ stets mit einem Epitheton aus mehreren Teilen charakterisiert, dessen Struktur den Variationsparallelismus enthält: moj ku lyź, vurd ku lyz' 'mit Biberfell beschlagene Skier, mit Otterfell beschlagene Skier'. Die Tochter des reichen Mando gibt den Gästen nicht nur Mammutnarten, sondern auch die väter- 
lichen Skier, die unten mit Biberfell, mit Otterfell beschlagen sind. Auf ebensolchen Skiern treten auch Vater und Sohn zum Zweikampf mit dem Feind an. Und der Held Jüngster Nyngroo ergreift das Lasso und eilt auf ebensolchen wunderbaren Skiern in die Tundra (KNÈ Nr. 6, 360-364; Nr. 1, 174-176; Nr. 7, 104-113, 206-214). Natürlich haben weder die Kolvinen noch andere nördliche Jäger ihr Skier unten mit so teuren und unpraktischen Fellen wie Biber oder Otter beschlagen, sondern mit billigeren und praktischen, für langen Gebrauch geeigneten Beinfellen von Rentier, Elch oder Kuh. Solche Skier hießen dann im Alltag tel'a $k y s$ lyź oder lola kys lyz 'mit Beinfellen vom Rentier beschlagene Skier, mit Beinfellen vom Elch beschlagene Skier'.

Übrigens war den Kolvinen, ähnlich wie anderen syrjänischen ethnischen Gruppen der Sinn des altsyrjänischen Wortes moj 'Biber' unverständlich. Nach dem Verschwinden dieses kostbaren Pelztiers aus dem Gebiet der Syrjänen vor einigen Jahrhunderten wurde das Wort in der syrjänischen Alltagssprache vergessen, aber in der komi-syrjänischen Folklore blieb es erhalten, zum Beispiel in dem bei den Kindern äußerst beliebten Märchen „Šyr kyvtökatö" (Eine Maus fährt [im Boot] den Fluß entlang): Eine Maus fährt den Fluß entlang und rudert „moj lopta pelysön“, d. h. mit Rudern, deren Blätter aus Biber (d. h. aus Biberschwänzen ${ }^{37}$ ) gemacht sind. Um so poetischer, rätselhafter und um so besser geeignet für eine Poetisierung erschien das den syrjänischen Erzählern. Auf unsere hartnäckige Frage, wie die Erzähler selbst dieses alte Wort moj verstehen, erhielten wir in allen Komigebieten die stereotype Antwort: Kučemke taj dona zver-a 'irgendein teures Tier'.

Der Held dieser wunderbaren Skier, der Rentierzüchter und Skiläufer der ižma-kolvinischen Lieder, erinnert gleichermaßen an den nenzischen Helden und an den finnopermischen Helden Pera, der die Jagdskier dem Rappengespann des Zaren vorzieht und dieses an Schnelligkeit weit übertrifft. Die Schnelligkeit des ižma-kolvinischen Helden auf seinen Wunderskiern erinnert auch an den komisyrjänischen Jäger Jirkapa, der an den Hängen des Ural das blaue Ren überholt. Eine beliebte und konstante Formel für die Schnelligkeit der Wunderskier im ižma-kolvinischen Epos lautet: 
Kứ ved lyżnumes vörźedim da, Als wir uns mit den Skiern in Bewegung setzten,

Börlazdoranum purga, purga bergale, stiebt hinter uns ein Schneegestöber, ein Schneegestöber auf, Voźlazdoranum mića... vor uns ist der klare Himmel.

(KNÈ Nr. 6, 993-996, 1056-1059; Nr. 7, 123-133, 245-250, 492-493)

Zu den beliebtesten der ižma-kolvinischen stereotypen Epitheta gehört auch das Adjektiv y̌̆yd 'groß', das einen Nachhall der urgesellschaftlichen Epoche, die Idee der großen Sippe, der großen Familie enthält: Y̌̌yd S'udbej 'der große S'udbej', Y̌̆yd Marko 'der große Marko', Y̌̌̆yd jon sörja starik 'der große starke mächti-

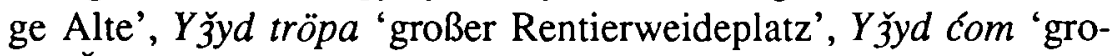
Ber Čum', Y Y̌yd kör tabun 'große Rentierherde'. Meistens tritt das

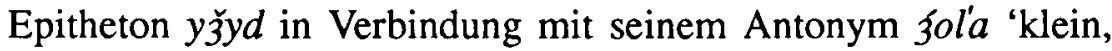
der jüngste' auf, mit dem es einen einheitlichen und konstanten künstlerischen Komplex bildet: Y̌̌yd com tydale - 3ol'a com tydale 'Ein großer Čum wird sichtbar, ein kleiner wird sichtbar', Y 3̆yd Marko - 3ol'a Marko 'Der große Marko, der kleine Marko', Y̌̌yd tröpa - 3ol'a tröpa 'Ein großer Rentierweideplatz, ein kleiner Rentierweideplatz'.

Es gibt noch eine weitere Besonderheit der ižma-kolvinischen Epitheta, die sie nicht so sehr der finnopermischen als vielmehr der samojedisch-ugrischen poetischen Struktur annähert. In diesen Epitheta haben sich Spuren des alten Tabuismus erhalten. Bekanntlich erhalten im samojedisch-ugrischen Epos die Helden ihren Namen nach den Namen ihrer Rentiere, nach ihrem Äußeren oder nach ihrer Kleidung: Heller Zugbulle, Weißer Pelz, Eiserner Gürtel, Tuchdecke, Langnase, Langhaar, Kurzhals usw. Ebensolche Spitznamen sind auch für die ižma-kolvinische Poesie typisch. Die ižma-kolvinischen Folkloretexte kennen weder den Ivan, die Marija oder Marfa der syrjänischen Märchen noch den Pera, Miza oder Antipa der syrjänischen Überlieferungen und auch nicht den Zaren Levonok, Kirjan-Varjan, Pedor Kiron oder Roman, wie sie in den epischen Liedern vorkommen. Zwar kommen darin ebenso wie in der gemeinsyrjänischen Folklore jaran bur pi, der 'gute jaranische Bursche' und jaran bur nyy 'das gute 
jaranische Mädchen' vor, die dem gemeinsyrjänischen mića nyy 'schönes Mädchen' und mica zon 'schöner Bursche' der Lieder entsprechen, doch dafür sind alle handelnden Personen des ižmakolvinischen Epos, ähnlich den samojedischen Helden, mit vielsagenden Epitheta bzw. Beinamen charakterisiert, die sich beispielsweise auf äußere Merkmale ihrer Rentiere beziehen: Je ̌̆yd byk vizys 'Herr des weißen Rentiers', S'öd byk viłys 'Herr des schwarzen Rentiers', N'ol'kyń rožaa viźyś 'Herr der vier polarfuchsmäuligen Rentiere', Haptorka vizys 'Herr der gelten Rentierkuh', Halengat 'Herr des Rentiers, das sich von Fisch ernährt', Yrgen pil'oo 'Herr des Rentiers, das kupferfarbene Geweihverzweigungen hat'. Epitheta und Beinamen werden dem Rentierzüchter auch nach seiner Kleidung gegeben: Böža ku parka 'Kapuzenpelz aus Hermelin', Jeз̌yd parka 'Weißer Kapuzenpelz', S'era parka 'Gemusterter Kapuzenpelz', Va oš ku parka pi 'Sohn des Besitzers eines Kapuzenpelzes, der aus dem Fell eines weißen Bären genäht ist', S'umed paskema nyy 'Mädchen in Birkenrindenkleidung', Pu kyrś paskema nyy 'Mädchen in Baumrindenkleidung', Moj ku pi 'Sohn des Herrn eines Biberpelzes'. Und schließlich weisen die Epitheta und Beinamen auf ein charakteristisches Merkmal im Äußeren der handelnden Person hin: $N^{\prime} \boldsymbol{e}$ byd jursia nyy 'das Mädchen Weiche Haare', Jě̌yd jaran nyy 'Blondes Jaranenmädchen', Zol'a (oder Sörkost und Y̌̌̆yd) kyčyl' nyr 'Nase mit kleinem (oder mittlerem und großem) Buckel', Kört nyra starik 'Eisennasiger Alter', Kört moresa starik 'Eisenbrüstiger Alter', Kok pöla starik 'Einbeiniger Alter', Sin pöla starik 'Einäugiger Alter'.

Wie schon weiter oben bemerkt, überschneidet sich die Stilistik des nenzischen Epos an vielen Stellen mit der des ižma-kolvinischen. Ebenso wie die ižma-kolvinischen epischen Lieder sind auch die nenzischen sudbabc und jarabc überreich an spezifischen Metaphern, Hyperbeln und Epitheta, deren Sinn sich ohne einen historisch-ethnographischen Exkurs nicht dechiffrieren läßt. Die nenzische Metapher zeichnet sich gleichzeitig durch Feierlichkeit und Alltäglichkeit aus. In dem jarabc ,Die zwei Sèrotèta“ wird berichtet, daß die Herren des Lagers die beiden reitenden 
Boten, die im Lager eingetroffen waren, zu haschen begannen, sie einfingen und dann zu Ehren der Ankömmlinge Rentiere schlachteten. Der Sinn dieser stets gleichbleibenden metaphorischen Formel vom Einfangen der Gäste wird verständlich, wenn man berücksichtigt, daß nach dem nenzischen Hochzeitsritual die eingetroffenen Mitglieder des Hochzeitszuges schon in der Nähe des Cums eingefangen werden mußten, während der Hochzeitszug trotz der Behinderungen dreimal den Čum der Braut umrunden mußte (Kuprijanova S. 741).

Die unübersehbaren Weiten der Tundra, die von den Rentierzucht betreibenden Nenzen ständig überwunden werden mußten, ließen in deren Dichtung konstante Hyperbeln entstehen, die den Traum des Menschen von märchenhaft schneller Fortbewegung wiedergeben und verkörpern. Die Phantasie des Polarkreisbewohners hat die Bilder des märchenhaften, durch die Luft fliegenden Helden, der schnellfüßigen Rentiere und der Wunderskier hervorgebracht. Mehrmals wird im Epos von dem Helden berichtet, daß er „vom Ende seines Bogens" abspringt und auf das Schlachtfeld fliegt oder, der entgegengesetzte Fall, sich auf diese Weise vor dem Feind rettet. In einem von M. A. Castrén aufgezeichneten sudbabc heißt es:

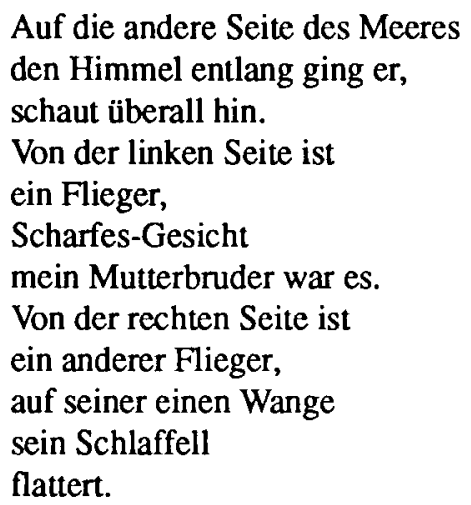

(MSFOu Nr. 83, S. 138; MSFOu Nr. XC, S. 254, 268, 232, 233, 261)

In Castréns Aufzeichnungen wiederum begegnet auch das typisch märchenhafte Motiv, daß der Held auf einem Adler, einem Schwan 
oder einfach auf einem Vogel fliegt: Der Ehemann der von den Feinden geraubten Frau verfolgt die Räuber auf einem Vogel; der Held fliegt auf einem Adler ins fremde Land, um dort um eine Braut zu freien; der Held fliegt auf einem Adler und seine Begleiterin auf einem Schwan; der Bruder kommt auf einem Schwan oder einem Vogel geflogen, um die Schwester zu retten, die von Räubern entführt wurde (MSFOu Nr. 83, S. 309, 312- 313, 315, 318, 319, 321, 326, 332). In den Aufzeichnungen T. Lehtisalos und Z. N. Kuprijanovas kommt dieses Märchenmotiv weniger häufig vor.

Ebenso wie in den ižma-kolvinischen Lieder ist das schnelle Fahren stets mit schnellfüßigen Rentieren oder den Wunderskiern des Helden verbunden. Dabei weisen die und die nenzischen bildhaften Formeln oft recht große textuelle Ähnlichkeiten auf. Von dem schnellen Lauf des Rentiers werden ganze Schneewehen aufgeworfen:

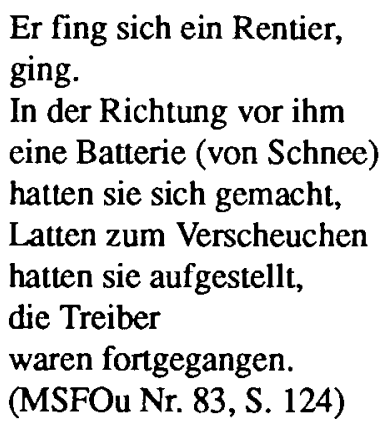

Die nenzische stereotype bildhafte Formel von den Wunderskiern, die im Epos für die märchenhafte Geschwindigkeit des Menschen stehen und seinen Traum von der Überwindung von Zeit und Raum verkörpern, erinnert zwar an die ižma-kolvinische, hat aber doch ihre eigene Spezifik. Die nenzische Formel folgt in ihrem Aufbau ebenfalls dem Prinzip des Parallelismus: Der eine Ski ist nicht mit Rentierbeinfell beschlagen, der andere ist mit Otterfell beschlagen. Die kolvinische Formel lautet: ein mit Biberfell beschlagener Ski, ein mit Otterfell beschlagener Ski. 
Der eine Schneeschuh (ohne Fell) rasselt, der andere hat einen Boden von Otterfell...

(MSFOu Nr. XC, S. 310)

Strukturell sind die beiden Formeln, wie wir sehen, gleichartig aufgebaut, jedoch enthalten die Bilder kein gleichartiges, dem Leben entnommenes Material, was sich letztendlich aus der unterschiedlichen Geschichte der beiden benachbarten Völker erklärt. Davon zeugt ein Vergleich der nenzischen und der komi-syrjänischen bildhaften Formel von den Wunderskiern: Der komi-syrjänische Jäger des Epos, Jirkap, fertigt zwei Schneeschuhe an, einen aus gewöhnlichem Holz, den anderen aus einem Wunderzwillingsbaum. Das heißt, auch in dieser Prosaerzählung haben wir es mit einer poetischen Struktur zu tun, der ein Variationsparallelismus zugrundeliegt.

Die poetische Ähnlichkeit in der Struktur zeigt sich auch an anderen charakteristischen "nördlichen" Epitheta. So hat sich im nenzischen Epos zum Beispiel die Bestimmung „Mammut-“ ebenfalls zu einem wertenden Epitheton gewandelt: Die stabilsten, haltbarsten Narten sind natürlich die Mammutnarten; die besten, treffsichersten Pfeile sind die aus Mammutknochen. Alles, was das Mammut betrifft, bekommt einen hyperbolischen, epischen Sinn. Der Held verfügt über zwei Mammut-Rentiere und erhält nach dem Mammutgespann seinen bezeichnenden Namen:

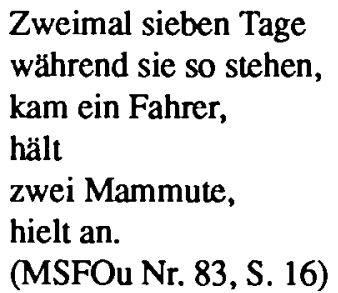

Nach M. A. Castrén führt T. Lehtisalo Belege noch eines anderen Aspektes von Epitheton und Bild in Verbindung mit dem Mammut an: den einer kultischen heiligen Bedeutung. Nach der Erzählung verfügen zwei Brüder, die Helden, über sieben Schamanentrommeln, von denen eine aus Mammutknochen gemacht ist: 
„He, mein älterer Bruder,

du pflegst zu sagen:

Deine vom Vater gehaltenen

sieben Zaubertrommeln sind

von der Schöpfungszeit.

Die siebente Trommel aus Mammutknochen

bringe doch."

(MSFOu Nr. XC, S. 210)

Von dieser kultischen Bedeutung des Epithetons „Mammut-“ zeugen die nenzischen Prosaerzählungen von dem RentierzüchterHelden und dem Schamanen, dem die Zaubertrommel aus Mammutknochen hilft, sich vor den Feinden zu retten, die seinen Čum eingekreist haben. Das sind die sogenannten „Ursprungssagen“ (MSFOu Nr. XC, S. 4-6).

Von den anderen literarisch-anschaulichen Formeln, die dem poetischen Stil des nenzischen Epos seine ,polare“ Spezifik verleihen und für die es im ižma-kolvinischen Epos bestimmte Analogien gibt, verdienen die folgenden genannt zu werden:

a) Die zentrale handelnde Person wendet sich an die Sonne, den Himmel oder die sad'ej's und bittet sie, seinen Wunsch zu erfüllen, der stets stereotyp gehalten ist, zum Beispiel:

Während ich so schaue:

auf der anderen Seite des Flusses

waren Sjaadais.

Ich dachte:

Wenn ich mit den von mir gehaltenen Rentieren

über diesen Buchtverzweigungsfluß

galoppiere,

wäre es gut.

(MSFOu Nr. XC, S. 282-283)

Es lohnte sich für den Helden, so zu denken und um die Erfüllung dieser Gedanken zu bitten, denn das Gedachte erfüllt sich sofort.

b) Der Held trifft in der Tundra ein Rentiergespann und schneidet ihm mit seinem den Weg ab. Das wiederholt er einige Male, und eine solche Begegnung verläuft bei weitem nicht immer friedlich. Der Held des śudbabc Siv Noecja begegnet erst Sidja 
Pariseè, danach Pèkocja Huhur und Tivak Vakacjami. Über eine dieser Begegnungen heißt es: „Sidja Pariseè scheuchte zwei schwarze Rentiere auf. Den ganzen Tag fährt er mit Getöse. Als es dunkel wurde, erschien plötzlich Siv Noecja auf der Bildfläche. Sidja Pariseè schnitt ihm mit den Zugsträngen den Weg ab (Kuprijanova S. 82). Und die Reaktion Siv Noecjas erfolgt unmittelbar darauf: „Siv Noecja sprang sofort mit den eisernen Bögen über die Zugstangen der beiden Schwarzen. Und wanderte sogleich weiter." Als Sidja Pariseè versuchte, seinen Streich zu wiederholen und dem Helden mit den Zugsträngen den Weg zu versperren, gerät dieser in Wut und tötet den zudringlichen Gegner.

c) Die erbärmliche Lage des Hirtenknechts oder Sklaven wird durch den Hinweis auf ,seinen Platz“ im Čum des Herrn oder in dessen Nähe unterstrichen. Der Platz des gedemütigten Knechts ist entweder in einem schmutzigen Lastschlitten, mit dem verrußtes Gerümpel transportiert wird, oder direkt neben dem Eingang des Cum auf gespaltenem Holz:

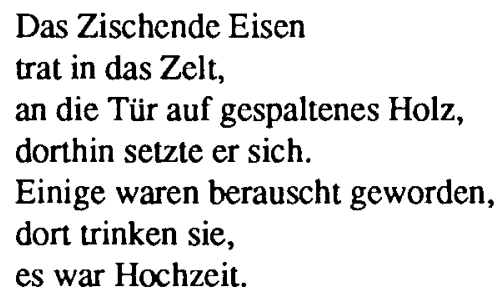

(MSFOu Nr. 83, S. 41)

In vielerlei Beziehung wird die poetische Stilistik des ižma-kolvinischen und des nenzischen Epos durch die Besonderheiten bedingt, die für ihre poetische Struktur charakteristisch sind, nämlich durch die Nichtformelhaftigkeit und die Ungleichmäßigkeit des Liedverses. Freilich gilt das für das nenzische Folklorematerial nur unter Vorbehalt. Die nenzischen Liedertexte in der Sammlung Z. N. Kuprijanovas „Epische Lieder der Nenzen“ sind bekanntlich in Prosa wiedergegeben, und deshalb kann ihr Material zu Vergleichszwecken leider nur indirekt im Sinne eines Exkurses herangezogen werden, abgesehen von einer Beilage zu dem Sam- 
melband mit Aufzeichnungen des Leningrader Folkloristen und Musikwissenschaftlers B. M. Dobrovol'skij, die nur einen geringen Umfang hat (Kuprijanova S. 757-780). Die wertvolle Sammlung A. O. Väisänens "Samojedische Melodien“ (MSFOu Nr. 136) ${ }^{38}$ wiederum enthält kein Textmaterial. Über Castréns Sammlung teilt deren Herausgeber T. Lehtisalo das folgende Detail mit: In seinen nenzischen Folkloretexten hat Castrén weder die Verse gekennzeichnet noch Interpunktionszeichen gesetzt, und nur seine russischen und schwedischen Übersetzungen halfen dem Herausgeber, die dichterische Strophik des nenzischen epischen Textes zu rekonstruieren. Deshalb mußte auch dieses Material mit bestimmten Vorbehalten betrachtet werden. Folglich dienten nur die Notizen Lehtisalos und die Materialien unserer oben erwähnten wissenschaftlichen Folklore-Expedition von 1972 in das Gebiet von Kanin-Pečora als Grundlage unserer Beobachtungen über die Struktur des nenzischen epischen Verses. Natürlich haben die genannten Umstände die Basis der Beobachtungen geschmälert und bewirkt, daß die Schlußfolgerungen bezüglich der Struktur des nenzischen epischen Verses starken Vorbehalten unterliegen und künftiger Überprüfung und Präzisierung bedürfen. Da der nenzische Vers hier jedoch unter dem Aspekt, inwieweit er sich von dem ižma-kolvinischen unterscheidet bzw. ihm ähnelt, untersucht wird, erscheint das Vergleichsmaterial für das Anfangsstadium einer solchen Untersuchung mehr oder weniger ausreichend.

Im ižma-kolvinischen Epos lassen sich hinsichtlich der poetischen Struktur zwei miteinander verbundene Tendenzen feststellen: einerseits die führende Rolle der Improvisation, eines improvisierenden Elementes, und andererseits das Streben nach einer Regelung und, in gewissen Grenzen, nach einer Vereinfachung des epischen Verses. Beide Tendenzen lassen sich mit praktischen Gründen erklären. Weiter oben war schon von dem beachtlichen Umfang vieler ižma-kolvinischer epischer Lieder die Rede, die bis zu 1500 Verse umfassen können. Wenn der epische Vers unterschiedlich zusammengesetzt und nicht formelhaft war, stellte die Improvisierung solcher Lieder bzw. Poeme mit wenigen 
Ausnahmen eine bedeutende Schwierigkeit dar.

Die Nichtformelhaftigkeit des epischen Verses drückte sich vor allem in der weit verbreiteten Tatsache aus, daß die musikalischen und die sinngemäßen Phrasen nicht zusammenfallen, wenn ein und dieselbe sinngemäße Einheit und sogar ein Wort in zwei und mehr musikalische Verse zerschlagen sein kann:

Voisnys taj i \örkost

Vokys dore $i$, suas...

(KNÈ Nr. 9, 118-119, 416-418)

Tenad tol'ko važen

Ö'tik ved $\chi$ oro jando

Ponmyd ved-ej völi.
Sie kamen zu dem mittleren

Bruder...

Du hattest doch früher nur

einen Hund, einen jando-

Rüden.

(KNÈ Nr. 8, 138-140, 158-163, 241-245, 905-909)

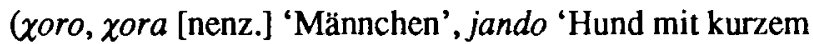

Fell und Stehohren' [nördlicher Schäferhund].)

Važja da starikjaslen

Pustej pöslevića

Löśedlema, suas.

(KNÈ Nr. 11, 199-201)
Die Alten der Vorzeit

haben dieses leere Sprichwort erdacht.

Nicht selten werden auch Teile eines Wortes von einem Vers in den anderen hinübergezogen:

N'arevej ćomnys völemaej (völemaej) Kujim ozyr

Kańin Höźainjaslen.

(Aus dem Archiv des Verf.)
Der sämischlederne Čum gehörte drei reichen Kanin-Herren.

Die Improvisation des nichtformelhaften ižma-kolvinischen epischen Verses wird dadurch begünstigt, daß er zahlreiche Wörter und Partikeln vom Typ taj, ved', nin enthält, die keine Bedeutungsträger sind. Besonderer Beliebtheit erfreut sich das parenthetische Wort šuas (wörtlich 'er sagt' Futur), das dem russischen mol, molvit 'er sagt' entspricht. Im epischen Text enthält das Wort keinerlei semantische Befrachtung, sondern fungiert als eine Art Füllsel zur Ergänzung des Versrhythmus. Das Verb šuas als eine bedeutungstragende Wortart ('er sagt') begegnet in allen syrjä- 
nischen Märchen und Überlieferungen auf Schritt und Tritt: S'ojisjuvis Ölöksej, seśsa i munny kolö, ötnas vöd, gažtöm, a kol'ny sarstvo žal'.

- Myjla, - šuvas, - me vośti tajös-a. Ez kov, - šuvö, - vostny menam 'Aleksej aß und trank, aber dann muß er gehen, denn allein ist es langweilig, und es tut ihm leid, das Reich zu verlassen.

- Warum, sagt er, habe ich es (dieses Reich) entdeckt. Ich hätte es, sagt er, nicht entdecken sollen'.

In den ižma-kolvinischen epischen Liedern und Erzählungen wird in einer vergleichbaren Situation das synonyme Verb vistalas, viśtale 'sagt er' verwendet, jedoch nie das Wort šuas, šue. Nicht selten begegnet das eigenartige Doppelverb šuas-viśtalas, wo nur der zweite Teil, vistalas, Bedeutungsträger ist; bei einer Übersetzung des ižma-kolvinischen Textes in eine andere Sprache ist folglich nur der zweite Teil des Doppelverbs zu übertragen:

„Me ved da, šuas, götraśny möda,
Poźe ali oz, suas,
Vokjas, suas?“”
„Pöra ńin.“
Mońjas bara viśtaleny:
„Pöra da, šuas, loi-i,
Poźe, šuas, götraśny.“ (KNË Nr. 1,90-96)
„Ich (sagt er,) heirate,

ist das möglich oder nicht (sagt er), Brüder (sagt er)?"

„Es ist schon Zeit."

Die Schwiegertöchter sagen wieder: "Die Zeit (sagt er - ?) ist gekommen, du kannst (sagt er - ?) heiraten."

Auf was bzw. auf wen sich in diesem Fragment das Wort šuas bezieht, ist völlig unklar, nach dem Kontext wird es überhaupt nicht benötigt, und daß ihrer grammatischen Form nach (Singular und Plural, Präsens und Futur) so verschiedene synonyme Verben wie viśtaleny-šuas 'sagen sie - sagt er', die sich auf dieselben Personen, nämlich die Schwiegertöchter, beziehen, so nahe beieinanderstehen, kann einen Übersetzer, der nicht mit der Spezifik des ižma-kolvinischen Epos vertraut ist, vollends verwirren. Die Situation mit dem Rhythmusfüllwort šuas verkompliziert sich noch mehr, wenn es in dem gesungenen Vers das einzige Wort bleibt: Der ganze Vers hört auf, so wie sonst Bedeutungsträger zu sein, und spielt nurmehr die Rolle eines rhythmischen Füllsels: 
Me taj peti da, šuas, ved, Ich ging (sagt er,) auf die Straße hinaus,

Suas, ved, (sagt er) ja,

Vurd ku da lyźes kömalem böram taj... Zog die mit Otterfell beschlagenen Schneeschuhe an...

(KNÈ Nr. 6, 596-598, 667-671, 1019-1023, 1138-1140, 1231-1234;

Nr. 5, 917-923; Nr. 7, 215-217, 773-776; Nr. 8, 946-949)

Man kann annehmen, daß die zahlreichen, genauer gesagt, zahllosen Wiederholungen des Wortes šuas im ižma-kolvinischen Epos ein spezifisches Rudiment darstellen, das auf das samojedische kompositionelle Verbindungselement „Gesang" oder den ižmakolvinischen „Ursänger“ zurückgeht und einen Hinweis auf die uralte Existenz dieser Epen darstellt.

Die Vereinfachung bzw. Regelung der poetischen Struktur im ižma-kolvinischen Epos wurde zu wesentlichen Teilen durch die Anwendung anaphorisch-epiphorischer Reihen in Verbindung mit Variationsparallelismus bewirkt. Wie schon weiter oben gesagt, werden in den ižma-kolvinischen Liedern, anders als in den ostseefinnischen und den obugrischen Heldenliedern, Variationsparallelismen in recht beschränktem Umfang verwendet, was in voller Übereinstimmung mit ihrer nicht formelhaften poetischen Natur steht. Der Variationsparallelismus spielt in der ižma-kolvinischen poetischen Struktur nur eine begrenzte Rolle. Und dennoch kann der Variationsparallelismus in seiner klassischen Form mit konsequent durchgehaltener Wortfolge im Vers auftreten, besonders in den stereotypen formelhaften Bildern, die ja das Skelett der epischen Improvisation bilden:

More ji vylas dyr on oo,

S'inmyd da, suas, yžde,

S'inmyd da, šuas, yžde,

Sustavyd-ej turde,

Sustavyd-ej turde.

(KNÈ Nr. 3, 455-460)
Auf einer Eisscholle im Meer lebt man nicht lange, die Augen (Pupillen) erweitem sich, die Augen (Pupillen) erweitem sich, die Gelenke erstarren, die Gelenke erstarren. 
Ötor da bökam viźlyši -

N'ölys stopa, Suas,

Mödor da bökam viźlysi -

N'ölys tol'ko stopa.

(KNÈ Nr. 2, 690-693; Nr. 1, 17-19)
Er sah nach der einen Seite eine gewaltige Menge Pfeile, er sah nach der anderen Seite eine gewaltige Menge Pfeile.

Die absolute Anzahl der streng durchgeführten Variationsparallelismen im ižma-kolvinischen Epos ist nicht besonders groß. Häufiger sind solche Variationsparallelismen, bei denen durch Änderung der Wortfolge im Vers eine Akzentverschiebung bewirkt wird. Durch eine solche Variierung des Verses erreichte man den nötigen harmonischen Klang des Verses, Intonationsdynamik und Polyphonie:

$1 \quad 2 \quad 3$

N'inemnys abu nyle-en,

$\begin{array}{lll}3 & 1 & 2\end{array}$

Nylenlen ńinemys abu...

(KNÈ Nr. 9, 3-4)

Gaske, korke vojłycke nin

Tỉ ńin i aźł́yślemny-yd, Gaske, ńin i vojß̌yk, Suas, A3́źyślemnyd ti, suas...

(KNĖ Nr. 9, 361-364; Nr. 10, 3-6, 9-10, 12-16; Nr. 11, 245-249)

Siź taj mi virse karim, So vergossen wir Blut,

Siź taj virse mi karim... (Aus dem Archiv des Verf.) $\begin{array}{lll}1 & 2 & 3\end{array}$

Nichts haben sie

$\begin{array}{lll}3 & 2 & 1\end{array}$

Sie haben nichts...

Sicherlich seid ihr euch irgendwann früher

schon begegnet,

Sicherlich, auch früher

seid ihr euch begegnet...

Mit einer Variante der ižma-kolvinischen Parallelismen haben wir es auch dann zu tun, wenn in einem Vers einzelne Wörter des vorhergehenden Verses ausgetauscht werden. Durch einen solchen Austausch wird oft der Sinn eines Verses präzisiert und konkretisiert:

Lamdo nyy taj peti, Zil'l'a da źol'l'a peti... (KNÈ Nr. 9, 385-386)
Lamdos Tochter kam heraus, mit Lärm und Getöse kam sie heraus... 
Gaške i kyśke korke ał̧́a,

Gaß̌ke i korke öt'ikes ał́áa...

(KNÈ Nr. 7, 145-146, 147-148)
Vielleicht werde ich irgendwoher irgendwann erblicken, vielleicht werde ich irgendwann eines (ein Tier) erblicken...

Der ižma-kolvinische Variationsparallelismus kennt drei Typen anaphorisch-epiphorischer Wiederholungen: gemischt anaphorisch-epiphorische, rein anaphorische und rein epiphorische Reihen. Deutlich bevorzugt werden die gemischt anaphorisch-epiphorischen Reihen des folgenden Strukturtyps:

Menam taj mame nuede, Höżajkalunse nuede,

Menam taj mame nuede, Höźainlunse nuede.

(KNÈ Nr. 3, 1-8)

Kerca-ju bökyn olam

Kujim vok olam,

Kujim vok olam.

(KNÈ Nr. 1, 1-3)

Dase da pasluh vyjim,

Dase da tyśeća kör-e vyjim.

(KNĖ Nr. 1, 6-7; Nr. 4, 129-131; Nr. 5, 70-75; Nr. 6, 304-309, 340-344; Nr. 8, 696-716; Nr. 11, 27-35, 41-45, 57-61, 70-71, 75-80)

S'iźim da ńija tydale, S'ižim voža ńija tydale...

S'iźim saju taj voisnys, S'ižim dad'd'en voisnys... (Aus dem Archiv des Verf.)
Meine Mutter macht, die Arbeiten der Hausfrau macht (sie), meine Mutter macht, die Arbeiten des Hausherm macht (sie).

Am Ufer des Kerca-Flusses leben wir, als drei Brüder leben wir, als drei Brüder leben wir.

Es sind zehn Hirten da, es sind zehntausend Rentiere da.
Sieben Lärchen sind zu sehen, sieben weitverzweigte Lärchen sind zu sehen.

Sieben saju-Feinde sind gekommen, auf sieben Narten sind sie gekommen...

Eine rein anaphorische Reihe begegnet etwas seltener und dient der poetischen Präzisierung und der semantischen Erweiterung des künstlerischen Bildes: 
Rožaes i ćapalis,

Rožae stavys vireś loi. (KNÈ Nr. 3, 592-594)

Kön ne, suas, bajdykys, Kön ne, suas, d'ikejyd? (KNÈ Nr. 3, 755-756, 780-781, 790-791)

Vyle taj ńin ćeććis, Harej vyytiys taj cecćcis, Skaken taj ńin ćeććis, Vyle kojd taj nin rečis. (Aus dem Archiv des Verf.)
Mein Gesicht zerkratzte sie, Mein Gesicht ist ganz voll Blut.

Wo ist denn das Rebhuhn, wo ist denn das wilde (Rentier)?

Im letztgenannten Fall umrahmt die Anapher lediglich die epiphorische Reihe. Eine rein epiphorische Reihe, wobei sich ein Wort am Zeilenende wiederholt, ist im Epos auf Schritt und Tritt anzutreffen:

N'öövửes taj bośti,

Kijam taj bośti.

(KNÈ Nr. 2, 742-743)

Vays taj nooledle, More vays nooledle, Va kylasse nooledle.

(KNË Nr. 3, 537-539; Nr. 4, 137-139)
Hoch sprang er, über die $\chi o r e j-S t a n g e$ sprang er, mit einem Satz sprang er, hoch sprang er.

Der nenzische epische Vers weist dieselben charakteristischen Merkmale auf, die wir weiter oben bei der Analyse der ižma-kolvinischen poetischen Struktur bemerkt haben. Das Nichtformelhafte des Verses, der fehlende Zusammenfall von sinntragender und musikalischer Zeile, das Hinüberziehen von Phrasen- und sogar von Wortteilen von einer Zeile in die nächste, die Ungleichmäßigkeit der Silben in den Verszeilen - all das gilt für den nenzischen Vers ebenso wie für den ižma-kolvinischen.

Irgendwoher

kommt ein Reiter.

(Kuprijanova, S. 767) 
Schnepfenkopf-Rentierochs

er sagte:

„Langsam,

schön

die männlichen Rentiere ziehe ab,

spăter die Burschen

schicke ich

dich zu holen.“

(MSFOu 83, S. 126)

(Er) siebzig männliche wilde Rentiere

im Guten

an jeden verteilte...

(MSFOu 83, S. 126)

Originell ist die poetische Struktur der nenzischen jarabc „Die zwei Söhne Parise" und "Sto Narolja“, die L. F. Bobrikova im Mai 1972 in dem Dorf Nes' von dem ungewöhnlich talentierten Erzähler A. F. Latyšev aufgezeichnet hat. Freilich zeigt sich auch in seinen jarabc die Nichtformelhaftigkeit des epischen Verses gleich zu Anfang und dann in allen anderen Teilen seiner jarabc:

Eines Tages

dreimal schlug

mich jemand, sagte er, wie man hört.

(Aus dem Archiv des Verf.)

Aber derselbe A. F. Latyšev liebt es, der poetischen Struktur auch seine persönliche subjektive Färbung zu geben. Ein Mittel zur Erreichung dieses Ziels bestand darin, ans Ende der Verszeile Wiederholungen, Refrains, zu setzen:

Er ging fort zu Fuß, zu Fuß,

schied die Rentiere, die Rentiere,

dreihundert Rentiere

schied er, schied er...

Mein jüngster Herr, Herr, der jüngste Sohn Parise, an mein Wort erinnere dich, erinnere dich...

(Aus dem Archive des Verf.) 
Das hier analysierte Faktenmaterial zeigt also, daß bei aller unzweifelhaften Verwandtschaft oder Ähnlichkeit das ižma-kolvinische und das nenzische Epos als völlig selbständige künstlerische Erscheinungen definiert werden müssen, die sich geraume Zeit hindurch nach ihren eigenen inneren Gesetzmäßigkeiten entwickelt haben und eine eigene, unwiederholbare Geschichte besitzen. Wir haben es nicht mit der einfachen Übersetzung eines literarischen Textes von einer Sprache in die andere zu tun, sondern mit zwei selbständigen nationalen Fassungen eines Jäger- und Rentierzüchterepos, die sich jeweils auf ein selbständiges künstlerisch-ideelles System stützen. Tundranenzen und Waldkolvinen, die lange Zeit unter ähnlichen Bedingungen lebten und auf demselben kulturellen Niveau standen, haben epische Traditionen geschaffen, die einander in ihrer künstlerisch-ideellen Tendenz nahe standen. Im Verlauf der letzten zwei Jahrhunderte wurden jedoch die Kolvinen in relativ größerem Maße als die Tundranenzen durch den Lauf der Geschichte in den gemeineuropäischen sozialen, ökonomischen und kulturellen Fortschritt einbezogen, und ihre traditionellen Lebens- und Kulturformen haben sich weniger gut erhalten, wobei die erhaltenen traditionellen Formen einer bedeutend stärkeren Transformation unterlagen. Gerade mit diesem Umstand kann man die Unterschiede zwischen dem ižma-kolvinischen und dem nenzischen Epos erklären.

Zum Abschluß bleibt uns noch die Frage zu beantworten, welches die heutigen Existenzformen des ižma-kolvinischen und des nenzischen Folklore-Epos sind. Kann man sie als eine lebendige, sich entwickelnde Erscheinung bezeichnen? Wahrscheinlich hat diese Frage bis noch vor relativ kurzer Zeit bejaht werden können. Freilich sind die Nachrichten darüber, daß unter den Nordvölkern ein Epos noch mündlich tradiert wird, nur dürftig. Schon M. A. Castrén schrieb über die Darbietung und die Existenz des nenzischen epos: „Lieder dieser Art (gemeint sind die sudbabc, A. M.) genießen bei den Samojeden höchstes Ansehen. Mit nahezu religiöser Andacht lauschen sie jedem Wort aus dem Mund des Sängers. So wie ein Schamane sitzt der Sänger auf einer Bank 
oder auf einer Truhe inmitten der Jurte, und die Zuhörer verteilen sich um ihn herum. Im Gouvernement Tomsk bemerkte ich, daß der Sänger sich bemüht, durch Bewegungen seines Körpers seine Anteilnahme am Schicksal des Helden auszudrücken. Sein Körper schwankt hin und her, seine Stimme zittert, mit der linken Hand bedeckt er sich immer wieder die Augen, die voller Tränen sind, und in der rechten hält er einen Pfeil, dessen Spitze zu Boden weist. Die Zuhörer sitzen gewöhnlich schweigend da, aber wenn der Held gesiegt hat, entringt sich ihnen ein lautes "hee", das unserem ,hurra" entspricht.“40 Hundert Jahre nach Castrén beobachtete Z. N. Kuprijanova auf Folklore-Expeditionen in die Bol'šezemel'skaja Tundra unter den Nenzen, daß sich das Verhältnis der Zuhörer und Sänger zu ihren epischen Liedern innerhalb eines Jahrhunderts kaum verändert hat, und schrieb, daß die epischen Lieder bei den Zuhörern eine beliebte Gattung der mündlichen Dichtung seien und daß die Vortragenden „sich allgemeiner Achtung und Bekanntheit erfreuen“ (Kuprijanova S. 24). Natürlich wird bei den Nenzen ebenso wie bei anderen Völkern das Epos als „Lieder über die Vergangenheit, darüber, was es irgendwann wirklich gegeben hat", aufgefaßt, wie Z. N. Kuprijanova es ausgedrückt hat (Kuprijanova S. 24), mit anderen Worten, als historisch-kulturelles Erbe früherer vergangener Epochen. Im Unterschied zu vielen zerstörten, aus der lebendigen Volksdichtung verschwundenen Epen ist das nenzische Epos, nach den Angaben der nenzischen Folkloristen und nach meinen eigenen $\mathrm{Be}$ obachtungen in Narjan Mar und im Dorf Nes' zu urteilen, immer noch ein vergleichsweise lebendiges historisch-kulturelles Erbe.

Dasselbe kann man auch vom ižma-kolvinischen Epos sagen. In der Siedlung Haruta tief im Innern der Bol'šezemel'skaja Tundra hatte ich in den 70er Jahren, hundert Jahre nach Castrén, die Gelegenheit, das folgende Bild zu beobachten. Es war, als hätte die Zeit keinen Einfluß auf die Emotionen der Zuhörer gehabt und als wäre seit Castrén alles in der Tundra unverändert geblieben. Nur anstelle eines Cums stand da ein modernes Holzhaus, anstelle einer Holzbank ein moderner Stuhl, und die Gäste saßen nicht auf Rentierfellen und nicht auf dem lata-Brett, sondern jeder, wo es 
sich gerade traf - auf Stühlen, auf dem Sofa und sogar, aus Platzmangel, auf dem akkurat gerichteten vernickelten Bett der Hausfrau. Aber ebenso glänzten die Augen der Zuhörerinnen, ebenso glühten die Gesichter der von den Liedern mitgerissenen Frauen, als die 92 jährige M. G. Čaklinova das Lied von den drei Vaj-Brüdern anstimmte. Sie sang mit brüchiger Greisinnenstimme. Anfangs konnten wir viele Wörter nur mit Mühe verstehen, aber es war offensichtlich, wie das Auditorium lebhaft auf jedes Wort des Liedes, auf jede Replik der Sängerin reagierte. Von Zeit zu Zeit äußerten die Frauen ihre Empfindungen mit dem vor hundert Jahren benutzten Ausruf ,hee" und mit einem beipflichtenden begeisterten Nicken. Eine ähnliche Szene habe ich auch fern der Bol'šezemel'skaja Tundra jenseits des Urals am Ob' im Dorf Muži erlebt, als der alte Rentierzüchter G. N. Valeev seinen Nachbarn das Lied vom jüngsten Herrn des Kerča-Flusses vorsang.

Bekanntlich gehören die epischen Werke der Nordvölker zum Repertoire der männlichen Sänger. Davon zeugt sowohl das Epos der Kolvinen als auch das der Nenzen. Großes Ansehen genossen und genießen in der Tundra die kolvinischen Sänger N. E. Kanev (*1880, Haruta), I. G. Pičkov (*1902, Nes'), G. N. Valeev (*1890, Muži), V. M. Batmanov (*1908, Jamgort), T. I. Arteev (*1902, Jarpi), I. G. Hatanzejskij (*1909, Abez'), I. O. Hatanzejskij (*1932, Abez') und viele andere. Nicht geringerer Autorität erfreuen sich dort auch die nenzischen Sänger O. I. Pyrerka, A. S. Tajbarej, S. A. Taleev (Kuprijanova S. 754-756). Sie alle sind oder waren Rentierzüchter oder arbeiten gegenwärtig als Rentierzüchter bzw. Hirten. Ihr ganzes Leben war oder ist noch heute verbunden mit der Tundra, die sie kreuz und quer durchwandert und durchfahren haben.

Bei Kolvinen und Nenzen gibt es jedoch neben dem Gesang der Männer auch den der Frauen. Als hervorragende Kennerinnen und Bewahrerinnen des ižma-kolvinischen Epos erwiesen sich die Sängerinnen A. I. Vyučejskaja (*1915, Haruta), E. V. Koskova (*1913, Haruta), U. A. Koskova (*1906, Kolva) und E. O. Hatanzejskaja (*1907, Abez'). Von den nenzischen Sängerinnen er- 
wähnt Z. N. Kuprijanova V. P. Tajbarej, A. E. Taleeva, E. M. Taleeva und M. V. Taleeva.

Von dem lebhaften Interesse der Kolvinen an den epischen Liedern und Erzählungen zeugt auch eine Art der Darbietung, bei der in den epischen Text verschiedenartige Repliken aufgenommen werden. Die ižma-kolvinischen Repliken erfüllen unterschiedliche Funktionen. Häufig dienen sie dazu, die Stellen zu kommentieren, die den Zuhörern im Laufe der Zeit unverständlich geworden sind. In der Erzählung „Der ungestüme Valej“ kam die Rede darauf, da $\beta$ in ferner Vergangenheit die Tundra in eigene und fremde Erde aufgeteilt war.

Und hier wandte sich der Erzähler an die Zuhörer und erklärte dieses Fragment: Vizly, bydsen burake jaranjaslen aslanys źeml'ajasnys jukemaes da siź i olenys as źeml'aanys. A mežays buśt'eke grańica sya, mežays. 'Siehst du, bei den Jaranen war früher das ganze Land aufgeteilt, so da $\beta$ jeder auf seinem eigenen Land lebte. Und die meža, das ist eine Art Grenze, die meža.' Ferner kann die Replik der Erklärung dialektaler Ausdrücke dienen. Viśtalis ńin i: „Mejko, vajly sutly.“ (Sie sagte ja: „Mejko, steh auf") - heißt es in dem Lied „Važen olis öti S'udbej" (Früher lebte ein S'udbej), und hier wird in der Replik die Bedeutung des lokalen Ausdrucks mejko erklärt und auf sein gemeinsyrjänisches Synonym moń 'Schwiegertochter' hingewiesen: Mejko, - sya mońys 'Mejko - das ist die Schwiegertochter'.

Besonders häufig werden die Repliken dazu benutzt, um eine Haltung zu dem gerade Geschehenen zum Ausdruck zu bringen oder um die erzählten Ereignisse zu beurteilen oder zu bewerten. In diesen Fällen lenken die Repliken die Aufmerksamkeit der $\mathrm{Zu}$ hörer auf die wichtigsten Ereignisse und Personen. Als I. O. Hatanzejskij, Sänger aus Abez', uns von der treffsicheren Schießkunst des Helden sang, unterbrach er vor Begeisterung über dessen Kriegskunst seinen Gesang und bemerkte in Prosa: Metkeja že lyje 'Gut schießt er', Topta že lyje 'Toll schießt er', Bahatyr bahatyr $i$ vyjim 'Er ist wirklich ein Held'. Die Einstellung zu den aktuellen Ereignissen und zu den Handlungen des Helden drücken sich in Repliken aus, die die Form einer rhetorischen 
Frage haben: $A$ ku\} ne oz ał̧y?? 'Ja, warum (sollte er es, ihn) nicht finden?', Kyće nin uźan? 'Wo (sollte er) hier auch schlafen?'; Kyće pörjedlasnys 'Ja, wie (sollte er) denn hier betrügen?' Der Sänger berichtet von dem enormen Appetit des Jüngsten Herrn vom Kerča-Fluß, der ein ganzes Rentier verspeiste, noch nicht satt war und um mehr bat. An dieser Stelle unterbrach der Sänger kurz seine Darbietung, um die folgende Replik einzuwerfen: Menurej tuša pulema da aby ved i pötlema, lešakyd. 'Sie hatte ihm ein (ganzes) Rentier gekocht, aber er ist nicht satt geworden davon, dieser Waldteufel.' Und noch ein Beispiel. Der Held hat seine Brüder zu einer Familienberatung zusammengerufen, in der es um seine künftige Braut geht. Man schlägt ihm eine Kandidatin vor, ein in der Nähe wohnendes Mädchen, benennt ihm eine zweite, eine dritte: Keine der Genannten ist dem Helden recht, und er ist mit den Argumenten der Brüder nicht einverstanden. Und da konnte der Sänger mit seiner eigenen Empörung nicht mehr hinterm Berg halten: Völi ved, viśtale, buř̌yk. Oj kuß nukl'ase. N'evesta ńikučem iz löśoo 'Es gab ja noch eine bessere. Ach, wie er sich ziert. Siehst du, keine Braut ist ihm gut genug.'

Die Darbietungsrepliken sind häufig von ausdrucksvolle Mimik und von Gesten begleitet. Das gilt zum Beispiel für die Darbietungen des Erzählers N. E. Kanev aus Haruta und des Sängers I. O. Hatanzejskij aus Abez'. So erzählte N. E. Kanev, daß der Ungestüme Valej durch die Tundra fährt und sich dabei auf das Vorderteil seiner Narte stützt, und erklärte uns dann ohne eine entsprechende Bitte unsererseits ausführlich: Korke taź voedam da dad' kokora vylanum leł̧sysam. Me taj sya una sutkijasen röbetńikas oli, siź ćomjas og $i$ vetly. Etaß́ ležca da öd'd'e i unmoośa. 'Früher war es so, wir fahren durch die Tundra und stützen uns auf das Vorderteil der Narte. Als Knecht bin ich ja viele Tage lang nicht in den Čum gekommen. So (zeigt es mit Gesten) stütze ich mich auf die Narte und schlafe sofort ein.'

Noch eine weitere verbreitete Form der Darbietungsrepliken und ihrer Einbeziehung in den epischen Liedtext gibt es: Prosarepliken, die den Inhalt des gerade gesungenen Liedteils genau wiederholen. Auf diese Weise wird die Aufmerksamkeit der $\mathrm{Zu}$ - 
hörer zweimal auf das Wichtigste, für das Verständnis des Sujets bzw. der jeweiligen Situation Wesentliche gelenkt. Dabei sind die Texte der Lied- und der Prosafragmente nahezu gleichlautend. Begnügen wir uns mit einem einzigen charakteristischen Beispiel. In dem betreffenden Liedfragment, dem Beginn des Liedes, geht es um den zehnjährigen Schlaf des jüngsten Bruders, des Helden. Vom langen Schlaf erwacht, sagt der Held:

Ötor da bökam viźlyši:

Jełyd da sera pim taj,

Mödor da bökam viźlyśi:

S'öd sera pim taj.

Og töd da kömoony,

Kuj́ kole kömoony,

Öt'ik i ćoje taj, suas,

S'ama taj i vơlema.

(Aus dem Archiv des Verf.)
Ich sah nach der einen Seite: weiße verzierte Rentierfellschuhe (stehen da), ich sah nach der anderen Seite: schwarze verzierte Rentierfellschuhe. Ich weiß nicht, welche anziehen, wie sie anziehen, meine einzige Schwester hat sich als Meisterin erwiesen.

Der Sänger, gleichsam ohne Hoffnung, daß die Zuhörer das Gesungene verstanden haben (und das gesungene Fragment ist für die Charakteristik des Helden und seiner Schwester sowie deren Beziehung zweifellos wichtig), beeilt sich, den Inhalt nachzuerzählen: Ötik Ćoj sama taj i völema. Pimjasse viłede. Kyk goz da, oz töd, kodes kömoonys. Ötor bökas jě̌yd sera, mödor bökas śöd sera pim. Oz töd, kodse. Kyknannys mića vurema Cojyslen. 'Die einzige Schwester hat sich als Meisterin erwiesen. Zwei Paar Schuhe aus Rentierfell stehen neben ihm. Er weiß nicht, welche er wählen soll. Auf der einen Seite stehen weiße verzierte, auf der anderen Seite schwarze verzierte Rentierfellschuhe. Er weiß nicht, welches Paar er wählen soll. Seine Schwester hat beide Paare schön bestickt.'

Von den lebendigen Prozessen, die abgelaufen sind oder noch heute ablaufen, zeugt besonders anschaulich die Erscheinung der Interpolation, die Aufnahme von solchen Einfügungen in den traditionellen Folkloretext, die erst in neuer, bisweilen auch erst in neuester Zeit entstanden sind. Beispiele für Interpolation gibt es im ižma-kolvinischen Epos bedeutend mehr als im nenzischen. 
Offenbar äußert sich in diesem Faktum eine eigene Gesetzmäßigkeit, nämlich die, daß es eine spätere Zeit war, die auf die Gestaltung des ižma-kolvinischen Epos in seiner heutigen Form Einfluß genommen hat, als die, die sich im nenzischen Epos bemerkbar macht. So werden in den alten Erzählungen neben dem Kessel mit sieben Henkeln (sizíim pel'a pört) ab und zu auch komyn vedrevej cajnik, ein 'dreißig Eimer fassender Teekessel', und sorokovkaböcka, ein 'Vierzigliterfäßchen' u. a. erwähnt. Im Vergleich zu dem Helden des nenzischen Epos läßt der des ižma-kolvinischen in größerem Maße Merkmale sowohl des Heidentums als auch des christlichen Glaubens erkennen.

Er verehrt nicht nur die heidnischen śad'ej-Idole, sondern auch das christliche Kreuz am Wegrand (KNE Nr. 11, 475-479, im Lied „Vavl'o pomlas" - 'Von Vavl'o'). Der Held des Liedes „Kujim Tyngos" (Die drei Tyngos) bittet ähnlich dem komi-syrjänischen Helden Pedor Kiron seine Mutter um ihren elterlichen Segen, bevor er sich zum Kampf begibt (KNÈ Nr. 7, 184-204).

In den vorausgegangenen Abschnitten wurde bereits festgestellt, daß die nenzischen und die ižma-kolvinischen Helden über so unabdingbare epische Fähigkeiten verfügen wie die, auf einem Wolkenfetzen zu segeln oder durch den engen mukota-Rauchabzug auf die Straße hinauszufliegen und sich so der drohenden Tötung durch die zahlreichen Feinde zu entziehen. Der Held des Liedes „Kujim Tyngos" (Die drei Tyngos) gebraucht, als er über seinen Flug spricht, einen für ein altes Epos höchst ungewöhnlichen Vergleich, er vergleicht seinen Flug nämlich mit dem eines ... Flugzeugs: Kuźe da kyk nööouŭ̌jas bośti da, kući taj vyli lebny, kuźi da me ved samolet, me taje lebny kuci, more da berege voi. 'Zwei lange Bögen nahm ich in die Hand, flog hoch hinauf, flog eine Weile ganz wie ein Flugzeug und ließ mich ans Ufer des Meeres hinab'. (KNÈ Nr. 7, 1040-1045.)

Auf eine nicht minder unerwartete Interpolation trifft man in dem Lied „Važen olis ötí S'udbej“ (Früher lebte ein S'udbej): Der Vater, der seine Tochter nicht einem der sieben rentierzüchtenden Brüder zur Frau geben will, begegnet ihnen feindselig und greift ... nicht nach Pfeil und Bogen, nicht nach der $\chi o r e j$-Stange, ja 
nicht einmal nach dem siebengliedrigen Säbel, wie es im ižmakolvinischen Epos gewöhnlich geschieht, sondern nach einer richtigen... Granate: S'udbejked mödeny vermaśny. S'udbeje taj $i$ petkedis: „Taje ne granatays. - S'udbeje taj $i$ vistalis. - Taje granatays. " S'izimede dad'd'a taj stanevićcisnys da. 'Mit dem sudbej wollen sie ihre Kräfte messen. Da drohte der sudbej: „Da habt ihr eine Granate. - Sagt der śudbej. - Da habt ihr eine Granate." Da blieben die sieben Narten sofort stehen.' (KNÈ Nr. 4, 51-57.)

Im Rahmen dieses Aufsatzes habe ich verschiedene Schnittpunkte des ižma-kolvinischen und des nenzischen Epos sowie der finnopermischen und der samojedischen epischen Traditionen unter drei verschiedenen Aspekten betrachtet: unter dem des Sujets, unter dem von Komposition und Stil und unter dem von Poetik und Struktur. Die Zusammenstellung dieser Aspekte zeugt von der selbständigen Entwicklung sowohl des ižma-kolvinischen als auch des nenzischen epischen Schaffens. Aber die historisch-kulturellen Kontakte der Finnopermier und Samojeden auf dem Gebiet der Folklore beschränken sich natürlich nicht auf das Epos. Einzigartiges Material für wissenschaftliche Schlußfolgerungen stellt zum Beispiel das Genre der lyrisch-epischen Liedimprovisationen, der nenzischen hynabc und jarabc einerseits und der komi-syrjänischen nurankyy andererseits dar. Diese Improvisationen zeugen ebenfalls von der Intensität und Produktivität der syrjänisch-nenzischen Folklorekontakte. Das wäre jedoch ein Thema für eine andere Untersuchung.

(Aus dem Russischen von Angela Plöger)

Literaturhinweise

1. Л. Н. Жеребцов. Историхо-культурные взаимоотнопения коми с соседними народами X - начало XX в. Москва, "Наука", 1982, S. 157-175.

2. В. И. Лытхин, Е. С. Гуляев. Краткий этимологический словарь коми языха. Москва, "Науха", 1970 S. 337; Y. Wichmann, T. E. Uoti- 
la. Syrjänischer Wortschatz nebst Hauptzügen der Formenlehre. Helsinki, 1942, S. 74.

3. K. Rédei. Obi-ugor jövevényszók a zürjén nyelvben. - NyK LXVI. kötet, I. szám, S. 3-15; Y. H. Toivonen. Über die syrjänischen Lehnwörter im Ostjakischen. - FUF, Bd. XXXII, Heft 1-2, S. 1-169; P. Hajdú. Die Benennungen der Samojeden. - MSFOu LIV, Helsinki, 1948-1950, S. $20-32$.

4. А. И. Туркин. Этногенез народа хоми по данным топонимии и лексики. - Eesti NSV Teaduste Akadeemia Ühiskonnateaduste Osakond. Preprint KKI - 31, Tallinn, 1985, S. 5.

5. Этногенез народов Севера. Москва, "Наука", 1980, S. 66; Л. В. Хомич. Ненцы и хоми Кольского полуострова. - Im Buch: Этнографическое изучение северо-запада СССР, Ленинград, "Наука" ЛО, 1977; ders. Об иноэтнических элементах в традиционной культуре ненцев. - Im Buch: Этнохультурные хонтахты народов Сибири. Ленинград, "Науха" ЛО, 1984, S. 14-29; Г. Н. Грачева. К этнокультурным связям нганасан. Классифихация паманов. - Im Buch: Этнокультурные хонтакты народов Сибири. Ленинград, 1984, S. 84-98; В. И. Васильев. Проблема формирования северосамодийских народностей. Москва, 1979; Л. В. Хомич. Ненцы. Историко-этнографические очерхи. Москва-Ленинград, "Наука", 1966.

6. Л. П. Лаштух. Формирование народности хоми. Москва, 1972, S. 64.

7. Житие св. Стефана епископа Пермсхого, нагисанное Епифанием Премудрым. С.-Петерсбург, 1897, S. 9.

8. Ich zitiere nach: М. Смирнов. Переяславль-Залесский, его проглое и настоящее. Москва, 1911, S. 60.

9. Л. И. Лапук. Очерк этничесхой истории Печорского храя. Сықтывкар, 1958, S. 64; ders. Формирование народности коми. МоскBa, 1972, S. 61-64.

10. В. И. Канивец. Канинская пещера. Москва, "Наука", 1964, S. 134.

11. Ю. Б. Симченко. Нехоторые данные о древнем этническом субстрате в составе народов Северной Азии. - Im Sammelband: Проблемы антропологии и исторической этнографии Азии. Москва, 1968 , S. 194-195, 212; Б. О. Долгих. Очерки по этнической истории ненцев и энщев. Москва, 1970, S. 49, 52.

12. Г. А. Старцев. Влияние самоедов на ихемсхих зырян (язык и быт). - "Коми му", Nr. 11, 1926, S. 31-34; В. А. Сорвачева. Ненецкие и хантыйские заимствования в говоре заурапьских хоми. Историко-филологический сборник Коми филиала АН СССР. Cықтывкар, 1960, S. 171-177; Y. Wichmann. Samojedisches lehngut im syrjănischen. - FUF, Bd. II, Helsinki, 1902, S. 165-183; K. Rédei. 
Juraksamojedische Lehnwörter in der syrjänischen Sprache. - ALHung. 1963, t. XIII, f. 3-4, S. 275-310.

13. А. И. Турхин. Этногенез народа коми...1985, S. 6-8; А. К. Матвеев. Топонимия Урала. Свердловск, 1985, S. 29-33.

14. P. Domokos. Handbuch der uralischen Literaturen. - Studia UraloAltaica 18. Szeged, 1982, 397 S.

15. M. A. Castrén. Nordische Reisen und Forschungen. Reiseerinnerungen aus den Jahren 1838-1844. Bd. I, St. Petersburg, 1853, S. 247-248.

16. А. К. Микупев. Эпические формы коми фольклора. Ленинграп, "Наука" ЛО, 1973, S. 124-172.

17. M. A. Castrén. Samojedische Volksdichtung. - MSFOu LXXXIII, Helsinki, 1940.

18. T. Lehtisalo. Juraksamojedische Volksdichtung. - MSFOu XC, Helsinki, 1947.

19. 3. Н. Куприянова. Епические песни ненцев. Москва, "Наука", 1965.

20. А. К. Михушев. Эпические формы..., S. 43-123.

21. Ebenda, S. 50-51.

22. M. A. Castrén und T. Lehtisalo. Samojedische Sprachmaterialien. MSFOu 122, Helsinki, 1960.

23. В. М. Кудряпова. Русско-коми фольклорные связи в устной прозе. Автореферат диссертации на соискание ученой степени кандидата филологических наух. Сыктывкар, 1985.

24. Néprajzi Múzeum. Etnológiai Adattár. EA, 4705.

25. Энногенез народов Севера. Москва, 1980, S. 55.

26. Ebenda, S. $\mathbf{5 7 .}$

27. Исландские саги. Редахция, вступительная статья и примечания М. Стеблин-Каменского. Москва, 1956, S. 536, 667, 718.

28. W. Steinitz. Der Parallelismus in der finnisch-karelischen Volksdichtung. - FF Communications, Nr. 115, Helsinki, 1934, S. 11-207.

29. H. Paasonens südostjakische Textsammlung. Herausgegeben von Edit Vértes. Band. I. - MSFOu 172, Helsinki, 1980, S. 3-247.

30. Б. О. Долгих. Мифологические схазки и исторические предания энцев. Москва, 1961, S. 155.

31. Г. Н. Грачева. Категория НГО у нганасан. Im Buch: Языки и топонимия. Томск, 1976, S. 172-176; dies. Трапиционное мировоззрение охотников Таймыра. Ленинград, "Наука" ЛО, 1983. S. 26-29.

32. A. Kannisto. Wogulische Volksdichtung. - MSFOu 109, Helsinki, 1955, S. $169,176$.

33. Исландские саги. Составление, вступительная статья и примечания М. И. Стеблин-Каменского. - In Serie: "Библиотеха всемирной литературы", Москва, 1973, S. 23, 204, 245, 287, 364, 369, 410, 427. 
34. М. А. Кастрен. Путешествие по Лапланщии, Северной России и Сибири. (1838-1844, 1845-1849). - Im Buch: Собрание старых и новых путешествий, т. VI, ч. 2, Москва, 1860, S. 467.

35. Б. Гаврилов. Произведения народной словесности, обряды и поверья вотяков Казанской и Вятской губерний. Казань, $1880, \mathrm{~S}$. 77; П. С. Кириллов. Мордовские народные песни. Москва, 1958, S. 111; В. Коукать. Марийские народные песни. Москва-Ленинград, 1951, S. 206; А. К. Михушев. Песенное творчество народа коми. Сыхтывкар, 1956, S. 67-68; В. М. Бердников, Е. А. Тудоровсхая. Поэтика марийских народиых песен. Иошкар-Ола, 1945.

36. Т. К. Борисов. Песни вожлых вотяхов. Ижевск, 1929, S. 7, 16, 28.

37. Ю. Г. Рочев. Челядь сьыланкывъяс да мойдхывъяс. Сыктывкар, 1969, S. 91.

38. A. O. Väisănen. Samojedische Melodien. - MSFOu 136, Helsinki, 1965.

39. И. А. Осипов. Висер вожса сьыланхывъяс да мойдкывъяс. Сыктывкар, 1941, S. 138.

40. М. А. Кастрен. Путешествие по Лапландии..., S. 343, 457.

Abkürzungen

KNÈ = Komi narodnyj èpos. Sammelband. Manuskript. Zusammengestellt von A. K. Mikušev. Aufbewahrt im Archiv des Lehrstuhls für Syrjänische Sprache und Literatur der Staatlichen Universităt "50. Jahrestag der UdSSR" Syktyvkar. Im Text werden in Klammern die Nummern der Lieder, danach die Nummern der Verse angegeben.

Kuprijanova $=3$. Н. Куприянова. Эпические песни ненцев. Москва, "Науха", 1965.

КЀРB = А. К. Микушев. Коми эпические песни и баллады. Ленинград, "Наука", ЛО, 1969.

AlHung. = Acta Linguistica Academiae Scientiarum Hungaricae. Budapest.

FUF $\quad=$ Finnisch-Ugrische Forschungen. Helsinki.

JSFOu = Journal de la Société Finno-Ougrienne. Helsinki.

MSFOu $=$ Mémoires de la Société Finno-Ougrienne. Helsinki.

NyK = Nyelvtudományi Közlemények. Budapest. 